\title{
PRESENCE OF ANTIBIOTIC RESISTANT SALMONELLA SPP. IN BACKYARD POULTRY AND THEIR ENVIRONMENT
}

\author{
A Thesis \\ presented to \\ the Faculty of California Polytechnic State University, \\ San Luis Obispo
}

\author{
In Partial Fulfillment \\ of the Requirements for the Degree \\ Master of Science in Agriculture
}

by

Nicole Land

December 2018 
(C) 2018

Nicole Land

ALL RIGHTS RESERVED 


\section{COMMITTEE MEMBERSHIP}

TITLE:

Presence of Antibiotic Resistant Salmonella spp. in

Backyard Poultry and Their Environment

AUTHOR: Nicole Land

DATE SUBMITTED: December 2018

COMMITTEE CHAIR: Jaymie Noland, DVM

Chair of Animal Science Department

COMMITTEE MEMBER: William Plummer, PhD

Professor of Animal Science

COMMITTEE MEMBER: Siroj Pokharel, PhD

Assistant Professor of Animal Science

COMMITTEE MEMBER: Silvio Favoreto Jr., PhD, DDS

Professor of Microbiology, Cuesta College 


\section{ABSTRACT \\ Presence of Antibiotic Resistant Salmonella spp. \\ in Backyard Poultry and Their Environment}

Nicole Land

As keeping backyard poultry rises, human contact with zoonotic pathogens will increase. One such pathogen that backyard enthusiasts have exposure risks to is Salmonella spp. which may cause a potential public health threat due to its increasing multidrug resistancy. Salmonella spp. were present in 33 of 50 samples collected from 29 sites with backyard poultry coops in San Luis Obispo County during March to May in 2014. Two different Hardy-CHROMETM Salmonella Selective Media plates were used to culture and isolate positive samples of Salmonella spp.. Each positive isolate was tested for antimicrobial sensitivity to 6 standard antibiotics: Ampicillin, Bacitracin, Erythromycin, Gentamicin, Penicillin, and Tetracycline, at the standard disk concentration levels. The Kirby-Bauer antimicrobial sensitivity test determined that 12 different profiles emerged from the Salmonella spp. isolates. All antimicrobial sensitivity profiles showed multidrug resistance in vitro with only high susceptibility to 2 major antibiotics, Gentamicin at $97 \%$ and Ampicillin at 51\%. All profiles were resistant to 1 or more of the antimicrobials tested, plus the control. One Salmonella isolated was resistant to all 6 antimicrobials and another isolate to 5. The Salmonella spp. isolates proved multidrug resistance between $73 \%-100 \%$ to the other 4 antibiotics tested.

The 24 Salmonella spp. positive sites displayed a lack of proper biosecurity and poultry husbandry practices. The criteria developed for accessing the poultry's environment ranged from dedicated shoes for cleaning, egg handling, access to other animals and wildlife, number of birds and breeds or species in a coop, cleaning routine, over-all biosecurity and human interactions. Human exposure to Salmonella spp. pathogenic strains could increase due to environmental cross contamination and deficiencies in sanitation. The presence of Salmonella spp. with a diversity of antibiotic resistance serotypes is an important source of zoonotic pathogens for animal and human diseases that has public health risk implications.

Keywords: Salmonella spp., antimicrobial resistance, Salmonella, backyard poultry, environmental Salmonella, backyard biosecurity 


\section{ACKNOWLEDGMENTS}

It is with much gratitude and appreciation that I would like to thank: Dr. Bill Plummer who can now fully retire as I have completed my thesis with his keen eye for edits; Dr. Jaymie Noland for her continued support by being on my committee; Dr. Siroj Pokharel for stepping onto my committee in the $11^{\text {th }}$ hour; and Dr. Jim Prince for his support and knowledge of navigating the Graduation process in order to complete my degree.

Silvio Favoreto Jr., PhD, MS, BS, DDS, Cuesta College

Great appreciation to Dr. Favoreto for his mentorship and continued support during the totality of this project.

Colleen Land, PhD (abd) MS, MS, BS

Grateful for the financial support to purchase the research materials and experimental supplies.

Much appreciation for their assistance in sample collection, acquiring sample locations and help in the laboratory.

\section{Ericka Brown, AS Delia Turner, BS}

Special thank you to Dr. Ron Rupert, Biology Department Chair and the Cuesta College Biological Department for the use of the microbiology laboratory for the experiments.

Much gratitude to Dr. Ericka Roberts for her coaching and guidance on formatting the written work done on this thesis for a "higher authority, "The Graduate Office."

But most importantly a special thank you to the poultry owners who permitted me to collect samples, ask questions regarding their husbandry practices, and take photographs of their birds and poultry housing. And of course, the numerous chickens, turkeys, geese, ducks, and pigeons who allowed me to invade their space to collect fecal and environmental samples. 


\section{TABLE OF CONTENTS}

LIST OF TABLES viii

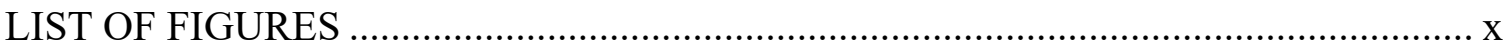

\section{CHAPTER}

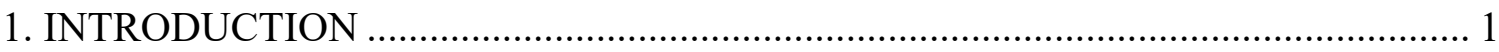

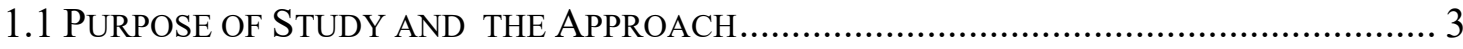

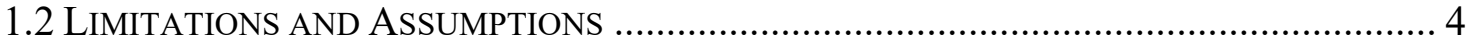

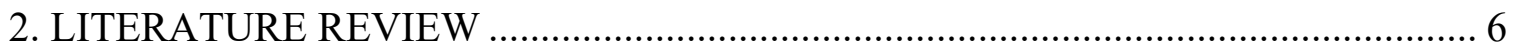

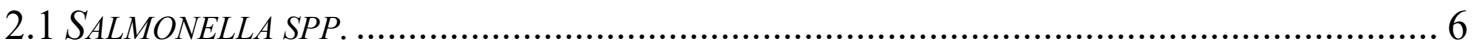

2.1.1 Mechanisms and Virulence of Salmonella Diseases....................................... 7

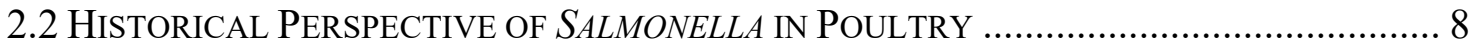

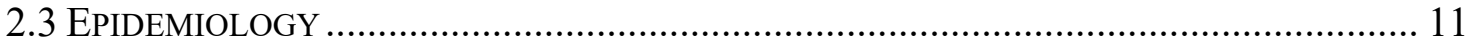

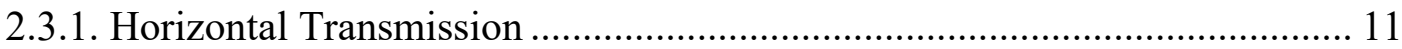

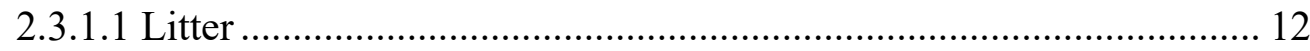

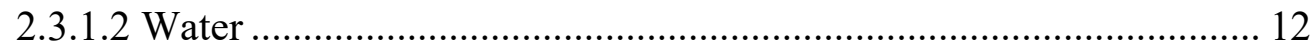

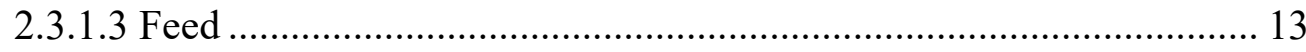

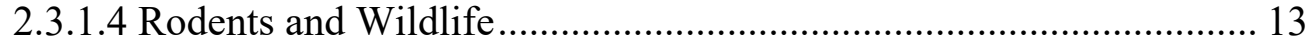

2.3.1.5 Stress ................................................................................... 14

2.3.1.6 Sanitation and Environment ................................................... 15

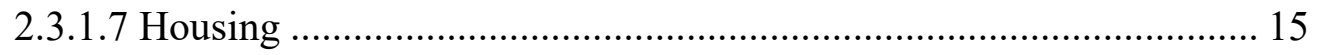

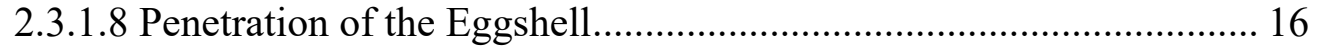

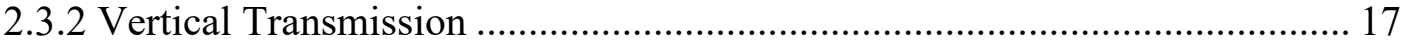

2.4 ANTIBACTERIAL RESISTANCE IN SALMONELLA ................................................... 18

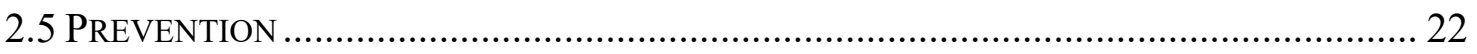

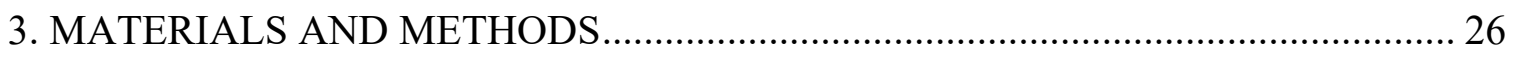

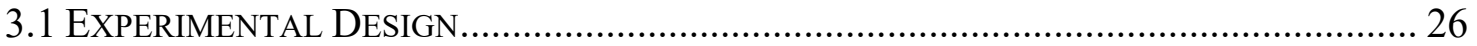

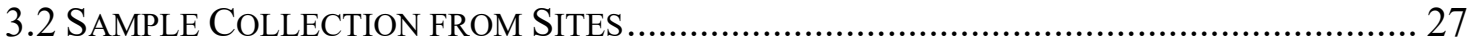

3.3 ISOLATION OF COLONIES ON PLATES .................................................................... 30

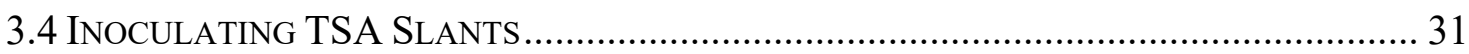

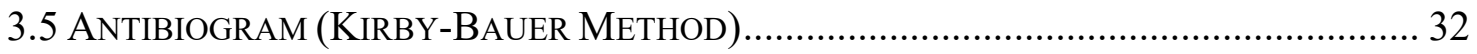

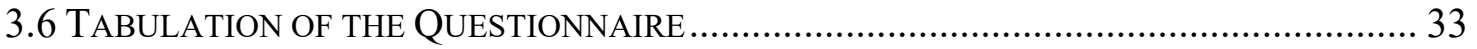

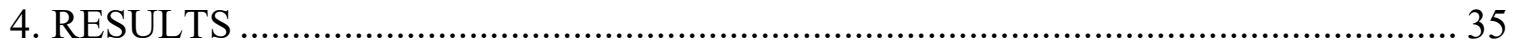

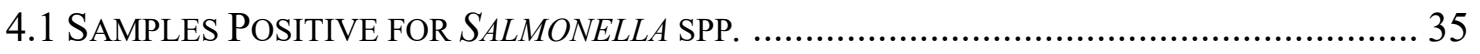

4.2 ANTIBIOGRAM PROFILES FOR SALMONELLA SPP .................................................... 38

4.2.1 Antibiogram Results Based on Antimicrobial Sensitivity Levels.................... 57

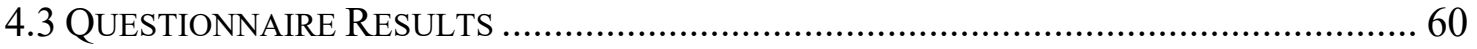

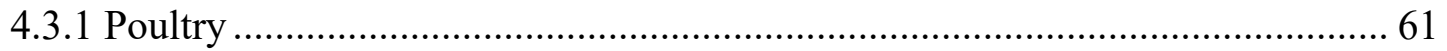


4.3.2 Feed 65

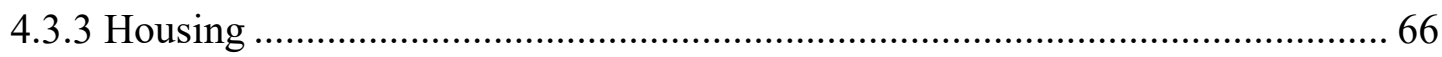

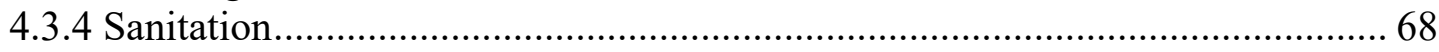

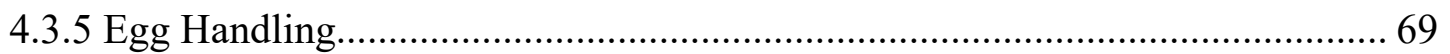

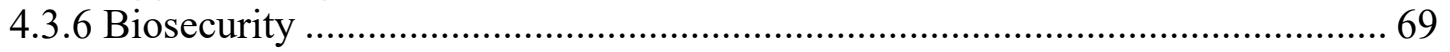

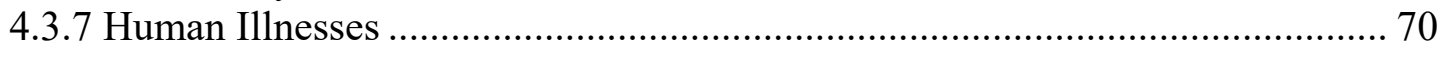

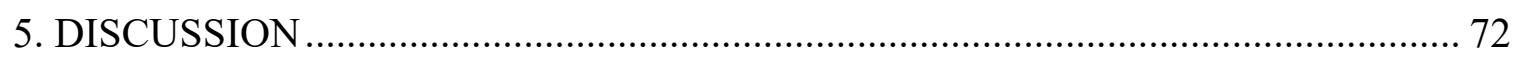

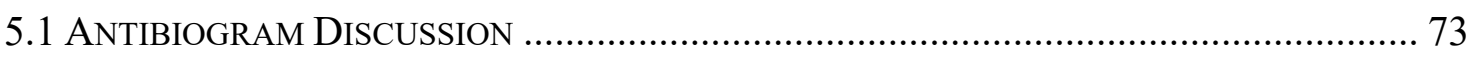

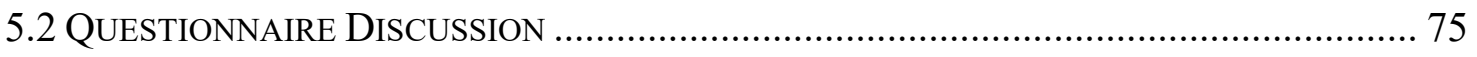

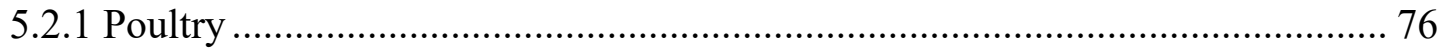

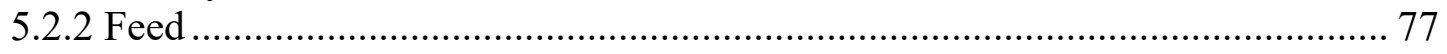

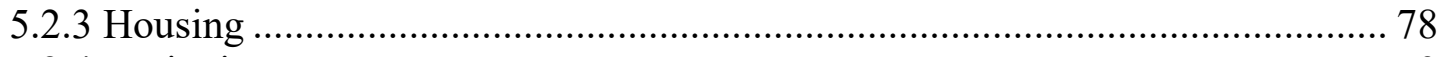

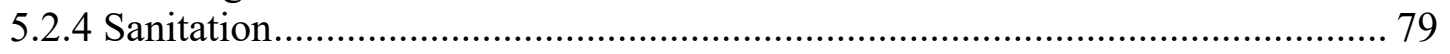

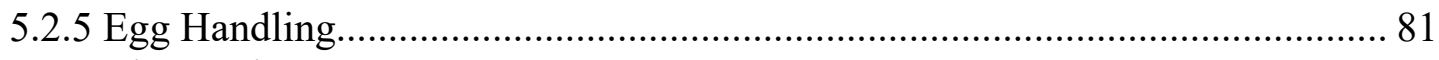

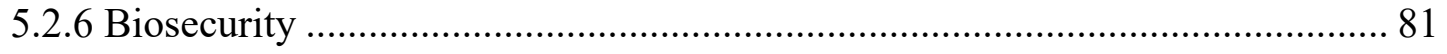

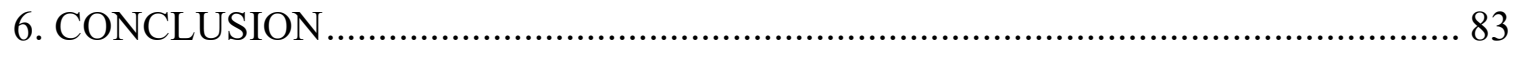

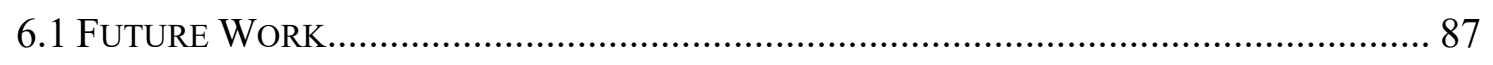

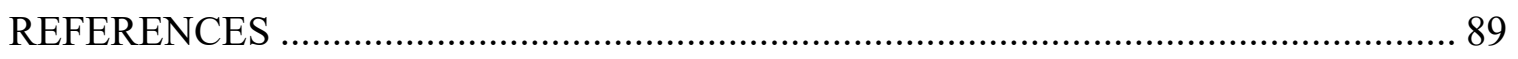

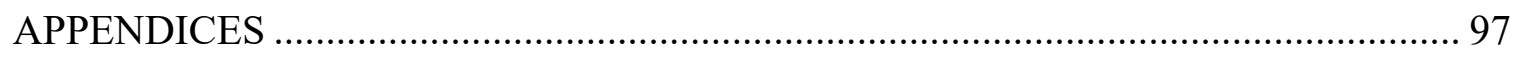

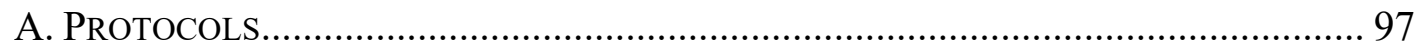

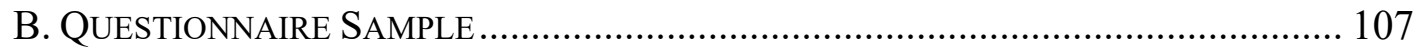

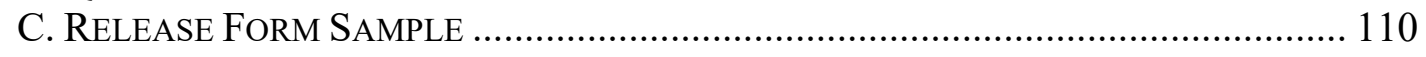

D. Antibiogram Sensitivity TeSt Results ................................................... 111 


\section{LIST OF TABLES}

Table

Page

1. Positive for Salmonella spp. based on Sites and Samples 36

2. Salmonella spp. Isolates based on $\mathrm{H}_{2} \mathrm{~S}$ Production. 36

3. Kirby-Bauer Antimicrobial Test Sensitivity Levels for Salmonella spp. based on CLSI (2012) 39

4. Antibiotic Sensitivity Levels Based on the 6 Common Antimicrobials Tested 57

5. Location of Sites by City 60

6. Types of Poultry on the Site: The chart lists the species of poultry by site and the positive samples

7. Poultry Breeds by Site: There were various breeds of poultry at the sites. Most sites had a variety of breeds mixed with each other and other sites had multiple species ... 62

8. Number of Poultry and Coops by Sites 63

9. Source of Poultry 64

10. Purpose of Poultry (some sites had dual purpose for the poultry). 65

11. Brands of Feed 65

12. Types of Feed and Supplements 68

13. Housing and Coop Types 66 


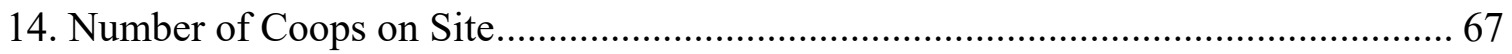

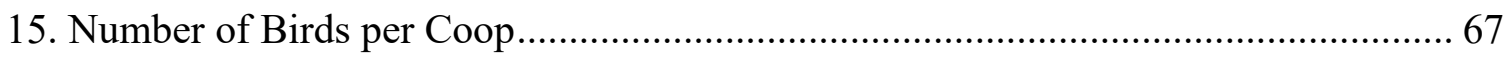

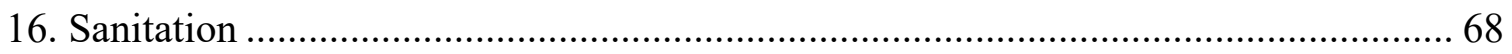

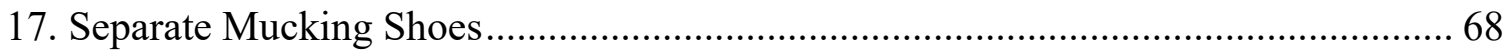

18. Proper Egg Handling: (standards from Colorado State University Extension) .......... 69

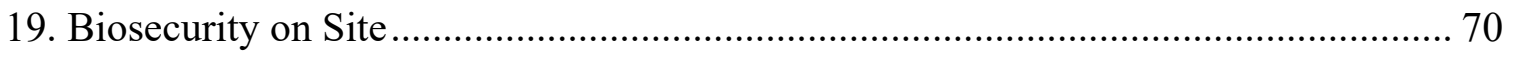

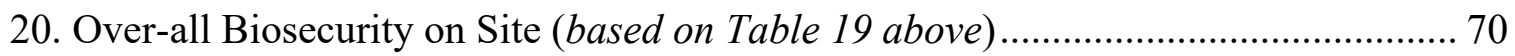

21. Antibiogram Sensitivity Test Results .............................................................. 111 


\section{LIST OF FIGURES}

Figures

Page

1. Epidemiological Triangle 23

2. Sample Sites Collected in San Luis Obispo County: The 5 Green locators are sites negative for Salmonella spp. and the 24 Red locators are sites positive for Salmonella spp. Due to the close proximity of sample site addresses: Locator 12 overlaps Locator 8; and Locator16 overlaps Locators 14 and 15 35

3. Sample representative positive plate of HardyCHROM ${ }^{\mathrm{TM}} \mathrm{SS}$ Plate. Colonies were either teal $\left(\mathrm{H}_{2} \mathrm{~S}\right.$ non-producing) or black $\left(\mathrm{H}_{2} \mathrm{~S}\right.$ producing $)$ to be a Salmonella positive colony.

4. Sample plate representative plate of positive for HardyCHROM ${ }^{\mathrm{TM}}$ Salmonella Plate. Salmonella spp. shows up as pink to magenta in color.

5. Antibiogram Profile 1: Salmonella Isolate 52314-6: Resistant to Penicillin (P), Bacitracin (B), Ampicillin (AM), Tetracycline (TE), Erythromycin (E), and Gentamicin (GM); Intermediate to none; Susceptible to none

6. Representative Antibiogram Plate of Profile 1. NOTE: This plate included Streptomycin and Neomycin disks not included in this study.

7. Antibiogram Profile 2: Salmonella Isolates 38145-C and 32214-3: Resistant to Bacitracin (B), Ampicillin (AM), Penicillin (P), and Erythromycin (E); Intermediate to Tetracycline (TE); Susceptible to Gentamicin (GM). This graph is an average of the 2 Isolates.

8. Representative Antibiogram Plate of Profile 2. NOTE: This plate has 2 Penicillin disks that measured the same.

9. Antibiogram Profile 3: Salmonella Isolate 51614-2L \#2: Resistant to Bacitracin (B), Penicillin (P), and Tetracycline (TE); Intermediate to Ampicillin (AM), and Erythromycin (E); Susceptible to Gentamicin (GM). 
10. Representative Antibiogram Plate of Profile 3. NOTE: This plate included Streptomycin and Neomycin disks not included in this study

11. Antibiogram Profile 4: Salmonella Isolates 3814-1, 32114-1, 51614-7, 51714-1, 52714-3R \#1: Resistant to Bacitracin (B), Penicillin (P), Erythromycin (E) and Tetracycline (TE); Intermediate to Ampicillin (AM); Susceptible to Gentamicin (GM). This graph is an average of the 5 Isolates

12. Representative Plate of Antibiogram Profile 4. NOTE: This plate has 2 Penicillin disks that measured the same

13. Antibiogram Profile 5: Salmonella Isolate 51614-2L \#3: Resistant to Bacitracin (B), Penicillin (P) and Erythromycin (E); Intermediate to Ampicillin (AM) and Tetracycline (TE); Susceptible to Gentamicin (GM).

14. Representative Antibiogram Plate of Profile 5. NOTE: This plate included Streptomycin and Neomycin disks not included in this study

15. Antibiogram Profile 6: Salmonella Isolates 32214-1, 41114-6R , 41114-10C and 51614-4: Resistant to Penicillin (P), Bacitracin (B), Ampicillin (AM), Tetracycline (TE), and Erythromycin (E); Intermediate to none; Susceptible to Gentamicin (GM). This graph is an average of the 4 Isolates

16. Representative Antibiogram Plate of Profile 6. NOTE: This plate has 2 Penicillin disks that measured the same

17. Antibiogram Profile 7: Salmonella Isolates 32114-2, 41114-3B, 41114-9G, 51614-1, 51614-5 \#1, 51614-5 \#2, 51614-6 B, 51614-6T, 52314-2H, and 52714-2: Resistant to Bacitracin (B), Tetracycline (TE), and Erythromycin (E); Intermediate to Penicillin (P); Susceptible to Ampicillin (AM) and Gentamicin (GM). This graph is an average of the 10 Isolates.

18. Representative Antibiogram Plate of Profile 7. NOTE: This plate has 2 Penicillin disks that measured the same 
19. Antibiogram Profile 8: Salmonella Isolates 51714-2LR \#1 and 51714-2LR \#2T: Resistant to Penicillin (P) and Bacitracin (B); Intermediate to Ampicillin (AM) and Erythromycin (E); Susceptible to Gentamicin (GM) and Tetracycline (TE). This graph is an average of the 2 Isolates profiles

20. Representative Antibiogram Plate of Profile 8. NOTE: This plate included Streptomycin and Neomycin disks not included in this study

21. Antibiogram Profile 9: Salmonella Isolate 51614-2L \#1: Resistant to Penicillin (P), Bacitracin (B) and Tetracycline (TE); Intermediate to Erythromycin (E); Susceptible to Ampicillin (AM) and Gentamicin (GM) 52

22. Representative Antibiogram Plate of Profile 9. (Out of focus) NOTE: This plate included Streptomycin and Neomycin disks not included in this study....

23. Antibiogram Profile 10: Salmonella Isolates 32214-2, 41114-5L, 51614-8, 51714-2 \#1, 51714-2 \#2, 52314-1, 52714-1, and 52714-3R \#2: Resistant to Penicillin (P), Bacitracin (B), Tetracycline (TE) and Erythromycin (E); Intermediate to none; Susceptible to Ampicillin (AM) and Gentamicin (GM). This graph is an average of the 8 Isolates profiles

24. Representative Antibiogram Plate of Profile 10. NOTE: This plate included Streptomycin and Neomycin disks not included in this study

25. Antibiogram Profile 11: Salmonella Isolate 3814-7G: Resistant to Penicillin (P), Bacitracin (B) and Erythromycin (E); Intermediate to Ampicillin (AM);

Susceptible to Tetracycline (TE), and Gentamicin (GM) 55

26. Representative Antibiogram Plate of Profile 11. NOTE: This plate has 2 Penicillin disks that measured the same

27. Antibiogram Profile 12: Salmonella Isolate 51614-3H: Resistant to Penicillin (P) and Bacitracin (B); Intermediate to Ampicillin (AM), Tetracycline (TE) and Erythromycin (E); Susceptible to Gentamicin (GM) 
28. Representative Antibiogram Plate of Profile 12. NOTE: This plate included Streptomycin and Neomycin disks not included in this study

29. Ampicillin Sensitivity: Isolates were 19\% Resistant; 30\% Intermediate; and 51\% Susceptible. 58

30. Bacitracin Sensitivity: Isolates were 100\% Resistant; 0\% Intermediate; and 0\% Susceptible.

31. Erythromycin Sensitivity: Isolates were $86 \%$ Resistant; $13 \%$ Intermediate; and 5\% Susceptible.

32. Gentamicin Sensitivity: Isolates were 3\% Resistant; 0\% Intermediate; and 97\% Susceptible.

33. Penicillin Sensitivity: Isolates were 73\% Resistant; $27 \%$ Intermediate; and 0\% Susceptible.

34. Tetracycline Sensitivity: Isolates were $81 \%$ Resistant; $11 \%$ Intermediate; and $8 \%$ Susceptible..

35. Coop at Site 2: Houses chickens and pigeons. Fecal matter is not removed but allowed to compost in the coop and was about 8 inches deep.

36. Coop at Site 7: Other animals have access to the coop by digging under the fence..... 82

37. Hardy Diagnostics Envirobootie ${ }^{\mathrm{TM}}$ II proper procedure on how to utilize it within the coop and enrich for micro-organisms. Published with permission of Hardy Diagnostics

38. HardyCHROM ${ }^{\mathrm{TM}}$ SS plates: Black centered colonies will be H2S producing Salmonella spp; and Teal centered colonies will be H2S non-producing Salmonella spp.. Published with permission of Hardy Diagnostics. 100 
Figures

39. HardyCHROM ${ }^{\mathrm{TM}}$ Salmonella plate: Salmonella with be magenta as it reacts to the pink substrates in the agar; the Blue substrates will be used by other bacteria (E. coli); there can be white or natural color colonies present too. Published with

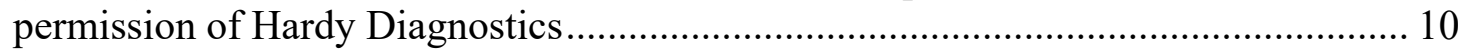

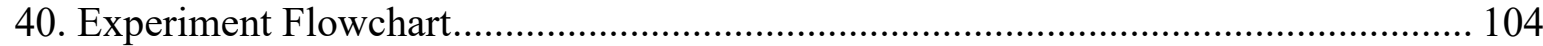




\section{INTRODUCTION}

A United States Department of Agriculture (USDA) study established that $1 \%$ of the urban population currently owns backyard chickens and $4 \%$ plan to buy chickens in the next 5 years as the homegrown food trend continues (UDSA, 2010). With this enthusiasm for hobby poultry increasing, so will the incidences of illness from handling chickens, ducks and turkeys rise. This health risk to human caretakers, their family members and other pets will be aggravated by the lack of proper biosecurity and sanitation methods. (Basler et al., 2016).

California's poultry industry had revenue of $\$ 1.7$ billion in 2015. In 2016, California's poultry product exports were $\$ 1.2$ billion or $6.4 \%$ of the total US poultry exports (CDFA, 2018). The California Department of Food and Agriculture (CDFA) and USDA have a significant concern regarding the lack of knowledge and biosecurity by backyard enthusiasts who could be the next source of an uncontrolled disease outbreak that threatens small poultry operations and agricultural businesses (USDA, 2011; USDA, 2014; CDFA, 2017). The concern of backyard poultry being a possible source of cross-contamination is a major factor in investigating this animal health issue.

There is a public health risk that threatens backyard poultry owners and their families and those that encounter these flocks especially as the perception of poultry turns from livestock to pet (Basler et al., 2016). The hobbyist's lack of knowledge about animal diseases, coupled with improper care and husbandry, will be a risk to them as well as the poultry industry. The threat is zoonotic poultry diseases that could be carried by the flock. These diseases are not easily detectable, especially if the birds look clean and healthy. 
Poultry are the reservoir for several human diseases that cause gastrointestinal disorders (Holt, 2000). In young, old and immune-compromised humans a more severe bacterial infection can emerge developing into a deadly form of the illness (FDA, 2012; Dale and Brown., 2013). In the United States, annually 1.2 million cases of Salmonella occur in humans resulting in 23,000 hospitalizations. One million of these cases are from food sources, with approximately 40,000 cases of salmonellosis reported owing to food poisoning from animal origin (CDC, 2013; Basler, et al., 2016). It is believed that 30-40 times more cases go unreported annually because of mild infections and/or those selfresolving in 5-7 days.

According to the Centers for Disease Control and Prevention (CDC), 11\% of the Salmonella outbreaks are from animal exposure (Behravesh et al., 2014). From 1990 to 2014, over 1581 reported cases of illness, 221 hospitalizations and 5 deaths were linked to humans acquiring Salmonella from live poultry (Behravesh et al., 2014; CDC, 2014). The cases of Salmonella from live poultry have increased 5-fold from 2015 to 2017. In 2015, there were 252 cases in 43 states with 0 deaths and 63 hospitalizations. Whereas in 2016, there were 895 cases in 48 states with 3 deaths and 209 hospitalizations. By September 2017, there had been 10 outbreaks of Salmonella due to live poultry with 1120 cases in 48 states that led to 249 hospitalizations and 1 death. These outbreaks were due to contact with live poultry for which $70 \%$ were from handling baby chicks and ducklings within 7 days of the onset of salmonellosis (Basler et al., 2016). Trace-back investigations indicated the following Salmonella serovars were the cause of these zoonotic outbreaks between 2015-2017: S. Enteritidis ser., S. Infantis ser., S. Muenchen ser., S. Mbandaka ser., 
S. Typhimurium ser., $S$. Litchfield ser., $S$. Braenderup ser. , $S$. Hadar ser. and $S$. Indiania ser. (CDC, 2017).

The rise in salmonellosis has been attributed to more backyard flock owners and an increase in handling of baby chicks, turkeys and ducklings which shed Salmonella easily (CDC, 2013; CDC, 2017). It is believed that $29 \%$ of illnesses that can be ascribed to live poultry exposure go unreported. Seventy-one percent of the illnesses were from owners practicing risky husbandry by keeping birds in their house and/or kissing their birds. In addition, $58 \%$ of these backyard flock owners were not aware that they could get Salmonella from their birds (Beam et al., 2013, Basler et al., 2016).

The World Health Organization (WHO) and the Food and Agriculture Organization (FAO) have declared salmonellosis to be one of the most important and common zoonotic diseases since 1950 (Bopp, 2003; Younus et al., 2012). This further emphasizes the need to understand the importance of Salmonella spp. in close proximity to humans. The best way to monitor and control Salmonella colonization in facilities, on farms, and among livestock or poultry is to do environmental sampling and testing (Waltman, 2000).

\subsection{Purpose of Study AND the Approach}

The purprose of this study was to obtain a clearer understanding of the commonness of Salmonella in backyard poultry and their environment with possiblity of this microbe posing a zoonotic risk. This study looked at the prevalence of Salmonella spp. in backyard poultry, and their coops within San Luis Obispo County. In order to accomplish this, samples collected from various sites around the county were cultured for Salmonella. Then 
to consider the public health aspects of backyard poultry ownership, the Salmonella spp. isolates were tested for antibiotic resistance to common antimicrobials. Finally, this study looked at the husbandry and biosecurity practices of backyard poultry owners that could play a role in the proliferation of zoonotic diseases.

\subsection{LIMITATIONS AND ASSUMPTIONS}

This study looked only at backyard flocks in San Luis Obispo County at one point in time. There were no further sample collections or follow-up collections in subsequent months to see if the shedding of Salmonella organisms were intermittent or continuous. The samples were collected from the poultry's housing environment with a concentration on fecal ridden areas and not cloaca samples. The sample isolates were not serotyped for specific Salmonella. The positive samples could have been cross contaminated from feed, wildlife feces, or other sources that were present in the coops. These contamination sources were not specifically isolated or tested but were assimilated into the coop sample by the means of collection methods.

This study makes the following assumptions:

- Salmonella will be present in backyard poultry and their environment. The prevalence of Salmonella in backyard poultry population will be similar to the positive isolates' percentages in international studies: 4\%-10\% in Paraguay (Leotta et al. 2010), 10.4\% in Australia (Manning et al., 2015), 26.8\% in India (Bhuvaneswari et al., 2015), 15.4\% to 66.7\% in Argentina (Xavier et al., 2011), and 14\% in the European Union (Van Hoorebeke et al., 2009). 
- Salmonella spp. isolates will show drug resistance in vitro to the most common antibiotics at the standard disk concentration levels. Furthering the idea that the Salmonella spp. has developed multidrug resistance in the poultry population and the environment (Helmuth, 2000; Wright et al., 2005; Marculescu et al., 2007; Leotta et al., 2010; Xavier et al., 2011; Manning et al., 2015).

- Backyard poultry enthusiasts will lack the knowledge for proper husbandry practices, are ill equipped to handle biosecurity, and lack the ability to recognize signs of disease in poultry, especially those that are zoonotic and/or can pose a public health risk. (Behravesh et al., 2014; Beam et al., 2013; Basler et al., 2016)

In the next chapter, Salmonella will be reviewed in general from its historical background and epidemiology in poultry to the development of its multidrug resistance. Then in Materials and Methods, the experimental design and protocols will be described as how samples were collected, cultured and tested. The study's findings are illustrated in graph and table form in the Results chapter; followed by the study's highlights in the Discussion chapter as it pertains to this study's assumptions. Finally, the Conclusion summarizes the study and elaborates on future work that can be generated from the foundation laid by this study. 


\section{LITERATURE REVIEW}

\subsection{SALMONELLA SPP.}

Salmonella is one of the most important bacteria that cause public health issues worldwide, with poultry being the main source of non-host specific Salmonella infections for humans. Live poultry, meat, eggs, and by-products are the largest Salmonella reservoirs in the food chain that affect humans. In poultry, $10 \%$ of all Salmonella spp. have been detected (Hafez et al., 2000; FDA, 2009; FDA, 2012; Dale et al., 2013; Foley et al., 2013; Gast et al., 2014).

Salman and Smith identified the bacterium genus of Salmonella in 1885. Salmonella is gram negative, non-spore forming, rod-shaped, diameters around 0.7 to $1.5 \mu \mathrm{m}$, and lengths from 2 to $5 \mu \mathrm{m}$, with peritrichous flagella which allow for motility. Salmonella is a facultative anaerobe, as well as, a chemoorganotroph that use energy obtained from oxidation and reduction reactions. Salmonella spp. may or may not produce $\mathrm{H}_{2} \mathrm{~S}$ as a chemical property (Waltman, 2000; Younus et al., 2012).

Salmonella belongs to the family enterobacteriaceae. Salmonella comprises over 2579 species that affect humans and animals. The Salmonella classification has become very convoluted over the years as scientists try to identify and categorize more species as discovered, thus revising the taxonomy numerous times. The current taxonomy has 2 main species classifications, $S$. enterica and $S$. bongori, which can be delineated into 6 subtypes: S. enertica (I), S. salamae (II), S. enterica arizonae (IIIa), S. diarzonae (IIIb), S. houtenae (IV), S. indica (VI) (Grimont 2000; Levinson, 2012). Numerous serovars are harbored in 
animals that can cause zoonotic outbreaks in humans who come in contact with live animals, eat meat and animal by-products. Many animals are asymptomatic when it comes to Salmonella, but can shed the organism for several months on end and may continue to shed it intermittently (Merck, 2012). It persists in various external environmental conditions such as feed, litter, soil, eggshells, surfaces, meat products, on fur or feathers, and on fomites. The microbe survives in temperatures ranging from $2^{\circ} \mathrm{C}$ to $54^{\circ} \mathrm{C}$. Environmental contamination is suggested to play a role in human-poultry salmonellosis (Brenner et al., 2000; Poppe, 2000; Aminov, 2010; Merck, 2012; Younus et al., 2012).

\subsubsection{Mechanisms and Virulence of Salmonella Diseases}

The main mode of Salmonella transmission in humans and animals is by the fecal-oral route or ingestion. Though in poultry, there are several more susceptible routes for infection including ingesting contaminated dander, dust, exposure to nasal droplets and transmission during ovipositioning (Merck, 2012; Younus, 2012). In healthy human adults, the estimated infective dose of the Salmonella organism is approximately 1000 microorganisms or less. With nontyphoidal Salmonella, the infective dosage could be as little as one cell depending on virulence of the serotype or strain and the health status and age of the human recipient (Davis et al., 2003; CFSPH, 2005; CDC, 2012; FDA, 2012).

Salmonella enters the system targeting the intestinal mucosa and multiplying in the gutassociated lymphoid tissue (GALT) yet can spread through various parts of the body. The bacteria adapts from free roaming in the body to living and multiplying in the host's cells. It thrives in the host's cell by utilizing the cell's nutrients and by surviving the defenses 
mechanism from infected cells of the oxidants, and nitric oxide which is produced intracellularly (Baumler et al., 2000; Poppe, 2000; Foley et al., 2013).

Some Salmonella penetrates the intestinal wall's outermost layer of epithelial cells. The initial invaders are killed by the host cell's defense mechanisms but also in the process causes inflammation that destroys resident intestinal flora and protective cells. These normal intestinal florae are a crucial factor in impeding colonization of Salmonella. The ability of resident flora to prevent the invasion and colonization of Salmonella is called bacterial interference. The mechanisms thought to be used by normal gut flora to stop colonization of invasive bacteria are the release of inhibitory substances, decreasing competition for tissue adhesion sites and limiting nutrients availability. To avoid bacterial interference, Salmonella adheres to the gut wall and penetrates the intestinal mucosa (Baulmer et al., 2000; Poppe, 2000). Bacterial data suggests that systematic surveillance of Salmonella especially the diseases caused by poultry is crucial for control of animal and human salmonellosis (Hendriksen, 2003; Scallan et al., 2011).

\subsection{Historical PersPective of Salmonella in Poultry}

Early historical outbreaks of Salmonella in poultry can be traced back to Salmonella Pullorum ser. and Fowl Typhoid, S. Gallinarum ser.. Both were common in the late 1800's and early 1900's in commercial poultry flocks (Helmuth, 2000; CFSPH, 2005).

One of the most important diseases of commercial poultry was Salmonella Pullorum, or Pullorum Disease, which was first recognized by Rattler as having the characteristically notable white diarrhea. Rettger described it as "septicemia of young chicks" or "fatal 
septicemia of young chicks." It later came to be identified as a common worldwide poultry disease by egg-transmission. Tests were developed to identify carriers of this disease, first a macroscopic tube-agglutination test, then a stained antigen test from whole blood (Helmuth, 2000; Barrow et al., 2012).

Fowl Typhoid is another important poultry disease. Its earliest documented outbreak was in England in 1888 which decimated a 400 chicken breeder farm. S. Gallinarum, Fowl Typhoid, is a septicemia disease that affects turkeys and chickens in almost every poultry producing country in the world (Hafez et al., 2000; Poppe, 2000; CFSPH, 2005).

Paralleling these two poultry diseases, there was $S$. typhi, a species-specific human form of Salmonella which caused Typhoid Fever. During the first half of 1900, due to surveillance and testing, Typhoid Fever outbreaks in humans declined primarily in Europe and the United States (Helmuth, 2000). But the prevalence of Fowl Typhoid and Pullorum Disease, 2 poultry Salmonella diseases, did not subside, but stunted the growth of the poultry industry worldwide with high mortality rates in flocks until testing and control measures were implemented (Helmuth, 2000; Poppe, 2000). Based on the success of monitoring and controlling the human $S$. typhi, the United States started a voluntary testing program of poultry breeding stock and progeny which decreased the incidences of Fowl Typhoid and Pullorum Disease. The program, started in 1935, was called National Poultry Improvement Program (NPIP) (USDA, 1997; Poppe, 2000). Over the years, NPIP's success not only showed less prevalence of these diseases in many developing countries; but currently, in USA, Canada, and Europe, there is no or very low prevalence of these poultry diseases. There are still some issues with these poultry diseases in Africa, Eastern Europe, China, Central and South America (Poppe, 2000; Younus et al., 2012). 
The most relevant growth of non-host specific Salmonella serovars since the 1940s can be attributed to humans and animals, particularly with $S$. Typhimurium which is prevalent in many countries and is zoonotic. Large outbreaks of salmonellosis have been traced back to primarily poultry products and live poultry as the main source of non-specific Salmonella infecting humans. Other animal products such as beef, pork, and dairy products have caused salmonellosis in humans, but poultry is the main culprit of this zoonotic public health risk (Poppe, 2000; CDFA, 2009; CDFA, 2012; Hafez et al., 2000; FDA, 2012; CDC, 2012; Merck, 2012).

Currently, the increase in incidents of salmonellosis can be attributed to contact with live poultry. In 2012, 195 people in 27 states were infected with Salmonella Infantis, S. Lille ser., $S$. Newport ser., and $S$. Mbandaka which were traced back to contact with chicks and ducklings, from the Mt. Healthy Hatcheries in Ohio. In 2013, 158 people in 30 states reported Salmonella incidents due to live poultry which could be again traced backed to the same hatchery in Ohio. In 2014, an Ohio hatchery was attributed with 363 people in 43 states and Puerto Rico contracting Salmonella from baby poultry (Helmuth, 2000; Poppe, 2000; CDC, 2013; CDC, 2014).

Also, in 2014 Salmonella Heidelberg ser. was reported in 9 cases from raw poultry products in Tennessee. However, the under-reporting of animal and human salmonellosis is still prevalent. Utilizing surveillance data systems, broad comparisons can be made to identify trends, reservoirs and transmission routes of Salmonella serovars (Poppe, 2000; CDC, 2012; CDC, 2013; CDC, 2014). 


\subsection{EPIDEMIOLOGY}

There are numerous sources of Salmonella infection in domestic fowl. Other animals, birds, humans, and the environment can be contaminated by Salmonella, all contributing to infections in poultry. Domestic poultry, wild birds, domestic and wild animals can be colonized with Salmonella spp.. Colonization may happen with or without clinical signs, asymptomatic (carriers or reservoirs), latently infected and/or subclinical carriers that may shed the bacteria intermitently or persistently in their feces becoming probable source of environmental contamination (Holt, 2000). There are two main modes of Salmonella transmission: horizontal and vertical (Steele, 1963; Henzeler et al., 1994; Poppe, 2000; Chiu et al., 2004; Merck, 2012) that can lead to the egg being infected with Salmonella spp.. It is estimated that 1 in 20,000 eggs has Salmonella in it (Spiller, 2000).

\subsubsection{Horizontal Transmission}

Poultry horizontal transmission of Salmonella is through litter, feed, water, bedding, straw, eggshells, equipment and other fomites. Reservoirs of Salmonella spp. can be rodents, domestic animals, insects, reptiles, wild animals, wild birds, and humans, which all have the potential of spreading Salmonella spp. (Henzeler and Optiz, 1992; Henzeler et al., 1994; Merck, 2012; Younus et al., 2012). These reservoirs shed different Salmonella serovars that can be species specific or multi-species affecting serovars. Many of these hosts or reservoirs regularly or intermittently shed the microorganisms into the environment at differing virulence up to weeks after an infection. Salmonella spp. can also be transported 
into poultry areas on fomites such as cleaning equipment, or by human clothing and shoes (Merck, 2012; CDC, 2013).

\subsubsection{Litter}

Salmonella is prevalent in chicken fecal litter and dust which is an important source of contamination of poultry. Salmonella is highly viable in fresh litter due to moisture content. The viability of the microorganism decreases as the litter is piled up or dried. As chickens, especially chicks, tend to peck at the fecal material and droppings of littermates, Salmonella in the litter can easily spread throughout the environment. Chickens housed on built-up litter are less likely to be infected by Salmonella spp. due to lack of moisture. When moisture is introduced to piled litter in direct contact with birds, the $\mathrm{pH}$ of the litter increased due to an ammonia reaction with water, the incidents of Salmonella multiplied under these conditions (Poppe, 2000). The possible explanation for the increase in Salmonella incidences is the number of viable microorganisms, and the facilitated transmission when water is introduced to piled dry litter (Henzeler et al., 1994; Poppe, 2000; Merck, 2012; Younus et al., 2012).

\subsubsection{Water}

The spread of Salmonella can be attributed to fecally contaminated water. Waterers placed on the barn floor where the poultry can defecate or walk in will harbor the microorganism. Poultry with debris on their beaks containing Salmonella can also contaminate the water sources of a facility. Incidences of Salmonella increases when using water troughs and plastic bell drinkers. Lower incidences were attributed to nipple drinkers. (Poppe, 2000; Merck, 2012; Younus et al., 2012). 


\subsubsection{Feed}

Poultry contamination by feed is lower than the contamination incidences of litter, water, and dust. When an environmental examination was done of broiler facilities, Salmonella contamination was found only in $13.4 \%$ of the feed samples, yet found in $46.4 \%$ of the litter samples and $12.3 \%$ of the water samples (Poppe, 2000, Younus et al., 2012). Feed contamination happens several ways: directly by the chickens or rodents who shed Salmonella by defecating or walking in the feed; or indirectly, during the growing/harvesting process by contaminated fertilizer, waters sources, equipment or wild animals and bird feces and/or further contamination at a processing facility that is tainted with Salmonella (Poppe, 2000; Wales et al., 2007; Ribeiro et al., 2011; Younus et al., 2012).

\subsubsection{Rodents and Wildlife}

As most farms have a resident and transient rodent population, these vermin play a vital role in the spread of Salmonella environmentally. They pick up the Salmonella organism from the environment then shed the microbes in the vicinity of poultry, especially contaminating the feed. In a study conducted by Henzler in 1994, it was found that one

pellet of mouse feces can contain as much as $10^{5}$ of $S$. Enteritidis (Henzler et al., 1994; Poppe, 2000). To emphasize, the spread of contamination via rodent populations, 5 separate poultry facilities were utilized. The study showed that $31.8 \%$ of the 483 mice collected had Salmonella spp. in their feces and $24 \%$ of 483 mice was specifically $S$. Enteritidis (Henzeler et al., 1994; Poppe, 2000). 
Other wildlife, especially wild birds, play a role in transferring Salmonella spp. to poultry. Wild birds are a large reservoir of many zoonotic diseases that can be transferred through the fecal-oral route by defecating into waterers, feeders and around the coops that poultry have access to. The poultry is then exposed to pathogenic diseases from wild birds through ingestion (Poppe, 2000; Saif, 2008; Sanchez et al., 2015).

\subsubsection{Stress}

Poultry under stressful conditions such as induced molting, over-crowding or the lowest in the pecking order hierarchy, have a higher ratio of Salmonella organisms in their system. Birds under stress develop a secondary immunodeficiency that allows for opportunistic microbes such as Salmonella spp. to flourish by out competing their own resident gut flora (Poppe, 2000; Merck, 2012).

Induced molting is a common management practice in poultry production whereby food and water are slowly reduced along with the gradual reduction of the photoperiod which shifts the birds into physiological changes allowing for a new egg laying cycle. This practice increases the Salmonella shedding levels as the stress of the process reduces the immunity and unbalances the residential gut microbes. Intestinal $S$. Enteritidis increased 100-1000 fold in molting hens versus hens that were not molting. The organism also spread more readily to neighboring caged hens, in turn infecting them (Henzler et al., 1994; Poppe, 2000; Spiller 2000; Saif et al., 2008; Wales et al., 2007).

Overcrowding increased the spread of Salmonella as the birds in closer proximity easily contaminated their feed, water, and environment. The stress of over-population can result in intensive pecking order interactions, thus increasing the shedding of Salmonella by the 
lowest birds in the hierarchy. In over-crowding situations, birds can also resort to cloaca pecking which can spread the microorganism through beak debris to feed, water and the environment (Poppe, 2000; Saif et al., 2008; Younus et al., 2012).

\subsubsection{Sanitation and Environment}

Sanitation practices on a production farm are important especially around disposal of manure or fecal matter which can be accessed by wildlife and insects. Rodents, wild animals, wild birds and insects, flies and beetles, that have access to lagoons or manure piles can acquire Salmonella environmentally, become carriers and shed the organisms intermittently or continuously where the poultry are housed or where the feed is stored (Wales et al., 2007; Saif et al.. 2008; CDC, 2012).

Environmentally, Salmonella is known to survive in soil for up to a year in moist conditions but only 5-7 days in water. When sewage is present in water, Salmonella's survivability increases from several days to months due to a nutrient source being provided (Poppe, 2000; Wales et al., 2007; Saif et al., 2008).

\subsubsection{Housing}

Housing management practices on a poultry facility play a vital role in the spread of Salmonella among the bird population. Caged birds where fecal matter drops away from the birds have lower incidents of Salmonella infection and colonization in the population than cage/free-range birds that are walking, sitting or more readily pecking at feces which may be tainted with Salmonella (Poppe, 2000; Saif et al., 2008) . 
Modern caged birds have fewer incidents of contamination from Salmonella-infected fecal matter than older caged systems as the fecal matter is swept away from the chickens rather than dripping down onto the next cage or sitting in the cage. In these caged systems, eggs are removed by conveyor belt which lessens the risk of exposure of environmental contamination from the cage (Whiley and Ross, 2015). When birds are cage-free or rangefree, there is more exposure to litter, feed, and environmental contamination from Salmonella. Though there is much debate around cage-free versus caged poultry production as to which system provides more increased exposure to Salmonella, it is important to note that cage-free birds and their eggs may have a prolonged time to be exposed to tainted Salmonella surroundings (Poppe, 2000; Wales et al., 2007; Saif et al., 2008; Whiley and Ross, 2015). Cage-free flocks tested positive 3.5 more times for Salmonella than caged poultry (Sanchez et al., 2015).

\subsubsection{Penetration of the Eggshell}

Poultry with heavy enteric Salmonella infections can contaminate the eggshell as it goes through ovipositioning and is eliminated from the cloaca. Fecal matter attached to the eggshell when it is still warm and porous can penetrate the shell before the proteinaceous cuticular barrier becomes solidified which acts as a barrier for any bacteria entering the egg. Also, eggs in range-free or cage-free systems that are not collected immediately will stay longer periods of time in the contaminated environment. These eggs have a higher risk of harboring Salmonella from prolonged exposure to tainted surroundings (Henzeler et al., 1994; Howard et al., 2012; Younus et al., 2012; Foley et al., 2013; Gast et al., 2014) 
Another mode of entrance into the innards of the egg is when the eggshell has cracks, checks or toe-picks allowing the microbes to enter the egg contents directly. Also, any infected fecal matter on the outside of the eggshell can contaminate the egg when broken opened for preparing food and infecting the surrounding environment if egg content material is spilled (Howard et al., 2012; Younnus et al., 2012; Foley et al., 2013; Gast et al., 2014).

\subsubsection{Vertical Transmission}

Two modalities of vertical transmissions of Salmonella exist: 1) as the egg develops in the oviduct or from infected follicles in the ovaries prior to oviposition (which is considered true vertical transmission); and 2) the egg and/or developing chick becomes infected by fecal matter on the outside of the eggshell or contamination on floor or litter penetrating into the interior of the egg during incubation. Further, the microorganism can be harbored in the lymphatic system, air sacs, ovaries, oviduct, peritoneum, cloaca, and ceca easily spreading Salmonella to other organs or systems in the animals (Poppe, 2000; Ahmed et al., 2011; Howard et al., 2012; Merck, 2012; Younus et al., 2012).

S. Pullorum and S. Gallinarum are the two main serovars naturally inhabiting the reproductive tract, oviducts, and ovaries which cause true vertical transmission of Salmonella in hatching eggs. For Salmonella to inhabit these areas, a systematic infection occurred and colonization occurred before oophoritis. S. Typhimurium, in vitro, $S$. Heidelberg and $S$. Menston ser. are more serovars that affect the reproductive system or are transovarial. More commonly $S$. Enteritidis colonizes liver, spleen, heart and intestines, 
which can spread to other organs producing systemic infections. It is not unusual for $S$. Enteritidis to infest the innards of eggs that are in the human food supply (Poppe, 2000; Barrow et al., 2012; Dale et al., 2013). It is estimated that 1 in 20,000 eggs contains Salmonella (Spiller, 2000). Moreover, it has been determined that $2 \%$ of the eggs on the market may have or have been exposed to Salmonella (Sanchez et al., 2015).

During the ovopositioning the egg is contaminated by infected tissue that is from the ovaries or in the oviduct where the organism can linger and multiply. Anywhere along the egg's path during oviposition, Salmonella can enter the egg if the bird is infected (Poppe, 2000; Saif et al., 2008; Barrow et al., 2012; Dale et al., 2013).

\subsection{ANTIBACTERIAL RESISTANCE IN SALMONELLA}

Microorganisms have a biological need to reproduce, multiply and thrive. These microorganisms acquire the ability to protect themselves from hostile environments or antimicrobials by developing resistance (Helmuth, 2000; Greene, 2006; Drlica and Perlin, 2011).

Microorganisms have mechanisms of adaptation to adjust to adverse and hostile environments, immune systems and chemotherapy which aid in antibacterial resistance. There are 3 mechanisms that allow microbes to survive and prosper which can lead to therapeutic failures: 1) intrinsic or innate resistance; 2) acquired resistance which are mutations in the chromosomal gene on the target site; 3) specific resistance genes with the ability to demolish or inactivate the antimicrobial agents that put selective pressure among spreading populations (Greene, 2006; Ashmed et al., 2011; Drlica and Perlin., 2011). 
For the veterinary field, antibacterial resistance, especially for Salmonella, has two areas of concern: microorganism resistance which will cause the general failure of antimicrobial chemotherapy in animals; and more importantly the resistance developed by microbes that creates zoonotic pathogens (Helmuth, 2000; Jones and Ricke, 2003; Greene, 2006; Drlica et al., 2011). When microorganisms develop a resistance to antibacterial drugs, it decreases the ability for the medical profession to manage zoonotic illnesses in humans--thus, increasing the public health risks (Greene, 2006; Marculescu et al., 2007; Foley and Lynne, 2008; Drlica and Perlin, 2011; CDC, 2012).

In livestock husbandry, production medicine or population medicine is the preferred practice over individual therapy. The flock is treated as a group or as a "whole" because microorganisms can spread rapidly throughout confined areas. Treatment of an individual bird can create higher stress levels by handling which leads to lower immunity and decreases production levels (Saif et al., 2008; Merck, 2012). Thus, in animal husbandry, antimicrobial agents are commonly used in the feed and additives for the following purposes: therapy, prophylaxis, and growth promoters (Poppe, 2000; Jones and Ricke, 2003; Greene, 2006; Saif et al., 2008). The overuse of antimicrobials as feed additives for therapeutic and prophylaxis use causes selective pressure on the bacterial population of which evidentially leads to antimicrobial resistance. These practices vary in regions around the world. In the United States where feed additives are widely used, selective pressure is higher on the Salmonella genes for antimicrobial resistance. In countries, such as Sweden where low levels of antimicrobials in the feed are used, there is lower selective gene resistance in Salmonella (Helmuth, 2000; Wright et al., 2005). Due to resistance emergence in pathogens such as Salmonella, the FDA and USDA began to restrict the use 
of antimicrobials as a feed additive for growth promotions and feed efficiency as of January 2017. As of January 1, 2018, California has taken it a step further, restricting the use of antibiotics in the livestock production industry by requiring veterinary supervision regarding treatment, control or prevention of any disease. The use of antibiotics in medicated feed continuously has been decreased or prohibited if used for growth promotion, feed efficiency and "regular pattern" preventive use or goes beyond the scope of veterinary oversight (CDFA, 2017).

Since the development of antimicrobials in the 1940's, microorganisms have been evolving and developing resistance to protect themselves and continue to prosper when selective pressure has been imposed. In the animal husbandry practices, minimum inhibitor concentrations (MIC) of antimicrobials are added to feed or water to control colonization of opportunistic microbes that disrupt the residential flora of animals. These MIC antimicrobials place selective pressure on microorganisms that want to thrive within livestock populations (Chin, 2000; Helmuth, 2000; Jones and Ricke, 2003; Wright et al., 2005; Greene, 2006; Saif et al., 2008).

Antimicrobials have been developed to disrupt the ability for microorganisms to multiply and thrive. There are five basic mechanisms that antibiotics were developed to interfere with microorganisms: 1) cell wall synthesis, 2) protein synthesis or translation, 3) the alteration of cell membranes or target sites, 4) nucleic acid synthesis and 5) the alteration of metabolic activity (Martinez et al., 2009; Drlica and Perlin, 2011). Some of the most common and widely used antibiotics are ones that interfere with the cell wall and inhibit protein synthesis. Antibiotics, used in this study, that inhibit cell wall production are Penicillin and Amoxicillin, both beta-lactams (Wreth, 2018). Antibiotics, used in this 
study, that interfere with protein synthesis are Tetracycline, a naphthacene, Erythromycin, a macrolide, Bacitracin, a polypeptide, and Gentamicin, an aminoglycoside, (Martinez and Baquero, 2009; Drlica and Perlin, 2011; Wreth, 2018). These antibiotics are commonly used in the livestock industry to therapeutically treat animals or for prophylactic purposes (Jones and Ricke, 2003; Saif et al., 2008; Martinez and Baquero, 2009).

To counteract antimicrobial chemotherapy, Salmonella spp. antimicrobial resistance genes spread by either individual genes and/or by movement of complex genetic material. Salmonella capitalizes on these two biological mechanisms by using the following: 1) transduction which is used by many Salmonella serovars to deliver genes by prophases or to inhabit biotopes with transducing phages; and 2) more importantly, resistance genes spread by conjugation using plasmids. These two mechanisms transfer Salmonella DNA with R-factors which are thought to carry genetic structures called transposons and integrons which allow the resistance genes to combine with the Salmonella's chromosomal DNA to encode for specific antimicrobial resistance (Helmuth, 2000; Ahmed et al., 2009; Martinez and Baquero, 2009; Ahmed et al., 2011; Keen and Monforts, 2012).

The ability of Salmonella to adapt and acquire antimicrobial resistance has been found to have patterns in the environment. Resistance has been isolated to geographical regions, within a specific serovar or even at a single facility (Helmuth, 2000; Ahmed et al., 2009; Ahmed et al., 2011; Keen and Monforts, 2012). Moreover, and of upmost concern, is the emerging multidrug resistance in many Salmonella serovars due to the chromosomal integration of these resistance genes. For many years, Salmonella resistance has been known for basic antimicrobial agents: tetracycline since 1956; streptomycin and sulphonamide in 1963; Ampicillin, chloramphenicol, and kanamycin in 1974; Gentamicin 
in 1983, Fluoroquinolones since 1990, trimethoprim since 1992. Though many of these antimicrobials are chemotherapy resistant specific, multidrug resistance became a major concern among a broad spectrum of Salmonella serovars during the 1980-1990s (Helmuth, 2000; Wright et al., 2005; Marculescu et al., 2007). Animal production is affected if therapeutic measures fail due to high multidrug resistance. Multidrug-resistant Salmonella (MDRS) from animals is a zoonotic public health issue that must be monitored for the rise in human illness and disease. The CDC has classified Salmonella's drug resistance as a "Serious Threat Level" to human health because $5 \%$ of all non-typhoidal Salmonella is resistant to 5 or more antibiotic classes. The over-all resistance rate in Salmonella is $8 \%$ (CDC, 2013). Salmonella surveillance data has shown an increase in resistance from approximately $30 \%$ in the 1990 s to around $70 \%$ in several countries in the 2000 s (Su et al., 2004). MDRS is a superbug that is climbing onto the world stage of zoonotic diseases and is one to watch (Bopp, 2003; Wright et al., 2005; Martinez and Baquero, 2009; Scallan et al., 2011).

\subsection{PREVENTION}

Prevention has two basic areas of focus: 1) to keep the introduction of microorganisms or disease out of a population or 2) to prevent the spread of any introduced disease or microorganism within a population. To arrest the spread within or introduction of an microorganism or disease to a population may be accomplished by husbandry practices that include vaccination, certified pathogen free programs, biosecurity, medicated feed, control exposure to diseased animals or wildlife, quarantining new animals before 
introduction into the population, having a farm health plan developed with a veterinarian, and controlling the movement of animals, humans, equipment in and out of the farm. Moreover, the prevention and control of a disease can be graphically shown by a break in a component in the Epidemiological Triangle (see Figure 1) that represents the totality of the aspects of the conditions that makes it ideal for a disease to survive within a population (Flynn, 2008; CDC, 2012; Merck, 2012).

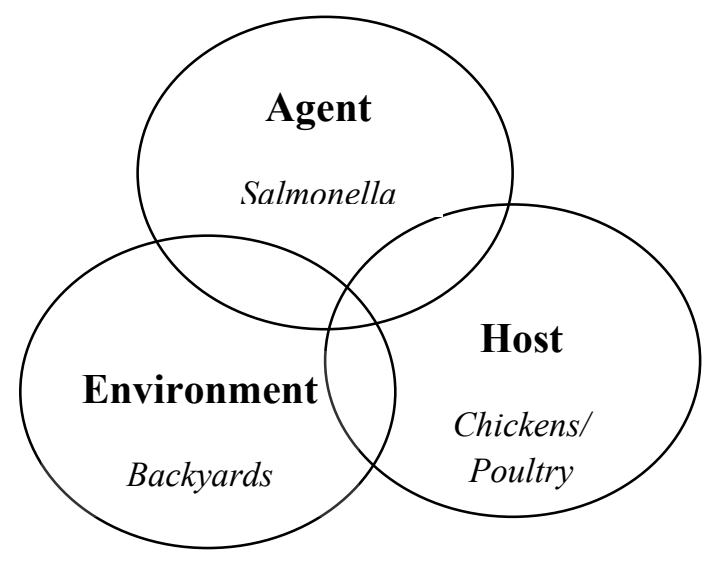

Figure 1: Epidemiological Triangle

There are three interconnecting components, Agent, Host, and Environment that play a key role in how a disease moves through a population. Once the Agent has been identified with virulence confirmation, understanding the Host and the Environment allows a disease to be controlled and contained. Being able to isolate these components by breaking their interconnectivity decreases the rate of a disease distribution in a population. A biosecurity plan, as part of a livestock risk management plan, must consider how to sever these relationships that create the optimum conditions for an opportunistic pathogen to develop into a large-scale livestock outbreak (Flynn, 2008; CDC, 2012). 
With the known Agent, Salmonella spp., in the above diagram, understanding the Host and Environment must be theorized to comprehend a pathogen's transmission throughout a population. The following areas need to be addressed in a biosecurity plan to arrest epidemiological spread of any disease especially a zoonotic pathogen:

- For the Host: Chicken/Poultry

- Location of the poultry to humans

- Density of the birds (concentration)

○ Movement of the poultry (backyard)

○ Purchasing "Certified Pathogen-Free" poultry

- Vaccination programs

○ "All-in, All-out" practices for movement of birds

- For the Environment: Backyard

○ Housing of the poultry

- Animal and human population density

- Combination of species by density

- Movement of animals

- Husbandry: feed, water and sanitation

$\circ$ Management practices

○ Biosecurity plan

○ Treating poultry as livestock versus pets

Prevention of a Salmonella outbreak that transfers into the human population can be controlled by the following prevention methods: purchasing birds from a "certified 
pathogen-free" breeder; proper sanitation and disposal of fecal matter; vaccination of birds; biosecurity plans; controlling environmental factors such as exposure to rodents and/or contaminated feeds and water; decreasing stress in the flock; and basic hygiene after handling poultry (Steele, 1963; Jaocb et al., 2003; Flynn, 2008; Whiley and Ross, 2015).

To decrease incidents of Salmonella exposure from backyard poultry, education of hobby farmers is imperative regarding proper husbandry and handling of poultry and poultry products. Understanding the necessity of washing one's hands after handling birds and collecting eggs is essential and can greatly decrease the risk of Salmonella borne illness. Teaching appropriate food preparation by fully cooking meat and eggs products, not eating poultry products raw and refrigerating eggs at a minimum of $35^{\circ} \mathrm{F}$ to slow any bacterial growth within an egg can decrease incidents of foodborne salmonellosis. Education and understanding of Salmonella as to its relationship to poultry and poultry products can decrease the inherent risk in owning flocks. Only by practicing proper husbandry skills and good hygiene can a public health risk be avoided (USDA, 1997; Davis et al., 2003; CDC, 2012; Basler et al., 2016). 


\section{MATERIALS AND METHODS}

\subsection{EXPERIMENTAL DESIGN}

This experimental study was designed to be 3-fold: sample collection, laboratory experiments and a questionnaire.

The first phase of the study was collection of environmental samples, especially fecal, from poultry houses and yards, then culturing them to isolate Salmonella spp.. The predicated percentage range from $4 \%$ to $26.8 \%$ of Salmonella prevalence in backyard population was based on the international studies dealing with epidemiology in flocks (Helmuth, 2000; Wright et al., 2005; Marculescu et al., 2007; Leotta et al., 2010; Xavier et al., 2011; Manning et al., 2015). Whereas, those studies mainly looked at chickens, in this study, poultry is defined as domestic fowl, chickens, ducks, geese, turkeys, and pigeons, as these species were housed together at times and all kept as backyard flocks (USDA, 2011).

The second phase of the study was designed to expose inherent disease risks that backyard poultry may pose to the public health and the agriculture industry. This study further tested the Salmonella spp. isolates for antimicrobial sensitivity. The Kirby-Bauer method used tested 6 antibiotics commonly prescribed by the medical and veterinary professions. It was predicted that the Salmonella isolates would have various resistance in vitro to the antibiotics tested based on Salmonella emergence with multi-drug resistance (Helmuth, 2000; Wright et al., 2005; Marculescu et al., 2007; Leotta et al., 2010; CDC, 2013) .

Finally, in the third phase, a questionnaire was developed to cover the husbandry and care practices of poultry ownership to gain greater insight into backyard poultry owner's 
knowledge and handling of live poultry. Again, based on the CDC study, most backyard poultry owners lack the knowledge of proper care, husbandry and biosecurity for their birds (Basler et al., 2016; CDC, 2017).

\subsection{SAMPle COLLECTION FROM SiteS}

This study had 29 collection sites from around San Luis Obispo County. The sites were determined by word of mouth among the county's poultry community. The sites were distributed ranging from the inland valleys to the coast and urban to rural areas. The samples were collected during the months of March, April and May in 2014 during a continuous drought in California.

At each site, the Questionnaire and Release Forms were filled out and signed by the poultry owner. Photographs were taken of each poultry coop or yard where a sample was collected. Each poultry area where the birds were housed or had access to was treated as 1 sample. Fifty samples were collected from theses 29 sites. Some sites had more than 1 coop or poultry area, thus, requiring more than 1 sample to be collected at that site.

Every sample was collected using sterile methods. As the samples were collected out in the field, precautions were taken to avoid any cross contamination. Each sample was collected using the same protocols.

Once the collection site was reached, the researcher had the owner sign the Release Form and answer the Questionnaire. The researcher then set up the field collection area in the back of the car by laying out supplies needed on a new clean, sterile Pet Pride Super 
Absorbent Training Pad $(53.3 \mathrm{~cm}$ x $53.3 \mathrm{~cm})$. The researcher's hands were sanitized with antibacterial gel (CVS) before putting on disposable rubber gloves (Adenna Miracle Nitrile Powder Free Examination Gloves).

Ten milliliters (ml) of Skim Milk 2x Broth (Hardy Diagnostics, California.) was used to moisten the Envirobootie ${ }^{\mathrm{TM}}$ II. The Skim Milk Broth was kept in a cooler on ice packs no more than 6 hours at a time. Otherwise, the Skim Milk Broth was refrigerated in between collection dates. Once gloved, the researcher took out 1 test tube of $10 \mathrm{ml}$ Skim Milk Broth $2 \mathrm{x}$ from the cooler, then wiped the lid of the test tube with an alcohol prep pad. The Sterile Alcohol Prep Pad (CVS Pharmacy- 70\% Isopropyl Alcohol) was disposed into a garbage bag. The outside of the Envirobootie ${ }^{\mathrm{TM}}$ II Whirl Bag was also wiped down with another alcohol prep pad. The Whirl Bag (Nasco, Inc., Wisconsin) was then labeled using a black sharpie with the sample number which consisted of the date, sample site number, distinguishing letter identifiers. The Skim Milk Broth was poured into the Envirobootie II's Whirl Bag. The Whirl Bag was closed and massaged to disperse the Skim Milk Broth evenly coating the Envirobootie ${ }^{\mathrm{TM}}$ II. After thoroughly coating the Envirobootie ${ }^{\mathrm{TM}} \mathrm{II}$, the Whirl Bag was placed in a sterile jar labeled with the same sample collection number matching the Whirl Bag's numbers (Hardy Diagnostics, 2009).

Plastic Boot Covers (Nasco, Inc., Wisconsin) were placed over collector's shoes for cross contamination control once the coop was reached and before entering it. Once inside the coop, the Envirobootie ${ }^{\mathrm{TM}}$ II was placed over one of the plastic boot covers. The sample was gathered by walking the entire coop/area, paying special attention to fresh feces, feces in laying/perch/bedding or communal areas and around the feed and waterers. Before leaving the coop, the Envirobootie ${ }^{\mathrm{TM}}$ II was removed from the covered shoe and placed 
back into the Whirl Bag. The Whirl Bag was folded, closed with a twist tie and placed into the sterile, labeled jar with the same sample number as the Whirl Bag. The labeled jar was placed in the cooler.

The plastic boot covers and gloves were both removed and disposed of. For each new poultry site collected or if a site had more than 1 coop or poultry yard on site, the same protocols were followed as above. The samples were taken to the laboratory within 6 hours of collection.

In the laboratory, the bench was wiped down with Envirocide ${ }^{\circledR}$, and a section of a sterile pad was laid on the lab bench. A Bunsen burner was lit to create an aseptic zone to process the samples. Disposable gloves were worn. Each sample jar lid was wiped down with alcohol before being opened. Also, between each sample, gloves were replaced. The Whirl Bag was opened to pour in $100 \mathrm{ml}$ of buffered peptone-enriched water (Hardy Diagnostic Inc). Then the Whirl Bag was closed loosely to avoid excess gas being trapped splitting the bag as bacteria growth happens. The Whirl Bag was swirled several times to disburse the liquid and placed back into its corresponding labeled jar. Jar lids were also loosely screwed back on. The jars were then placed in the incubator for 48 hours at $35^{\circ} \mathrm{C}+/-2^{\circ} \mathrm{C}$. (Hardy Diagnostics, 2009) 


\subsection{IsOlating COLONIES ON Plates}

The laboratory bench was prepared for aseptic conditions by being wiped down with Envirocide $^{\circledR}$, a sterile pad laid down, and a Bunsen burner lit and gloves donned. Under aseptic conditions, a sample was opened. After sitting in enrichment buffered peptone water for 48 hours to allow for microbial growth, a sterile cotton swab was dipped into the liquid that surrounded the Envirobootie ${ }^{\mathrm{TM}} \mathrm{II}$ in the Whirl Bag. The wet swab was used to cover the entire HardyCHROM ${ }^{\mathrm{TM}}$ SS Agar plate (Hardy Diagnostics, California). The standard microbiology method for swabbing a plate was used. After the wet swab was rubbed over the plate in a zigzag pattern, the plate was rotated $90^{\circ}$ to rub the swab over the plate again which was then rotated $90^{\circ}$ to repeated for a $3^{\text {rd }}$ time. The plate bottom was labeled with sample number, plus plating date. The plate was turned upside to be placed in the incubator for another 48 hours at $35^{\circ} \mathrm{C}+/-2^{\circ} \mathrm{C}$.

After 48 hours the HardyCHROMTM SS Agar plates were examined for colony growth. Two types of Salmonella colonies could grow on the media: 1) black colonies which are $\mathrm{H}_{2} \mathrm{~S}$ producing Salmonella spp. and 2) teal colonies which are non- $\mathrm{H}_{2} \mathrm{~S}$ producing Salmonella spp. (see Appendix A Figure 39). The black and/or teal colonies were then reisolated individually under aseptic conditions onto HardyCHROM ${ }^{\mathrm{TM}}$ Salmonella plates for a secondary verification. Using a flamed loop, an isolated colony whether black or teal from the HardyCHROM ${ }^{\mathrm{TM}} \mathrm{SS}$ plate was selected and then streaked onto the HardyCHROM ${ }^{\mathrm{TM}}$ Salmonella plate (Hardy Diagnostic Inc., California). The plate was streaked with the loop sample, then rotated $90^{\circ}$ to streak a second time, rotated again to streak for a third time. Each streaking pattern crossed over the previous streak slightly. The streak pattern was the standard way a plate should be done for colony isolation. These 
plates were labeled with the sample number, whether teal or black and date inoculated on the bottom. Then the plate was put into the incubator upside down for 48 hours at $35^{\circ} \mathrm{C}$ $+/-2^{\circ} \mathrm{C}$. Plates were read in 48 hours for colony growth. Pink to deep magenta colonies indicated Salmonella spp.(see Appendix A Figure 39) (Hardy Diagnostics, 2009).

\subsection{INOCULATING TSA SLANTS}

Using aspectic practices as previously mentioned in above sections, selected pink or deep magenta Salmonella colonies were collected from the growth on the HardyCHROM ${ }^{\mathrm{TM}}$ Salmonella plates. These colonies were transferred onto Trypticase Soy Agar (TSA) slants for growth to be used for the antimicrobial sensitivity test (Bauer et al., 1966).

Before opening the TSA test tube, the cap was passed through the flame three times. Using a sterile loop, a colony was collected from the plate and put onto a TSA slant. The TSA agar was prepared as directed. The standard method of dragging in a squiggly pattern across the surface of the slant was used. Before recapping the tube, it was passed through the flame three times. Tubes were placed in the incubator for $24-48$ hours at $35^{\circ} \mathrm{C}+/-2^{\circ} \mathrm{C}$. Each tube was labeled with the date inoculated, sample number and whether the sample was from a teal or black colony.

After 48 hours, the samples were checked for growth. Once clear growth was identified, the slants were placed in the refrigerator at $4^{\circ} \mathrm{C}$ to preserve the colony and slow its growth. These samples were refrigerated to be processed in batches for the Antibiogram tests. (Hardy Diagnostics, 2009). 


\subsection{ANTibiogram (Kirby-BAUER Method)}

The Kirby-Bauer Method used is the standard antibiogram method or antimicrobial disk diffusion tests in microbiology (Bauer et al., 1966).

Under aseptic conditions in a clean zone, a flamed loop was used to pick a sesame seed size sample of the colony from the TSA slant. The loop was dipped into the Broth Media Test Tube and swirled around to disburse the sample within the Trypticase Soy Broth (TSB). The top of the tube was replaced and passed quickly through a flame 3 times. Then the tube was placed in the incubator for $12-16$ hours at $35^{\circ} \mathrm{C}+/-2^{\circ} \mathrm{C}$. Each tube was labeled with the date, sample number and Salmonella identifier of black or teal colony. The TSB culture broth must be made 12-16 hours before making the antimicrobial culture plate.

The following was all done under a biosafety cabinet with the vent on to prevent cross contamination of any pathogens in the laboratory room. The culture density was adjusted to $0.05 \mathrm{McF}$ arland which is the standard scale for Kirby-Bauer tests. The lines on the Wickerham card is viewed through the TSB to achieve this (Hudzicki, 2009). A sterile cotton swab was dipped into the broth culture mixture. The sample saturated swab was rolled over the entire agar plate to cover completely. The plate was allowed to dry for 5 minutes. Using an antibiotic disk dispenser, the antimicrobial disks were placed onto the agar plate $2 \mathrm{~mm}$ apart. The antibiotic disks as labeled were used were Ampicillin $10 \mu \mathrm{g}$

(AM), Penicillin 10 units (P), Tetracycline $30 \mu \mathrm{g}$ (TE), Bacitracin $10 \mu \mathrm{g}(\mathrm{B})$, Gentamicin $10 \mu \mathrm{g}(\mathrm{GM})$, Erythromycin $15 \mu \mathrm{g}(\mathrm{E})$. The disks settled into the agar for about 20 minutes with the plate lid on. Each plate was labeled with the date, sample number and Salmonella 
identifier of either black or teal colony. Then plates were put into the incubator for 24 hours at $35^{\circ} \mathrm{C}+/-2^{\circ} \mathrm{C}$. After 24 hours, the diameter of the "clearing" zone (halo) around the antibiotic disks were read. The halos around each disk were measured with a mm ruler. If the circles overlapped, the radius was measured from the center of the disk to the edge and multiplied by 2 to get the diameter of the halo. The results were recorded for each antibiotic disk for each Salmonella sample plated. To have consistency in the measurement readings, the same researcher read all the plates each time.

Interpretation of the antimicrobial results is based on the specifics for Salmonella spp. were available, otherwise, the measurements for enterobacteria were used from Kirby-Bauer Antimicrobial Test Levels in the Clinical and Laboratory Standard Institute (CLSI, 2012). Using the "clearing zone" chart for Salmonella spp., the size of the halo was interpreted as "resistant, intermediate or susceptible". The sensitivity levels for each antibiotic has predetermined numerical values for Salmonella spp., based on the CLSI clinical standards as to whether there is any resistance in vitro (CLSI, 2012).

\subsection{TABULATION OF QUESTIONNAIRE}

The questionnaire was developed to gain a greater understanding of the husbandry practices of the backyard poultry owners, clarity of their knowledge of biosecurity and in general the illnesses that the caretakers and family may have experienced since owning backyard poultry. The questionnaire focused on: poultry (species, strains, how acquired): feed (brand, type, supplements); housing (coop type or areas, and number of birds in coop); egg handling (collecting, washing, storage); sanitation (cleaning and composting); 
biosecurity (separate clothing, shoes and equipment, or access to other pets, people, and pests); and finally, the health of the caretaker and family members (illnesses types).

The questionnaires were tabulated based on the answers given and observations by the researcher. For example, when a feed brand was reported then it was added to the list of feed types, each subsequent mention of that brand gets recorded and tabulated. The process was done for all questions. In addition, sites positive, positive samples and percentages of sites and samples positive were tabulated for each answer reported or observed. 


\section{RESULTS}

\subsection{SAMPLES Positive FOR SALMONELLA SPP.}

Fifty samples were collected from 29 sites around San Luis Obispo County from March to May 2014. Out of the 29 sites, 24 were positive for Salmonella spp..

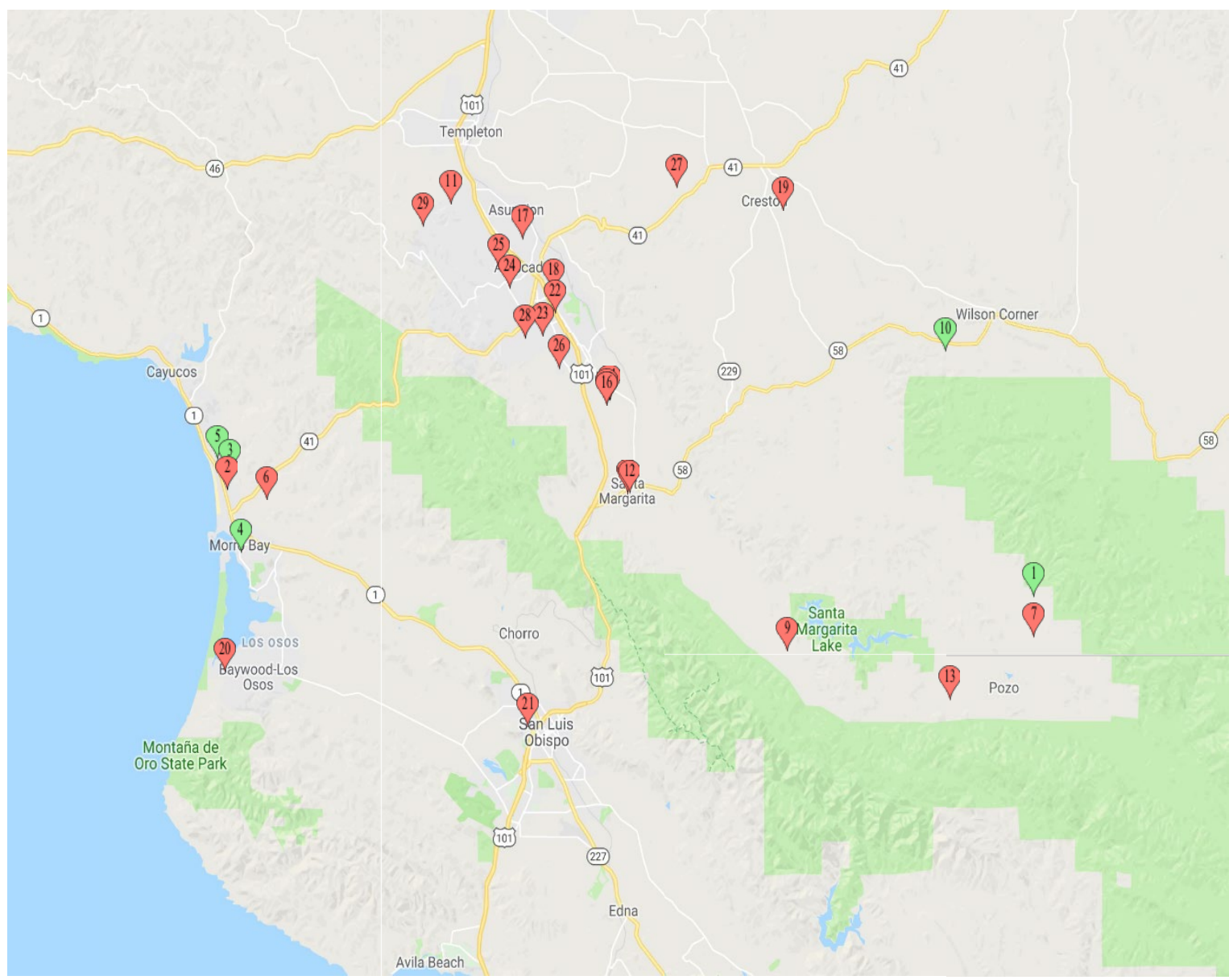

Figure 2: Sample Sites Collected in San Luis Obispo County: The 5 Green locators are sites negative for Salmonella spp. and the 24 Red locators are sites positive for Salmonella spp. Due to the close proximity of sample site addresses: Locator 12 overlaps Locator 8; and Locator16 overlaps Locators 14 and 15. 
Out of the 50 samples collected 33 were positive for Salmonella spp. by selective culture methods (see Table 1). Thirty-seven Salmonella spp. isolates were found with 7 samples positive for both $\mathrm{H}_{2} \mathrm{~S}$ producing Salmonella and non- $\mathrm{H}_{2} \mathrm{~S}$ producing Salmonella (see Table 2). Positive samples were initially cultured on HardyCHROM ${ }^{\mathrm{TM}}$ SS Plate media showing black centered colonies with clear edges as $\mathrm{H}_{2} \mathrm{~S}$ producing Salmonella or teal centered colonies as non- $\mathrm{H}_{2} \mathrm{~S}$ producing Salmonella (see Figure 3). All colonies were re-isolated on HardyCHROM ${ }^{\mathrm{TM}}$ Salmonella media confirming the cultures were positive for Salmonella spp. with pink to magenta colony growth (see Figure 4).

Table 1. Positive for Salmonella spp. based on Sites and Samples

\begin{tabular}{|l|c|c|}
\hline Collection & $\begin{array}{c}\text { Positive for } \\
\text { Salmonella } \text { spp. }\end{array}$ & $\begin{array}{c}\text { Percentage } \\
\text { Positive }\end{array}$ \\
\hline 29 sites & 24 & $82.8 \%$ \\
\hline 50 samples & 33 & $66 \%$ \\
\hline
\end{tabular}

Table 2. Salmonella spp. Isolates based on $\mathrm{H}_{2} \mathrm{~S}$ Production

\begin{tabular}{|l|c|c|}
\hline \multicolumn{1}{|c|}{ Salmonella spp. } & Samples & \% Isolates \\
\hline $\mathrm{H}_{2} \mathrm{~S}$ producing & 30 & $81 \%$ \\
\hline Non- $\mathrm{H}_{2} \mathrm{~S}$ producing & 7 & $19 \%$ \\
\hline
\end{tabular}

Thirty Salmonella Isolates were black colonies that are $\mathrm{H}_{2} \mathrm{~S}$ producing. The 7 remaining Salmonella Isolates (51614-2L \#1, 51614-2L \#2, 51614-2L \#3, 51614-3H, 51614-6T, 51714-2RL \#1, and 51714-2RL \#2) were teal colonies that are non- $\mathrm{H}_{2} \mathrm{~S}$ producing Salmonella spp. 


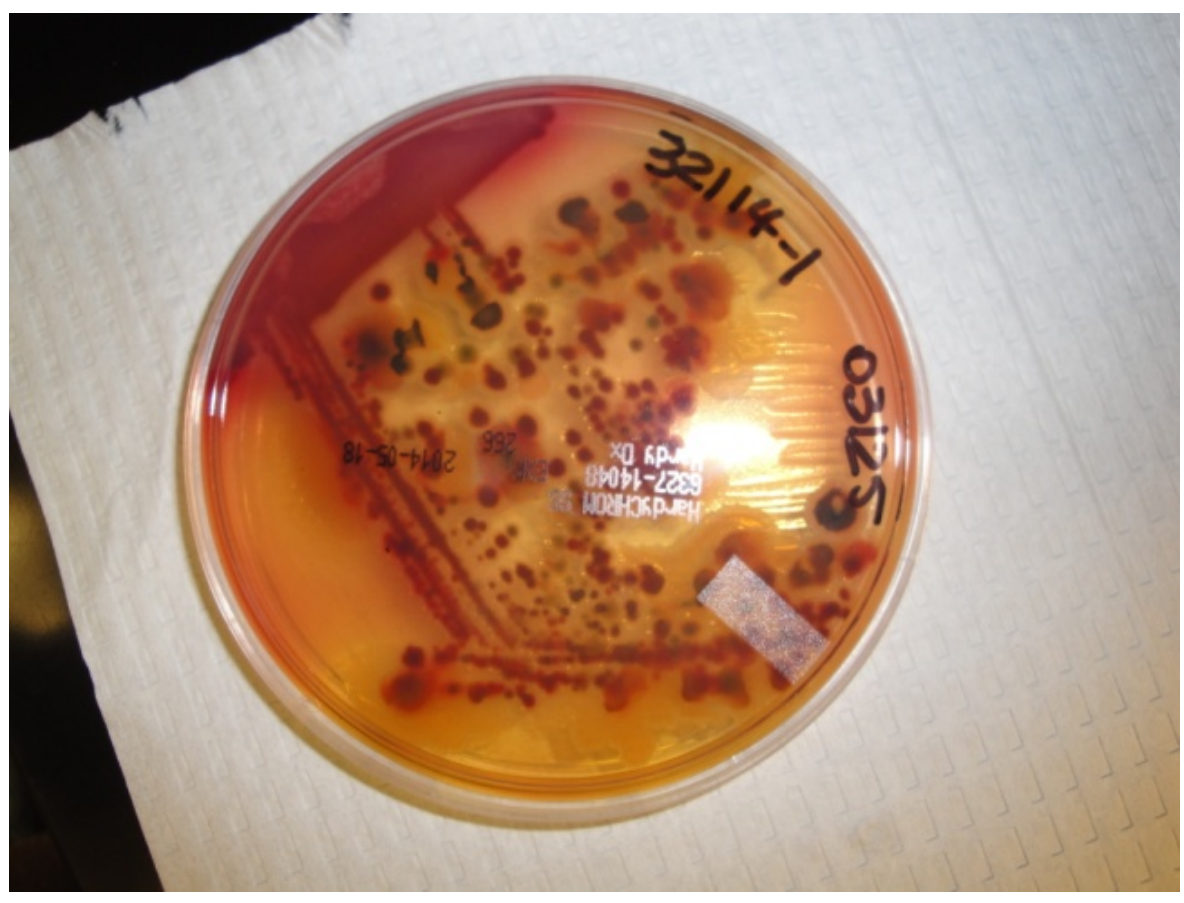

Figure 3: Sample representative positive plate of HardyCHROM ${ }^{\mathrm{TM}}$ SS Plate. Colonies were either teal $\left(\mathrm{H}_{2} \mathrm{~S}\right.$ non-producing) or black ( $\mathrm{H}_{2} \mathrm{~S}$ producing) to be a Salmonella positive colony.

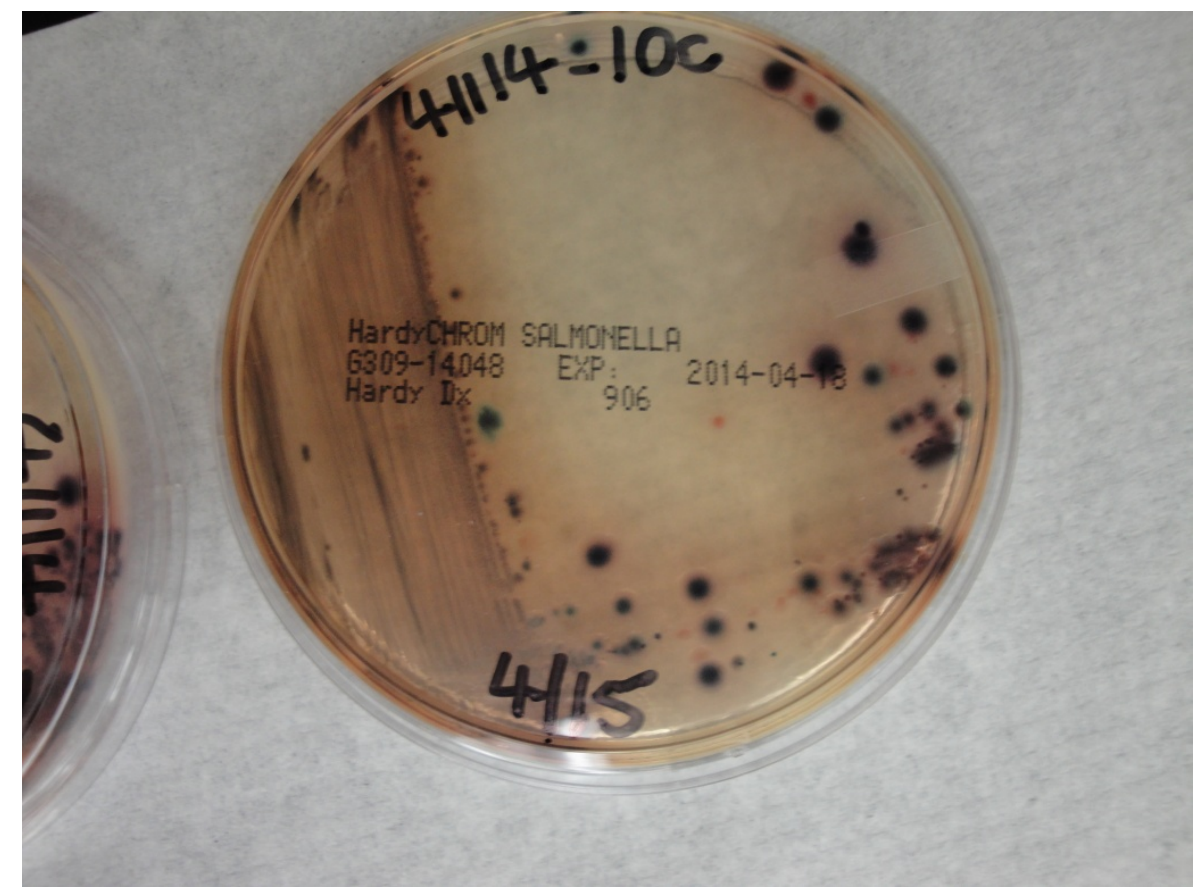

Figure 4 : Sample representative positive plate of HardyCHROM ${ }^{\text {TM }}$ Salmonella Plate. Salmonella shows up as pink to magenta in color. 


\subsection{ANTIBIOGRAM PROFILES FOR SALMONELLA SPP.}

All positive Salmonella spp. isolates were tested for the following antibiotics using the Kirby-Bauer method or disk diffusion method in the Antibiogram laboratory test: Penicillin (10 U), Bacitracin $(10 \mu \mathrm{g})$, Ampicillin $(10 \mu \mathrm{g})$, Tetracycline $(30 \mu \mathrm{g})$, Erythromycin (15 $\mu \mathrm{g})$, and Gentamicin $(10 \mu \mathrm{g})$. Each antibiotic has its parameters (see Table 3) for resistance, intermediate and susceptibility sensitivity levels specifically for Salmonella spp., an enterobacteria, based on Kirby-Bauer Antimicrobial Test levels from the Clinical and Laboratory Standards Institute (CLSI, 2012).

Interpretation of the Kirby-Bauer Antimicrobial Test levels is determined by the specifics for each microorganism based on the following: Resistant is defined as the microorganism is not inhibited by the antimicrobial based on halo size in vitro; Intermediate is defined as the microorganism is not fully resistant or susceptible to the antimicrobial based on halo size in vitro; Susceptible is defined as the microorganism being susceptible to the antimicrobial based on the halo measurment in vitro and the efficacy of antimicrobial agent is strong if the standard recommended dosage is used in vivo. Table 3 displays the sensitivity levels specifics for this study for Salmonella spp. growth based on the size of the "clear zone," "zone of inhibition" or "halo" around the diffused antibiotics embedded in the agar. 
Table 3. Kirby- Bauer Antimicrobial Test Sensitivity Levels for Salmonella spp. based on CLSI (2012).

\begin{tabular}{|c|c|c|c|c|c|c|}
\hline $\begin{array}{c}\text { Zone of } \\
\text { diameter } \\
(\mathbf{m m})\end{array}$ & $\begin{array}{c}\text { Bacitracin } \\
\text { (B) } \\
10 \mu \mathrm{g}\end{array}$ & $\begin{array}{c}\text { Ampicillin } \\
\text { (AM) } \\
10 \mu \mathrm{g}\end{array}$ & $\begin{array}{c}\text { Penicillin } \\
(\mathrm{P}) \\
10 \text { units }\end{array}$ & $\begin{array}{c}\text { Tetracycline } \\
\text { (TE) } \\
30 \mu \mathrm{g}\end{array}$ & $\begin{array}{c}\text { Erythromycin } \\
\text { (E) } \\
15 \mu \mathrm{g}\end{array}$ & $\begin{array}{c}\text { Gentamicin } \\
\text { (GM) } \\
10 \mu \mathrm{g}\end{array}$ \\
\hline Resistant & $\leq 8$ & $\leq 13$ & $\leq 11$ & $\leq 14$ & $\leq 13$ & $\leq 12$ \\
\hline Intermediate & $9-12$ & $14-16$ & $12-21$ & $15-18$ & $14-22$ & $13-14$ \\
\hline Susceptible & $\geq 13$ & $\geq 17$ & $\geq 22$ & $\geq 19$ & $\geq 23$ & $\geq 15$ \\
\hline
\end{tabular}

During this study, the results of the Kirby-Bauer Antimicrobial Sensitivity Test or Disk Diffusion test revealed 12 profiles. These 12 Salmonella spp. Isolate Antibiogram Profiles showed varying degrees of antimicrobial sensitivity and drug resistance. The profiles were the results of grouping like isolates together with the same sensitivity level graph patterns in the areas of "resistant, intermediate and susceptible". The 12 profiles are as follows:

Profile 1 (see Figure 5 and 6): Salmonella Isolate 52314-6 is resistant in the lab to all antibiotics tested. Based on the clearing zone sizes observed of $7 \mathrm{~mm}$, this sample isolate is resistant to: Bacitracin, a polypeptide, Ampicillin, and Penicillin, both beta-lactams, which are antibiotics that inhibit cell wall growth and Erythromycin, a macrolides antibiotic which inhibits protein synthesis. The isolate is also resistant to 2 more antibiotics that inhibit protein synthesis: Gentamicin, an aminoglycoside, with the halo size recorded of $12 \mathrm{~mm}$ and to Tetracycline, a naphthacene, with a halo that measured $9 \mathrm{~mm}$ (Wreth, 2018). It can be concluded that Profile 1's Salmonella Isolate is multidrug resistant in vitro to the antibiotics tested. Profile 1 is very concerning as there is the possibility of this Salmonella spp. which is multidrug resistant within the poultry population being in close proximity and within contact of the owners. 


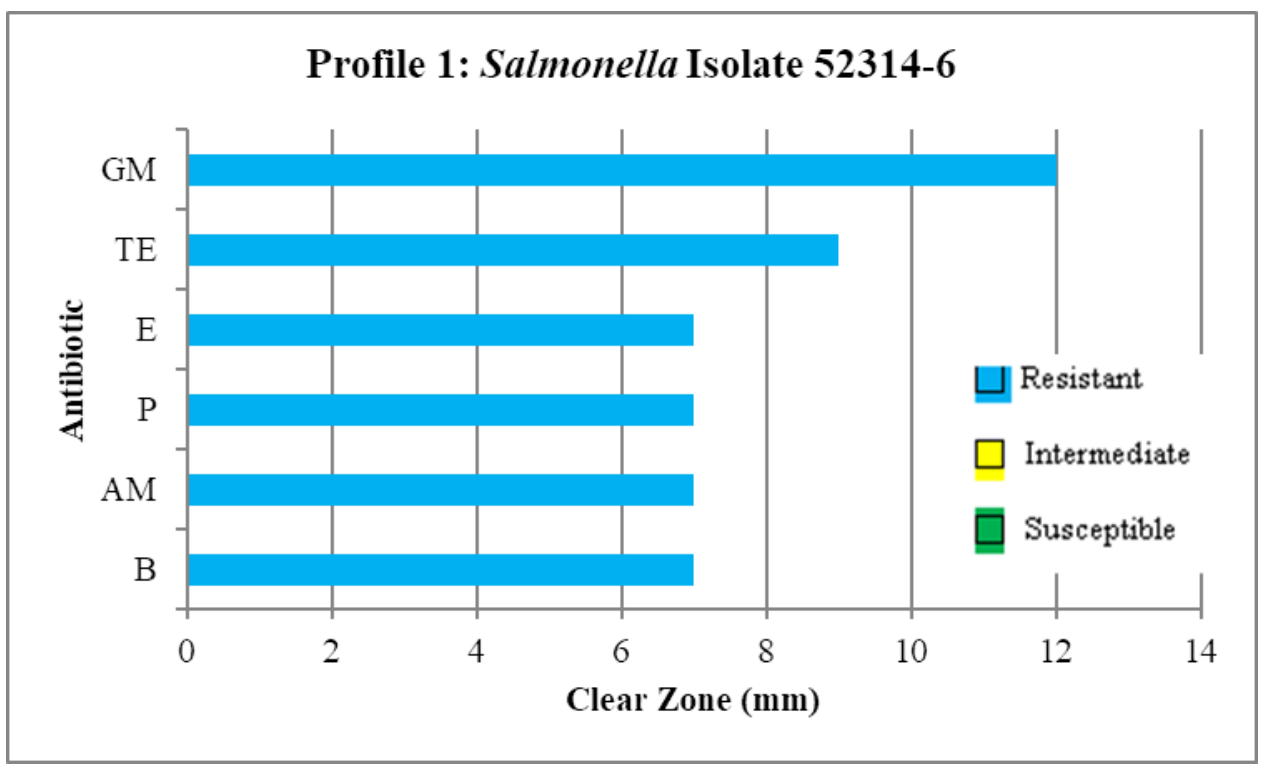

Figure 5. Antibiogram Profile 1: Salmonella Isolate 52314-6: Resistant to Penicillin (P), Bacitracin (B), Ampicillin (AM), Tetracycline (TE), Erythromycin (E), and Gentamicin (GM); Intermediate to none; Susceptible to none.

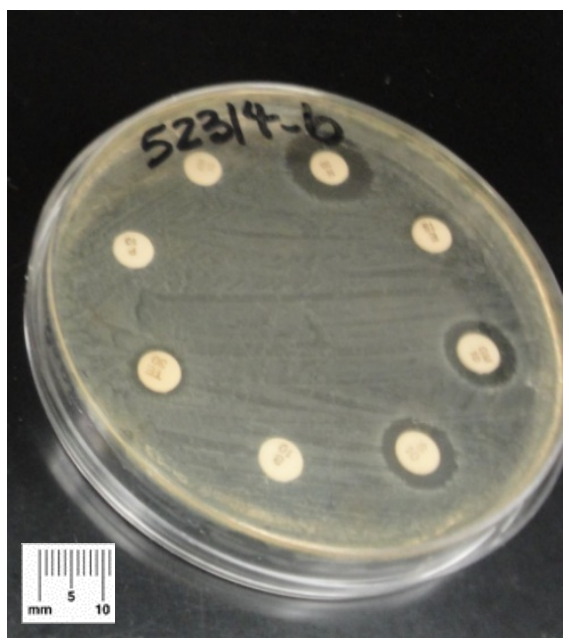

Figure 6. Representative Antibiogram Plate of Profile 1. NOTE: This plate included Streptomycin and Neomycin disks not used in this study.

Profile 2 (see Figure 7 and 8): Salmonella Isolates 3814-5C and 32214-3 were grouped together based on susceptibility to Gentamicin, intermediate to Tetracycline and resistant to Erythromycin, Penicillin, Ampicillin and Bacitracin. 
Resistance was observed by Bacitracin's halos both recorded at $6 \mathrm{~mm}$, Ampicillin's halos measured at $13 \mathrm{~mm}$ and $6 \mathrm{~mm}$ with an average of $10 \mathrm{~mm}$, Penicillin's halos both recorded at $6 \mathrm{~mm}$, and Erythromycin's halos recorded at $11 \mathrm{~mm}$ and $13 \mathrm{~mm}$ with an average of 12 $\mathrm{mm}$. Tetracycline is intermediate as both halos measured $15 \mathrm{~mm}$. The isolate is susceptible to Gentamicin with halos recorded at $18 \mathrm{~mm}$ and $23 \mathrm{~mm}$ respectively with an average of $20 \mathrm{~mm}$. These isolates are susceptible to Gentamicin, an aminoglycoside, which affects protein synthesis. At the standard antimicrobial level tested this isolate is not susceptible to Tetracycine, a naphthacene that inhibits protien synthesis. These isolates are multidrug resistant in vitro. Resistance is shown to be against Bacitracin, a polypeptide, Ampicillin and Penicillin, both beta-lactams, which all inhibit cell wall production and Erythromycin, a macrolide that disrupts protein synthesis (Wreth, 2018).

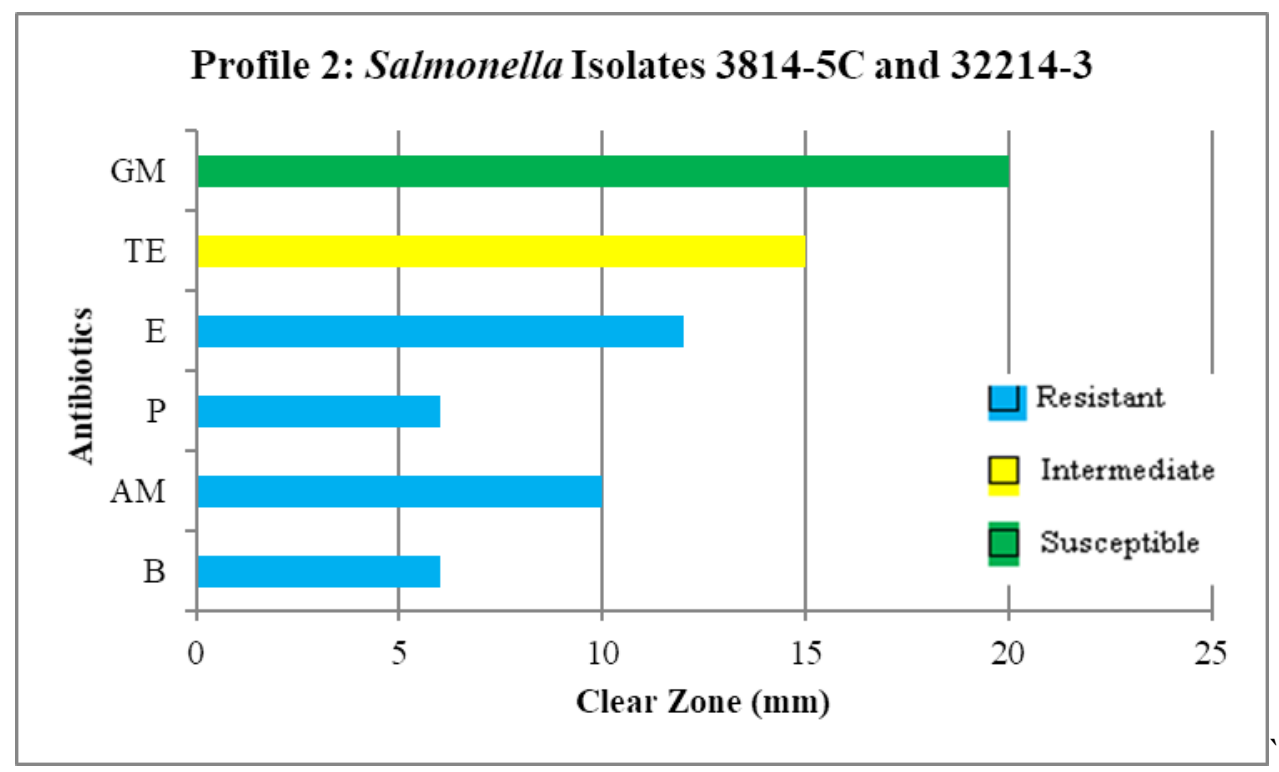

Figure 7. Antibiogram Profile 2: Salmonella Isolates 38145-C and 32214-3: Resistant to Bacitracin (B), Ampicillin (AM), Penicillin (P), and Erythromycin (E); Intermediate to Tetracycline (TE); Susceptible to Gentamicin (GM). This graph is an average of the 2 Isolates. 


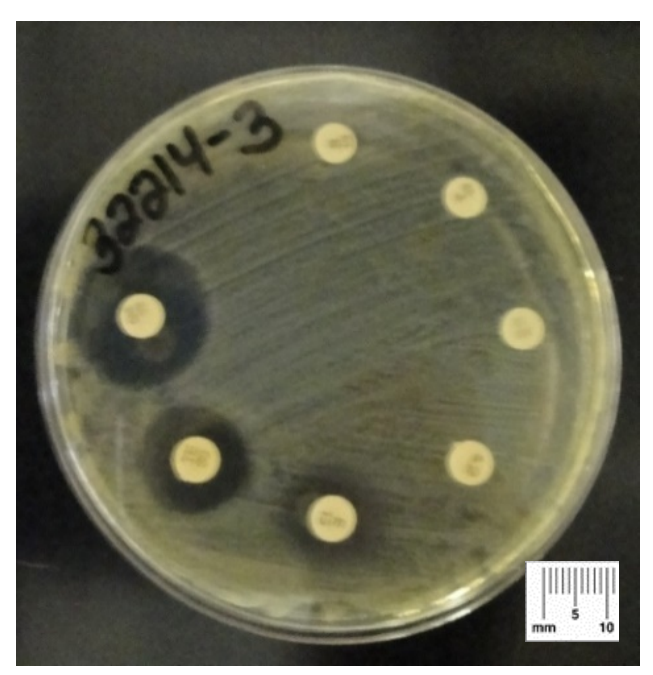

Figure 8. Representative Antibiogram Plate of Profile 2. NOTE: This plate has 2 Penicillin disks that measured the same.

Profile 3 (see Figure 9 and 10): Salmonella Isolate 51614-2L \#2 in vitro shows resistance to antibiotics that interfere with protein synthesis and cell wall structure. The halo sizes recorded for the following antibiotics indicate resistance to Bacitracin, a polypeptide, at 7 $\mathrm{mm}$ and Penicillin, a beta-lactam, at $7 \mathrm{~mm}$ both which inhibit cell wall production, and Tetracycline, a naphthacene, at $8 \mathrm{~mm}$ which inhibits protein synthesis. This isolate is considered intermediate to Ampicillin, a beta lactam which inhibits cell wall production, with a halo size measured at $16 \mathrm{~mm}$ and Erythromycin, a macrolide which inhibits protein synthesis, with halo recorded at $15 \mathrm{~mm}$ (Wreth, 2018). The isolate is susceptible to Gentamicin, aminoglycoside which inhibits protein sysnthesis, with a halo size of $23 \mathrm{~mm}$. This isolate shows multidrug resistance in vitro. 


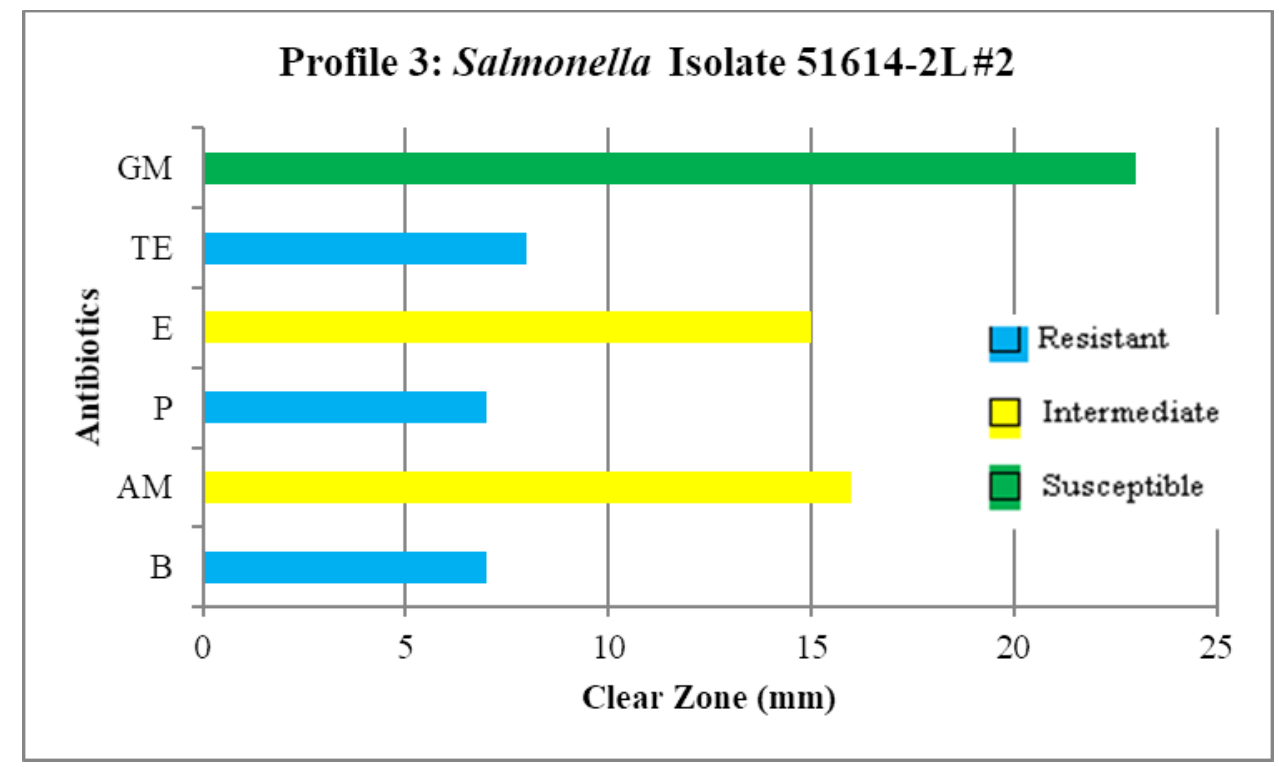

Figure 9. Antibiogram Profile 3: Salmonella Isolate 51614-2L \#2: Resistant to Bacitracin (B), Penicillin (P), and Tetracycline (TE); Intermediate to Ampicillin (AM), and Erythromycin (E); Susceptible to Gentamicin (GM).

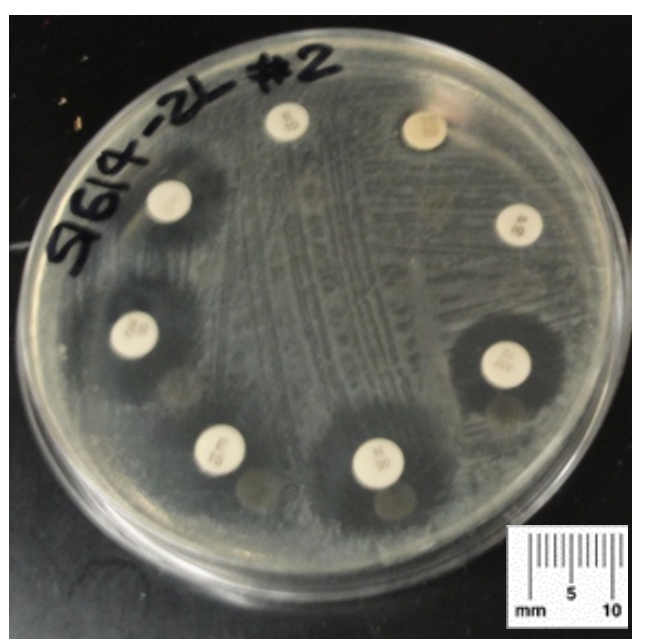

Figure 10. Representative Antibiogram Plate of Profile 3. NOTE: This plate included Streptomycin and Neomycin not used in this study. 
Profile 4 (see Figure 11 and 12): Salmonella Isolates 3814-1, 32114-1, 51614-7, 51714-1,

52714-3R \#1 are grouped together for this profile based on susceptibility to Gentamicin, an aminoglycoside, with an average halo size $20 \mathrm{~mm}$ which affects protein synthesis; intermediate to Ampicillin, a beta-lactam, with an average halo size of $14 \mathrm{~mm}$ which inhibits cell wall production. This isolate is resistant to Penicillin, a beta-lactam, with average halo size of $8 \mathrm{~mm}$ and Bacitracin, a polypeptide, with average halo sizes of $7 \mathrm{~mm}$, both antibiotics inhibit cell wall production, and Erythromycin, an aminoglycoside, with halo average of $8 \mathrm{~mm}$, and Tetracycline, a naphthacene, with the average halo size of 10 $\mathrm{mm}$, both antibiotics disrupt protein synthesis (Wreth, 2018). This isolate can be deemed to be multidrug resistant in vitro.

Profile 4 was determined by the above Salmonella isolates being grouped by: Gentamicin being susceptible, Ampicillin and Tetracycline being intermediate; and Penicillin, Bacitracin and Erythromycin being resistant.

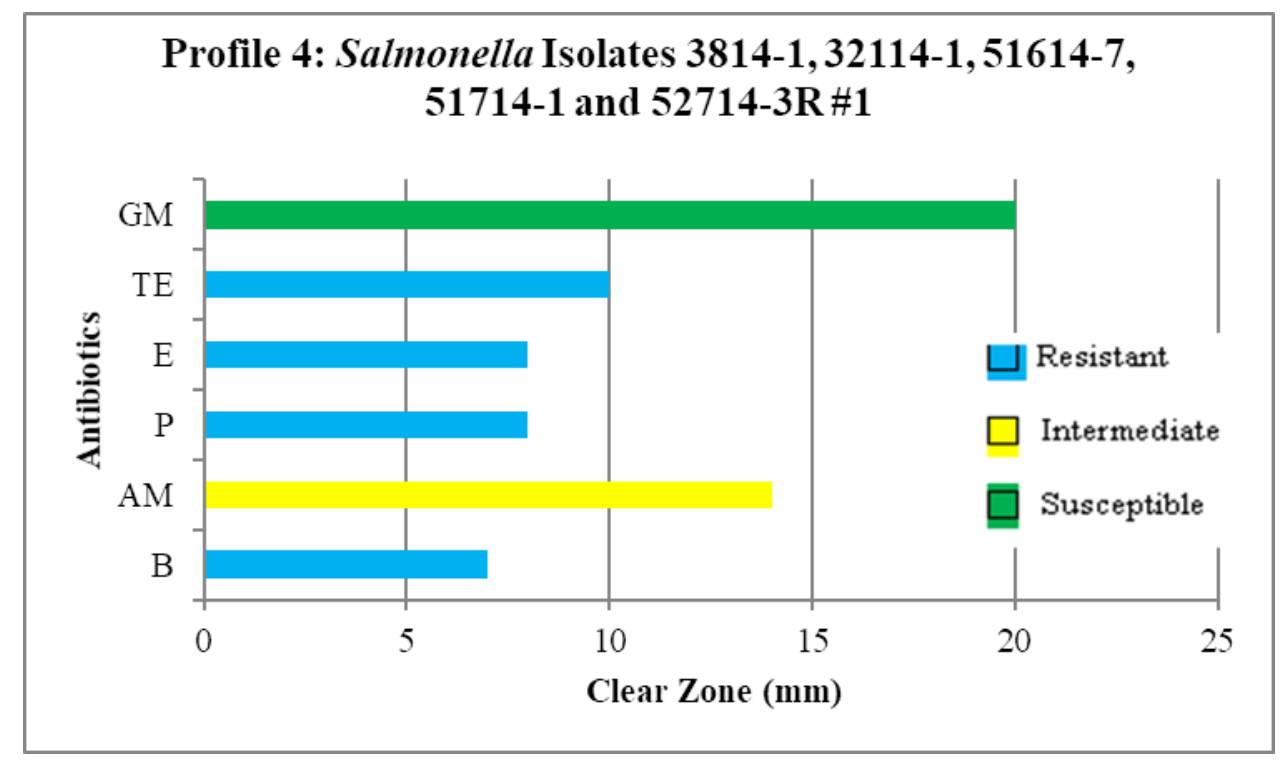

Figure 11. Antibiogram Profile 4: Salmonella Isolates 3814-1, 32114-1, 51614-7, 51714-1, 52714-3R \#1: Resistant to Bacitracin (B), Penicillin (P), Erythromycin (E) and Tetracycline (TE); Intermediate to Ampicillin (AM); Susceptible to Gentamicin (GM). This graph is an average of the 5 Isolates. 


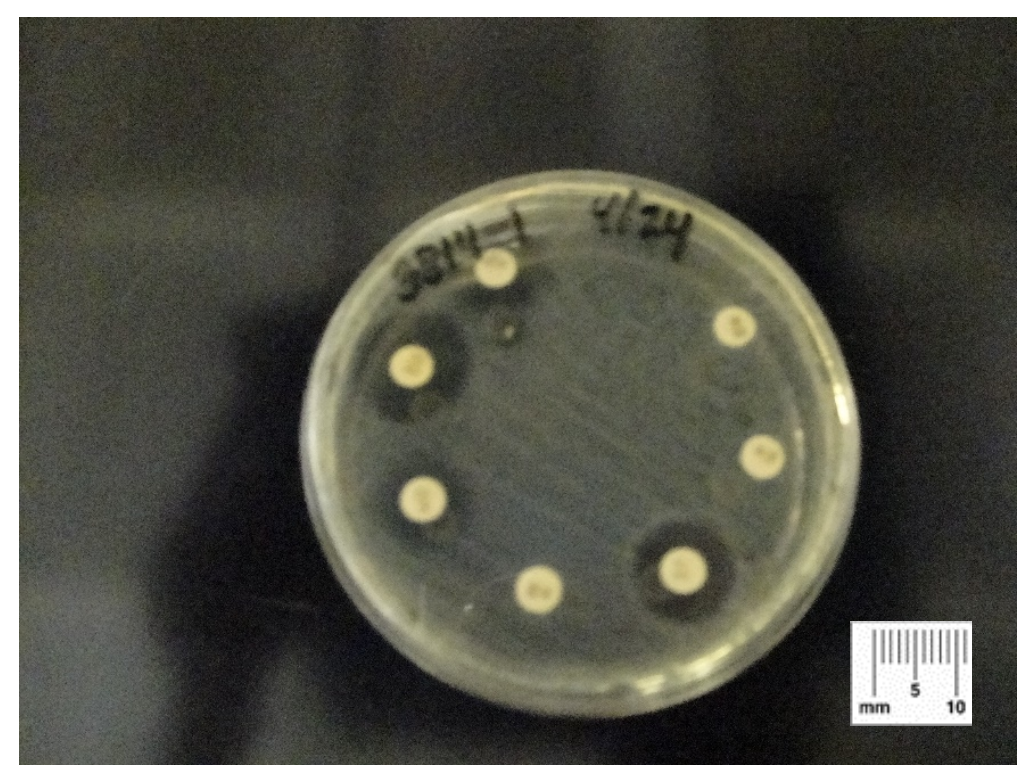

Figure 12. Representative Antibiogram Plate of Profile 4. NOTE: This plate has 2 Penicillin disks that measured the same.

Profile 5 (see Figure 13 and 14): Salmonella Isolate 51614-2L \#3 is multidrug resistant to Bacitracin, a polypeptide, with a halo size recorded at $7 \mathrm{~mm}$, Penicillin, a beta-lactam, with a halo size recorded at $7 \mathrm{~mm}$, and Erythromycin, a macrolide, with a halo recorded at 10 $\mathrm{mm}$. There is resistance to antimicrobials that inhibit protein synthesis and interfere in cell wall production. This isolate is intermediate to Tetracycline, a naphthacene and Ampicillin, a beta-lactam, with halo sizes recorded at $16 \mathrm{~mm}$ for both. with halo size of $21 \mathrm{~mm}$, it is susceptible to Gentamicin which is an animoglycoside that interferes with the bacterial protein synthesis (Wreth, 2018). 


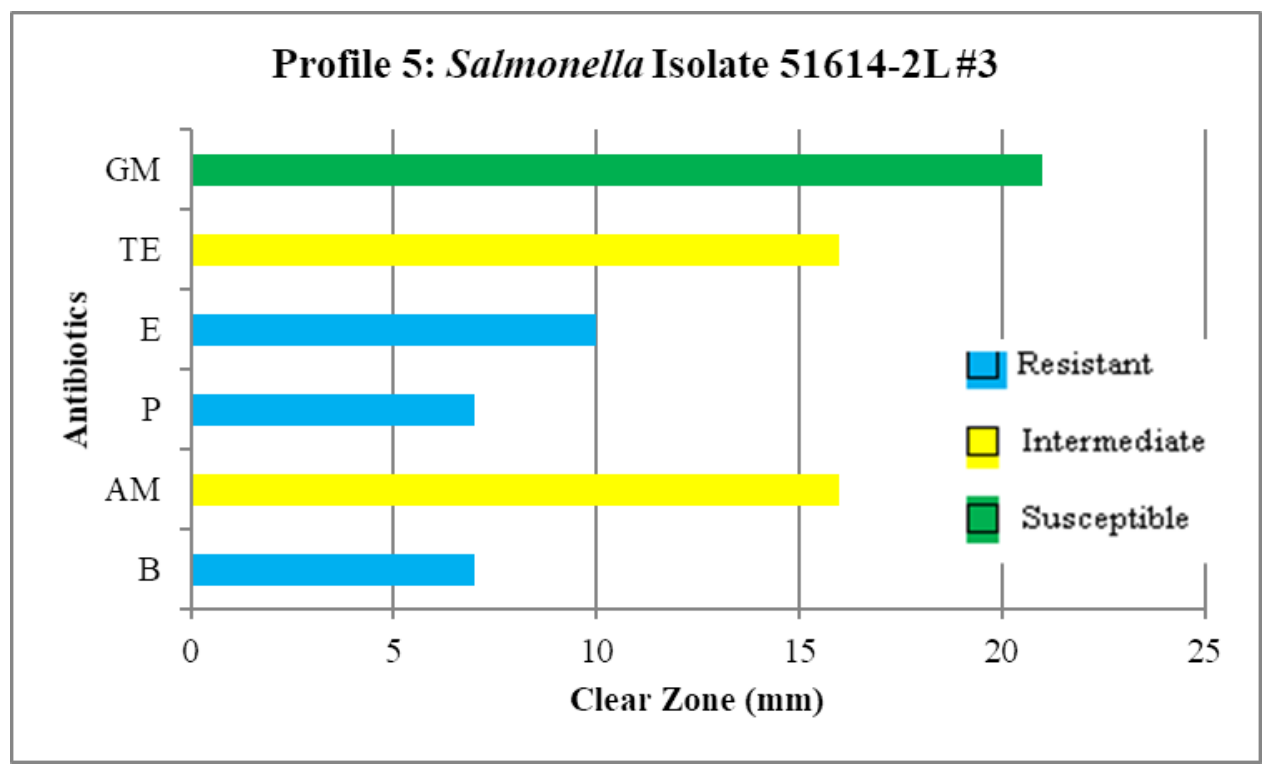

Figure 13. Antibiogram Profile 5: Salmonella Isolate 51614-2L \#3: Resistant to Bacitracin (B), Penicillin (P) and Erythromycin (E); Intermediate to Ampicillin (AM) and Tetracycline (TE); Susceptible to Gentamicin (GM).

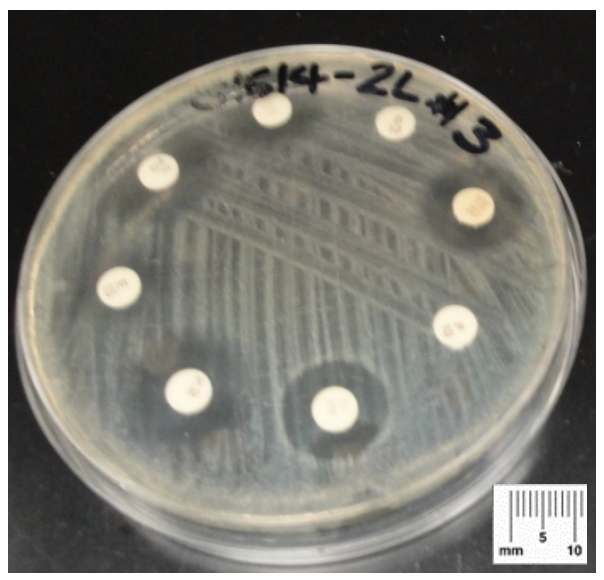

Figure 14. Representative Antibiogram Plate of Profile 5. NOTE: This plate included Streptomycin and Neomycin disks not used in this study. 
Profile 6 (see Figure 15 and 16): Salmonella Isolates 32214-1, 41114-6R, 41114-10C and 51614-4 are multidrug resistant in vitro. There was resistance to 5 antimicrobials: Penicillin, a beta-lactam, with an average halo size of $6 \mathrm{~mm}$, Bacitracin, a polypeptide, with an average halo size of $6 \mathrm{~mm}$, Ampicillin, a beta-lactam, with an average halos size of $7 \mathrm{~mm}$, Tetracycline, a naphthacene, with an average halo size of $7 \mathrm{~mm}$, and Erythromycin, a macrolide, with an average halo size $7 \mathrm{~mm}$. It does not have any intermediate sensitivity to the antibiotics tested. The isolates are susceptible to Gentamicin, an aminoglycoside which disrupts the protein synthesis (Wreth, 2018), with an average halo size of $18 \mathrm{~mm}$. These isolates were grouped together in Profile 6 based on the antibiotic pattern of: susceptibility to Gentamicin; intermediate to none; and resistant to Bacitracin, Ampicillin, Penicillin, Erythromycin and Tetracycline.

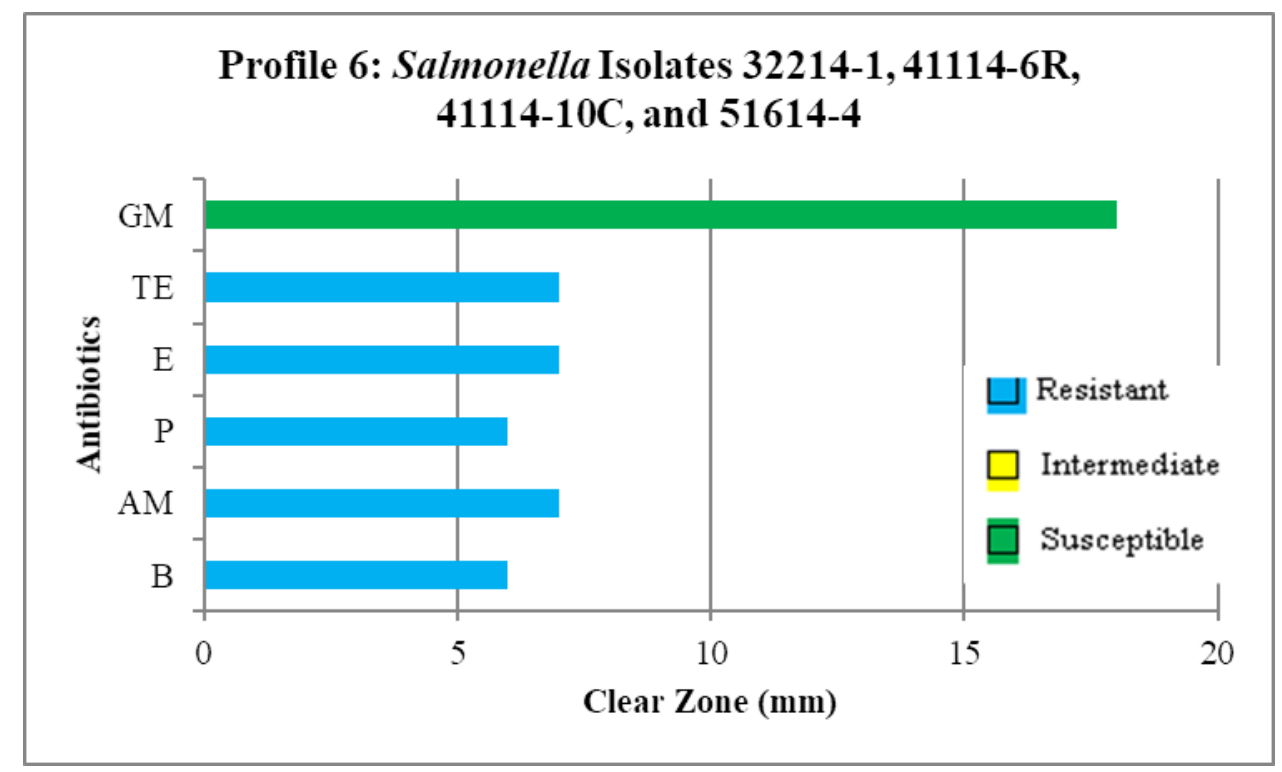

Figure 15. Antibiogram Profile 6: Salmonella Isolates 32214-1, 41114-6R , 41114-10C and 51614-4: Resistant to Penicillin (P), Bacitracin (B), Ampicillin (AM), Tetracycline (TE), and Erythromycin (E); Intermediate to none; Susceptible to Gentamicin (GM). This graph is an average of the 4 Isolates. 


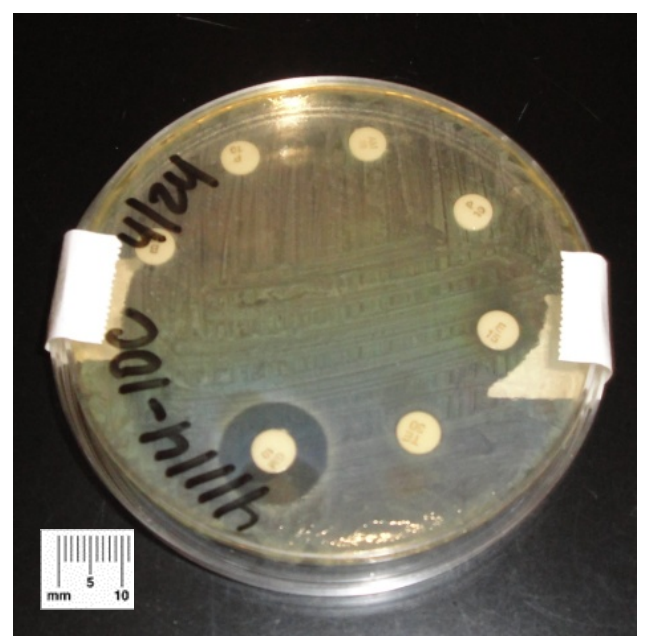

Figure 16. Representative Antibiogram Plate of Profile 6. NOTE: This plate has 2 Penicillin disks that measured the same.

Profile 7 (see Figure 17 and 19): Salmonella Isolates 32114-2, 41114-3B, 41114-9G, 51614-1, 51614-5 \#1, 51614-5 \#2, 51614-6 B, 51614-6T, 52314-2H, and 52714-2 are resistant to Bacitracin, a polypeptide, with an average halo size of $7 \mathrm{~mm}$, Tetracycline, a naphthacene, with an avaerage halo size of $8 \mathrm{~mm}$, and Erythromycin, a macrolide, with an average halo size of $7 \mathrm{~mm}$. The isolates are considered to be multidrug resistant in vitro. The isolates have an intermediate sensitivity to Penicillin, a beta-lactam, with the avaerage halo size of $13 \mathrm{~mm}$. The isolates are susceptible to Ampicillin, a beta-lactam, with an average halo size of $21 \mathrm{~mm}$ and Gentamicin, a aminoglycoside, with an avaerage halo size of $20 \mathrm{~mm}$. Based on the susceptibility to these 2 antibiotics, the isolates will have their protein synthesis and cell wall production inhibited (Wreth, 2018). These 10 isolates were grouped together for Profile 7 based on being susceptible to Gentamicin and Ampicillin; intermediate to Penicillin; and resistant to Bacitracin, Erythromycin, and Tetracycline. 


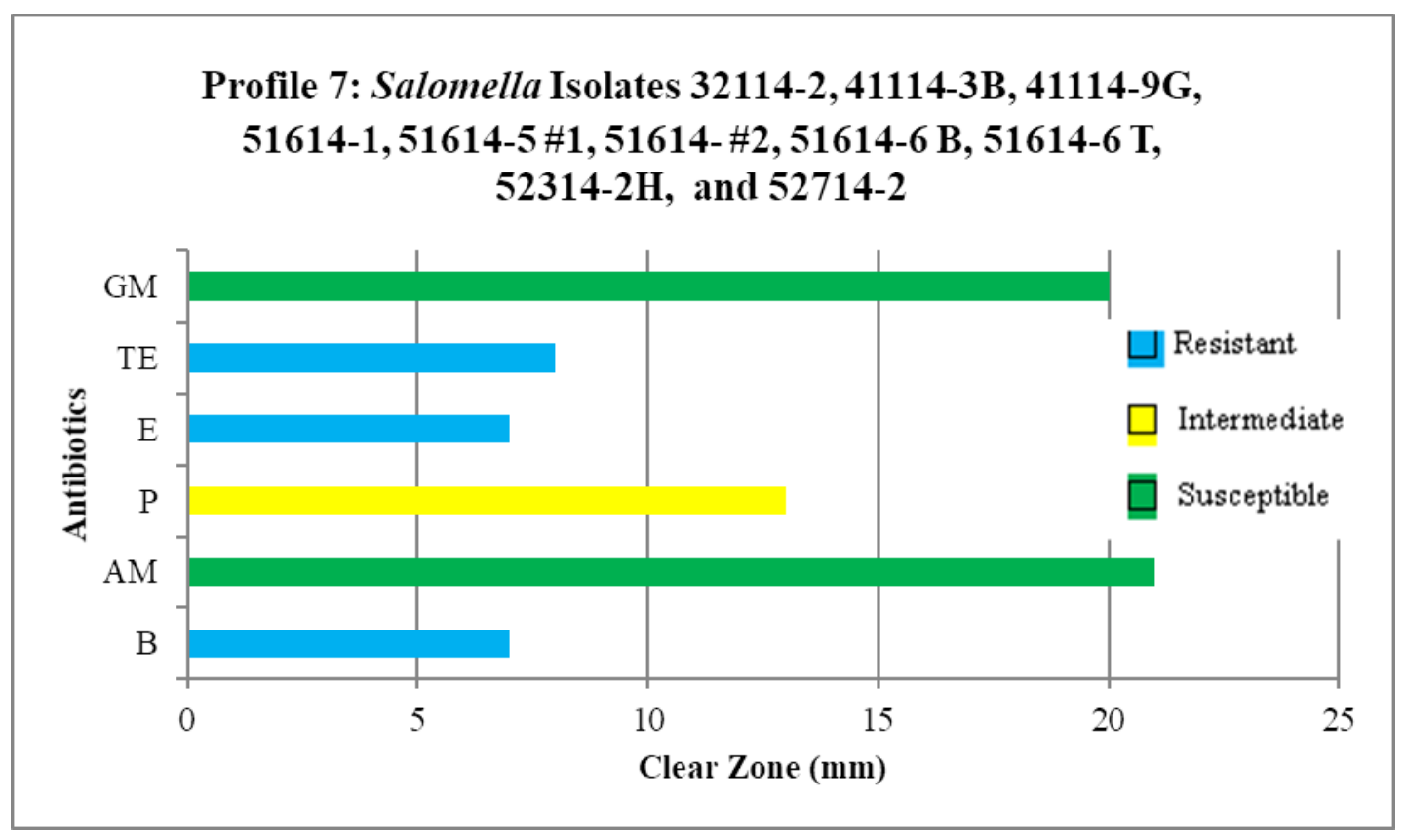

Figure 17. Antibiogram Profile 7: Salmonella Isolates 32114-2, 41114-3B, 41114-9G, 51614-1, 51614-5 \#1, 51614-5 \#2, 51614-6 B, 51614-6T, 52314-2H, and 52714-2: Resistant to Bacitracin (B), Tetracycline (TE), and Erythromycin (E); Intermediate to Penicillin (P); Susceptible to Ampicillin (AM) and Gentamicin (GM). This graph is an average of the 10 Isolates.

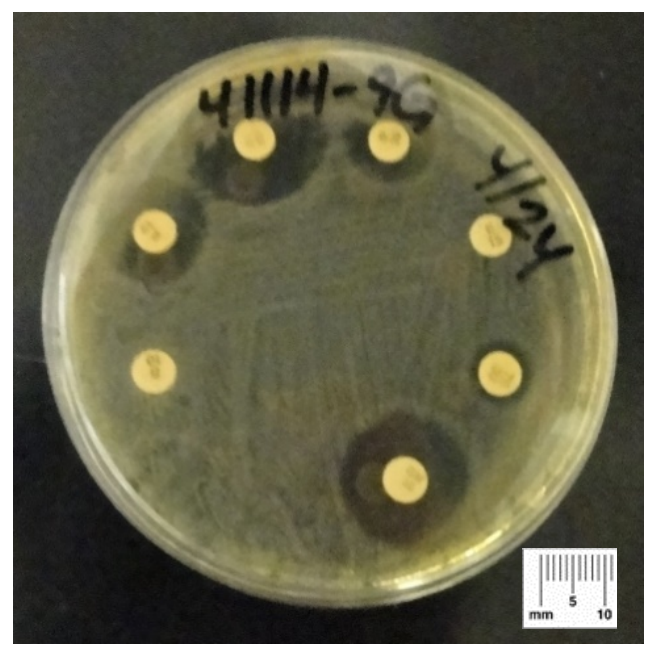

Figure 18. Representative Antibiogram Plate of Profile 7. NOTE: This plate has 2 Penicillin disks that measured the same. 
Profile 8 (see Figure 19 and 20): Salmonella Isolates 51714-2LR \#1 and 51714-2LR \#2T are resistant to Penicillin, a beta-lactam, with halo sizes observed at $7 \mathrm{~mm}$ and Bacitracin, a polypeptide, with halo sizes observed at $6 \mathrm{~mm}$ and $7 \mathrm{~mm}$ with an average of $6 \mathrm{~mm}$ in vitro. These isolates have intermediate sensitivity to Ampicillin, a beta-lactam, with halo sizes observed at $15 \mathrm{~mm}$ and Erythromycin, a macrolide, with halo sizes observed at 18 $\mathrm{mm}$ and $19 \mathrm{~mm}$ with average being $18 \mathrm{~mm}$. The isolates are susceptible to Tetracycline, a naphthacene, with halo sizes observed at $19 \mathrm{~mm}$ and Gentamicin, an aminoglycoside, with halo sizes observed at $22 \mathrm{~mm}$ and $23 \mathrm{~mm}$ with an average of $22 \mathrm{~mm}$ which both inhibit protein synthesis (Wreth, 2018). The Profile 8 isolates were grouped together based on the resistance to Penicillin and Bacitracin; intermediate to Ampicillin and Erythromycin; and susceptibility to Tetracycline and Gentamicin. This Profile is resistant to only 2 antibiotics, but it is still considered multidrug resistant in vitro.

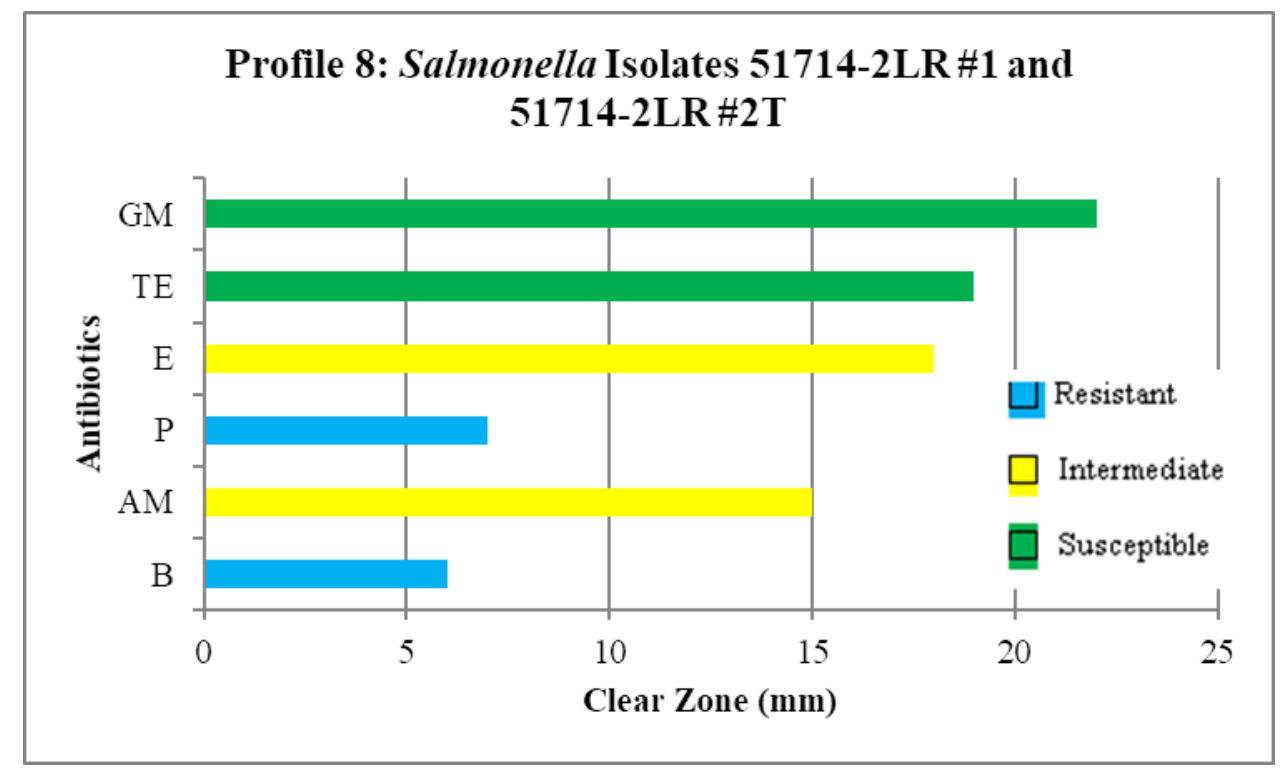

Figure 19. Antibiogram Profile 8: Salmonella Isolates 51714-2LR \#1 and 51714-2LR \#2T: Resistant to Penicillin (P) and Bacitracin (B); Intermediate to Ampicillin (AM) and Erythromycin (E); Susceptible to Gentamicin (GM) and Tetracycline (TE). This graph is an average of the 2 Isolates profiles. 


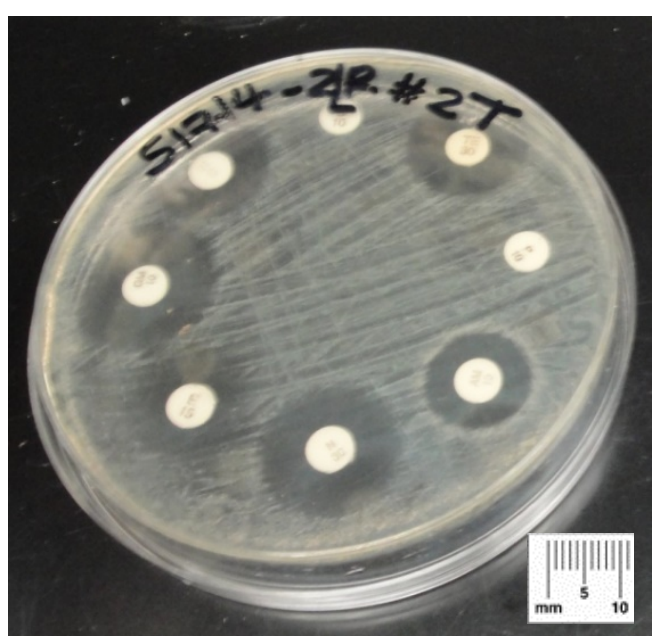

Figure 20. Representative Antibiogram Plate of Profile 8. NOTE: This plate included Streptomycin and Neomycin disks not used in this study.

Profile 9 (see Figure 21 and 22): Salmonella Isolate 51614-2L \#1 is resistant to Penicillin, a beta-lactam, with halo size recorded at $7 \mathrm{~mm}$, Bacitracin, a polypeptide, with halo size recorded at $7 \mathrm{~mm}$, and Tetracycline, a naphthacene, with halo size recorded at $8 \mathrm{~mm}$ in vitro. The isolate has an intermediate sensitivity to Erythromycin, a macrolide, with a halo size observed at $15 \mathrm{~mm}$; and is susceptible to Ampicilin, a beta-lactam, with halo size observed at $19 \mathrm{~mm}$ and Gentamicin, a aminoglycoside with halo size recorded at $20 \mathrm{~mm}$ in vitro (Wreth, 2018). The isolate's susceptibility to the above antibiotics makes it vulnerable to the inhibition of protein synthesis and cell wall production. 


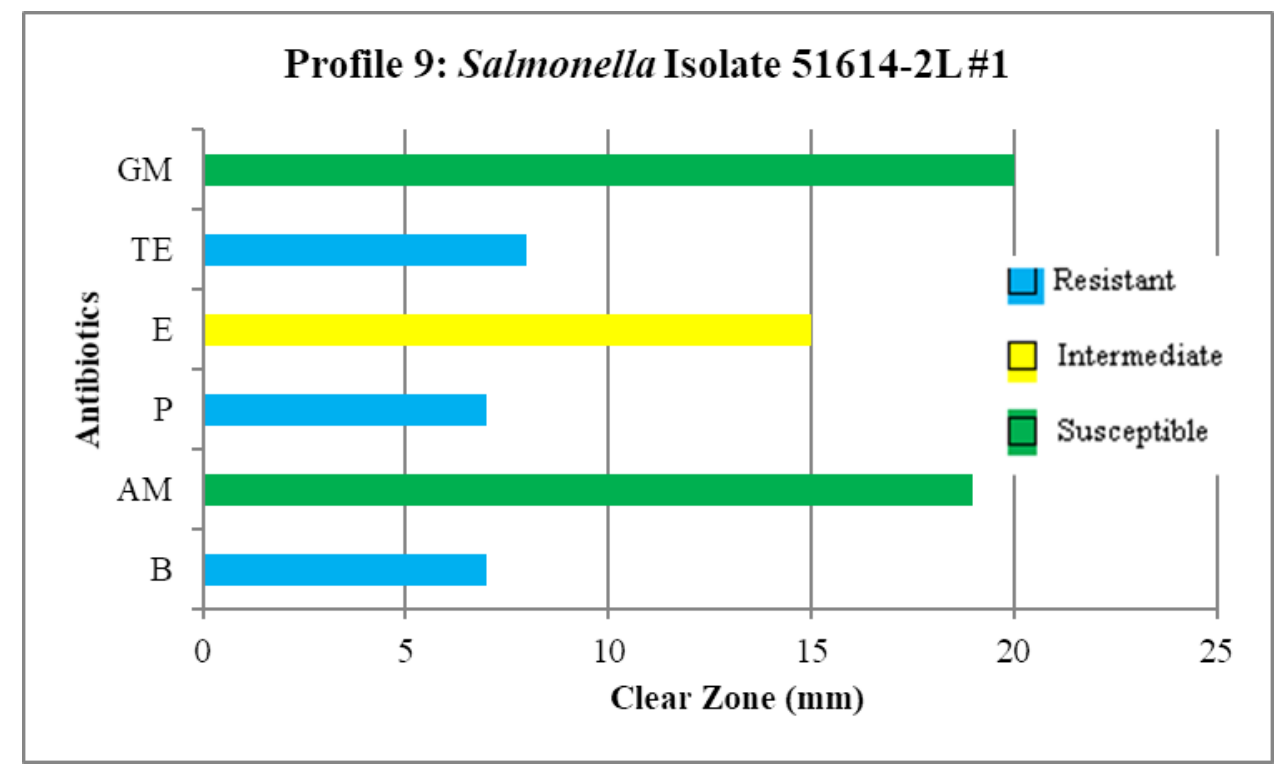

Figure 21. Antibiogram Profile 9: Salmonella Isolate 51614-2L \#1: Resistant to Penicillin (P), Bacitracin (B) and Tetracycline (TE); Intermediate to Erythromycin (E); Susceptible to Ampicillin (AM) and Gentamicin $(\mathrm{GM})$.

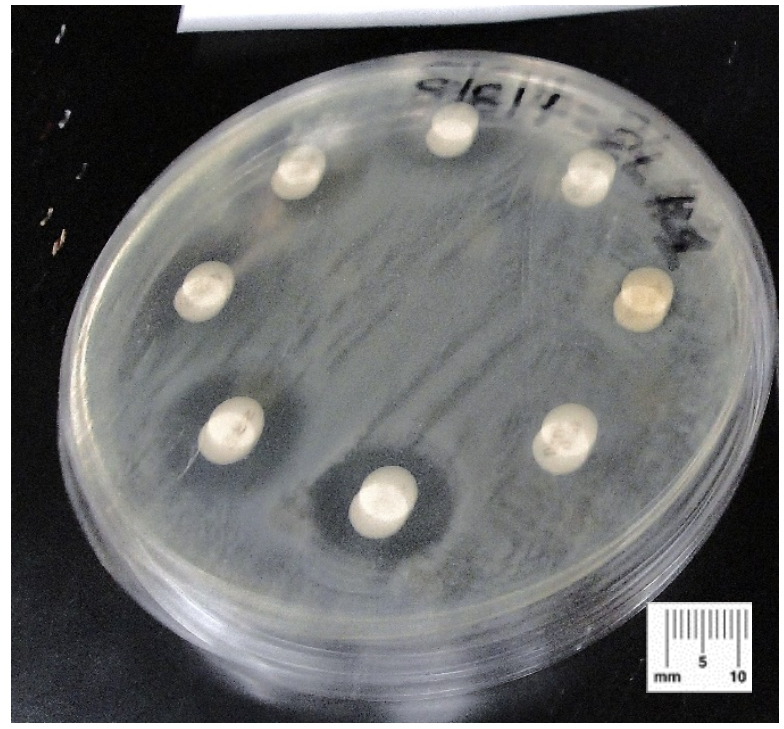

Figure 22. Representative Antibiogram Plate of Profile 9. (Out of focus) NOTE: This plate included Streptomycin and Neomycin not used in this study. 
Profile 10 (see Figure 23 and 24): Salmonella Isolates 32214-2, 41114-5L, 51614-8, 51714-2 \#1, 51714-2 \#2, 52314-1, 52714-1, and 52714-3R \#2 are all part of the second largest antimicrobial profile with 8 isolates. These isolates are multidrug resistant in vitro to Penicillin, a beta-lactam, with an average halo size of $9 \mathrm{~mm}$, Bacitracin, a polypeptide, with an aversge halo size of $7 \mathrm{~mm}$, Tetracycline, a naphthacene, with average halo size of $9 \mathrm{~mm}$, and Erythromycin, a macrolide, with average halo size of $7 \mathrm{~mm}$. There is no intermediate sensitivity. There is susceptible sensitivity to Ampicillin, a bata-lactam, with an average halo size of $19 \mathrm{~mm}$ and Gentamicin, an aminoglycoside, with an average halo size of $20 \mathrm{~mm}$ in vitro (Wreth, 2018). These Profile 10 isolates were grouped together based on the following pattern of resistance to Bacitracin, Penicillin, Erythromycin, and Tetracycline; intermediate to none and susceptible to Ampicillin and Gentamicin. Susceptibility inhibits protein synthesis and interferes with cell wall production.

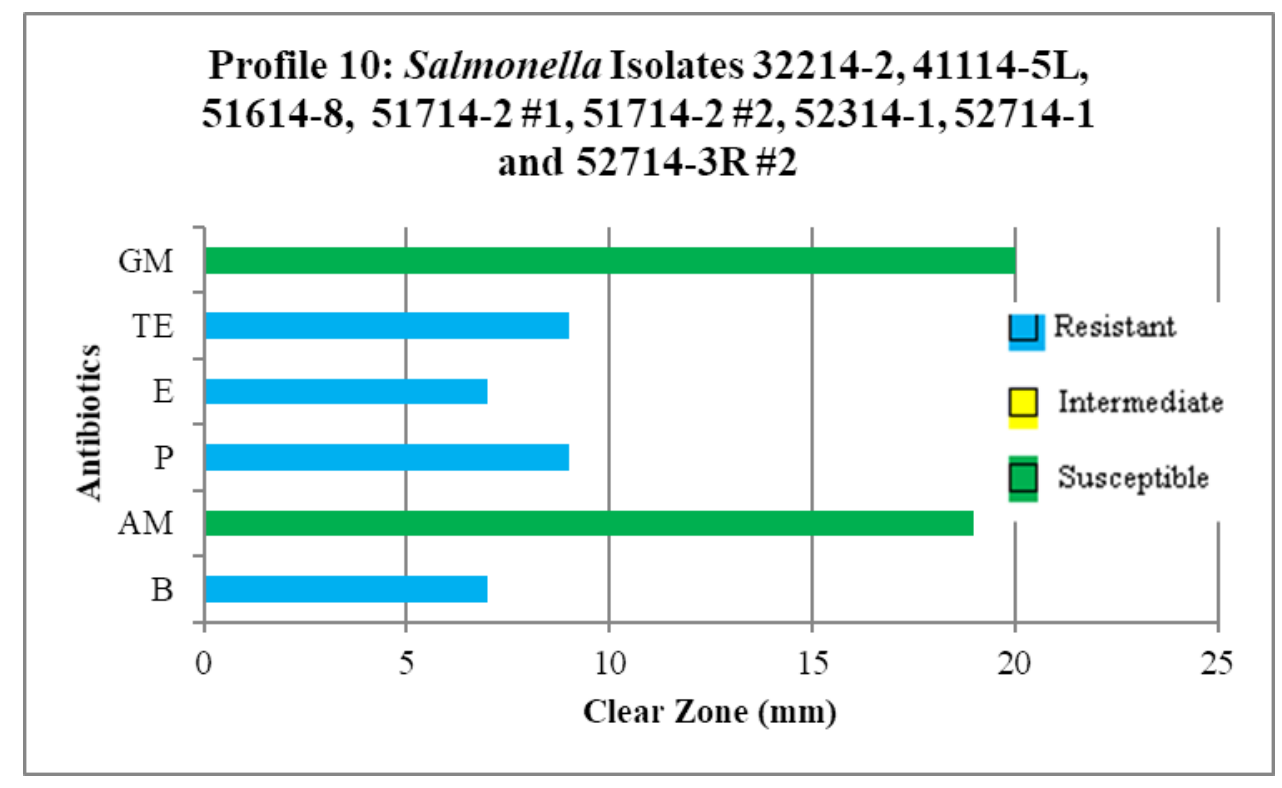

Figure 23. Antibiogram Profile 10: Salmonella Isolates 32214-2, 41114-5L, 51614-8, 51714-2 \#1, 51714-2 \#2, 52314-1, 52714-1, and 52714-3R \#2: Resistant to Penicillin (P), Bacitracin (B), Tetracycline (TE) and Erythromycin (E); Intermediate to none; Susceptible to Ampicillin (AM) and Gentamicin (GM). This graph is an average of the 8 Isolates profiles. 


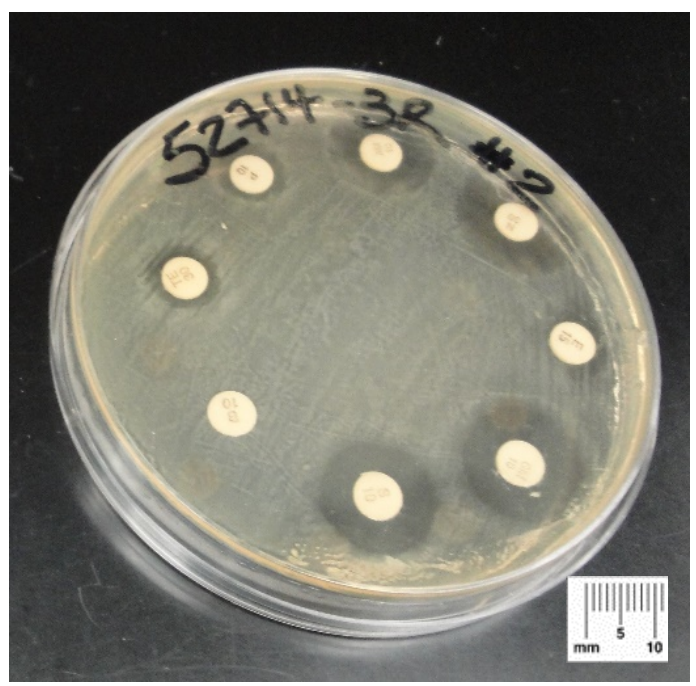

Figure 24. Representative Antibiogram Plate of Profile 10. NOTE: This plate included Streptomycin and Neomycin disks not used in this study.

Profile 11 (see Figure 25 and 26): Salmonella Isolate 3814-7G is resistant to Penicillin, a beta-lactam, with a halo size observed at $6 \mathrm{~mm}$, Bacitracin, a polypeptide, with a halo size observed at $6 \mathrm{~mm}$, and Erythromycin, a macrolide, with a halo size observed at $12 \mathrm{~mm}$ in vitro. Intermediate sensitivity is to Ampicillin, a beta- lactam, with a halo size observed at $15 \mathrm{~mm}$ (Wreth, 2018). The isolate is susceptible to Tetracycline, a naphthacene, and Gentamicin, an aminoglycoside, with halo sizes for both observed at $20 \mathrm{~mm}$ (Wreth, 2018). This isolate is susceptible to antibiotics that inhibit protein synthesis. 


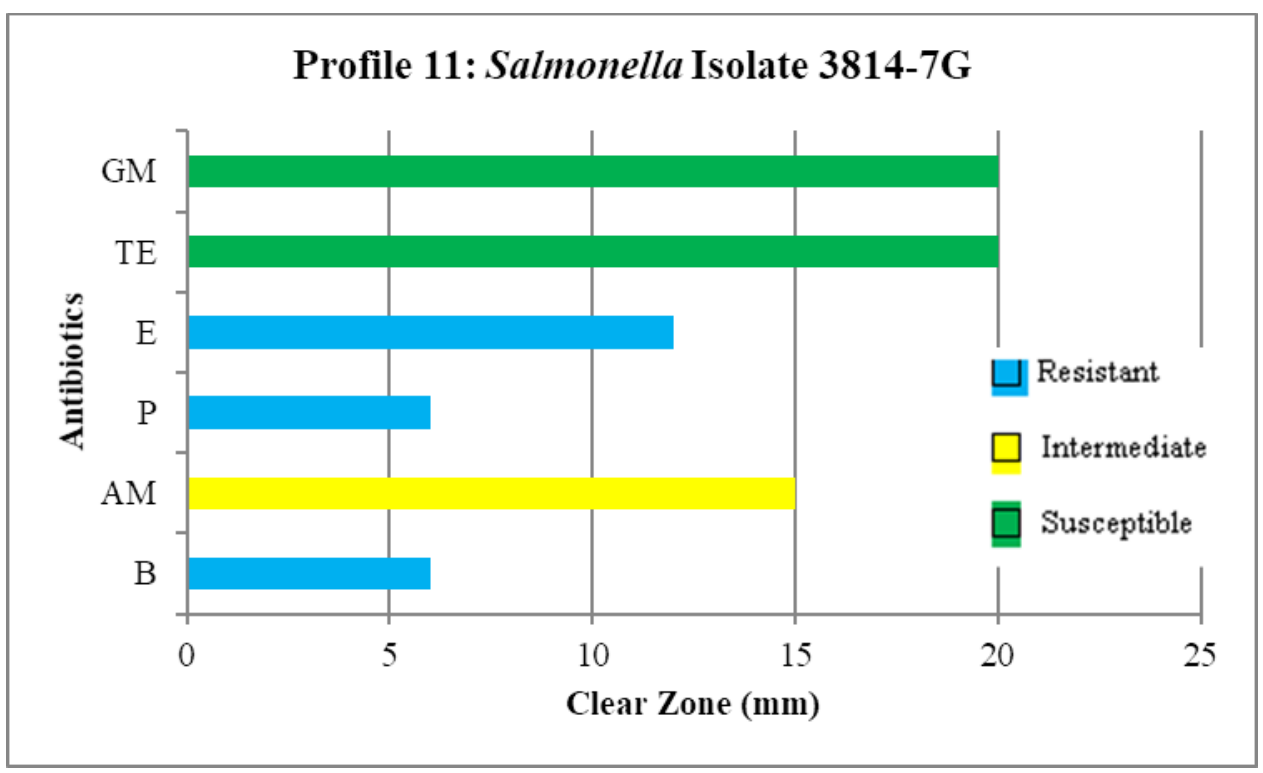

Figure 25. Antibiogram Profile 11: Salmonella Isolate 3814-7G: Resistant to Penicillin (P), Bacitracin (B) and Erythromycin (E); Intermediate to Ampicillin (AM); Susceptible to Tetracycline (TE), and Gentamicin (GM).

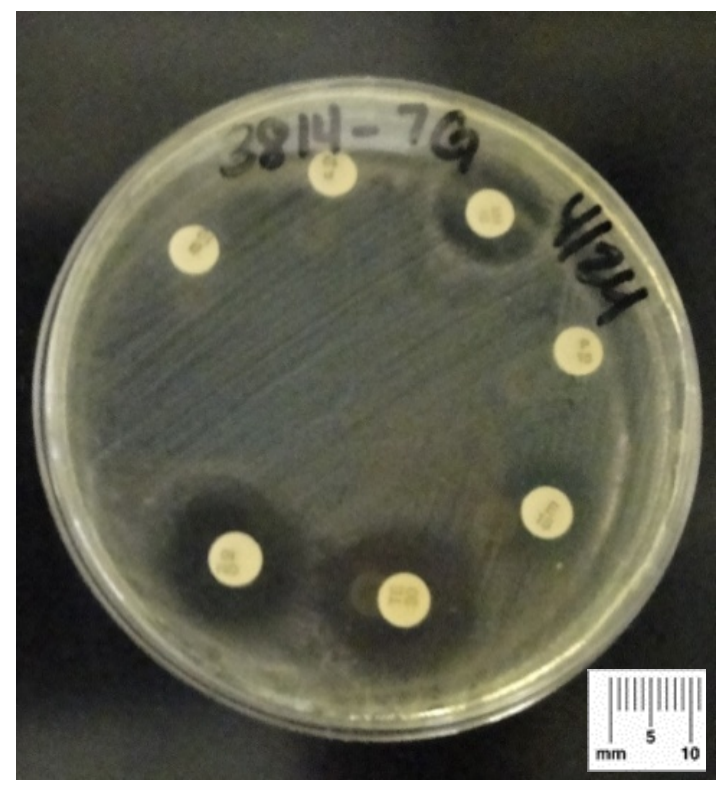

Figure 26. Representative Antibiogram Plate of Profile 11. NOTE: This plate has 2 Penicillin disks that measured the same. 
Profile 12 (see Figure 27 and 28): Salmonella Isolate 51614-3H is resistant to Penicillin, a beta-lactam, and Bacitracin, a polypeptide, both with halo sizes observed at $7 \mathrm{~mm}$. It has intermediate sensitivity to Ampicillin, a beta-lactam, with a halo size observed at $14 \mathrm{~mm}$, Tetracycline, a naphthacene, with a halo size observed at $18 \mathrm{~mm}$, and Erythromycin, a macrolide, with a halo size observed at $14 \mathrm{~mm}$; and is susceptible to Gentimicin , an aminoglycoside, with halo size observed at $17 \mathrm{~mm}$ (Wreth, 2018). This isolate is resistant to only 2 antibiotics that would interfere with cell wall production but is considered multidrug resistant in vitro.

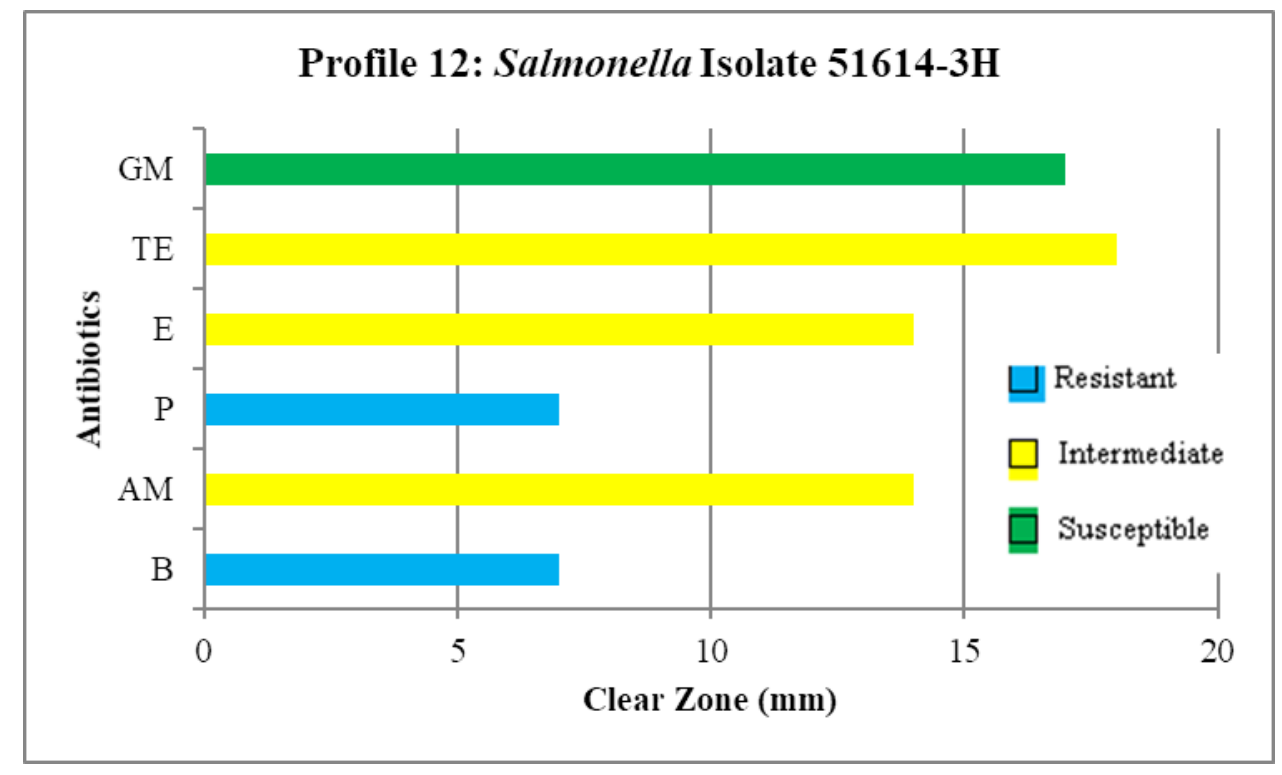

Figure 27. Antibiogram Profile 12: Salmonella Isolate 51614-3H: Resistant to Penicillin (P) and Bacitracin (B); Intermediate to Ampicillin (AM), Tetracycline (TE) and Erythromycin (E); Susceptible to Gentamicin (GM). 


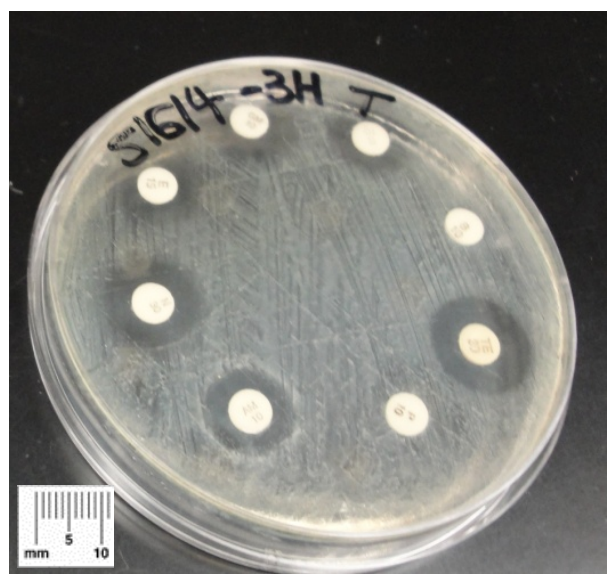

Figure 28. Representative Antibiogram Plate of Profile 12. NOTE: This plate included Streptomycin and Neomycin not used in this study.

\subsubsection{Antibiogram Results based on Antimicrobials Sensitivity Levels}

Thirty-seven Salmonella spp. isolates were tested against 6 common antimicrobials listed in Table 4. This Table references the antibiotics in the categories resistant, intermediate and susceptible. Figures 30-35 depict a different visual representation of the antibiotics listed in Table 4 based on the percentage that the Salmonella spp. isolates are resistant, intermediate, and susceptible to them.

Table 4. Antibiotic Sensitivity Levels based on the 6 Common Antimicrobials Tested

\begin{tabular}{|l|c|c|c|c|c|c|}
\hline \multicolumn{1}{|c|}{ Antibiotic } & Resistant & $\mathbf{\%}$ & Intermediate & $\mathbf{\%}$ & Susceptible & $\mathbf{\%}$ \\
\hline Ampicillin & 7 & 19 & 11 & 30 & 19 & 51 \\
\hline Bacitracin & 37 & 100 & 0 & 0 & 0 & 0 \\
\hline Erythromycin & 32 & 86 & 5 & 14 & 0 & 0 \\
\hline Gentamicin & 1 & 3 & 0 & 0 & 36 & 97 \\
\hline Penicillin & 27 & 73 & 10 & 27 & 0 & 0 \\
\hline Tetracycline & 30 & 81 & 4 & 11 & 3 & 8 \\
\hline
\end{tabular}




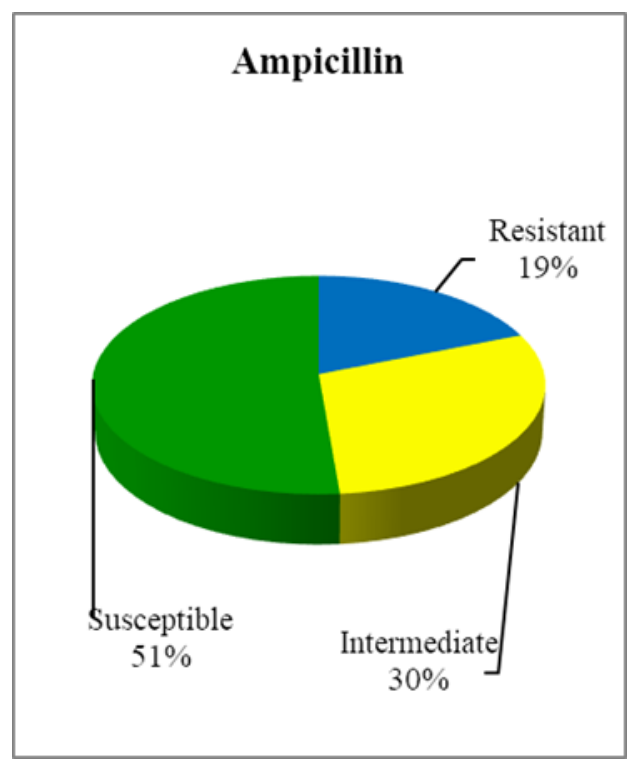

Figure 29. Ampicillin Sensitivity: Isolates were 19\% Resistant; 30\% Intermediate; and 51\% Susceptible.

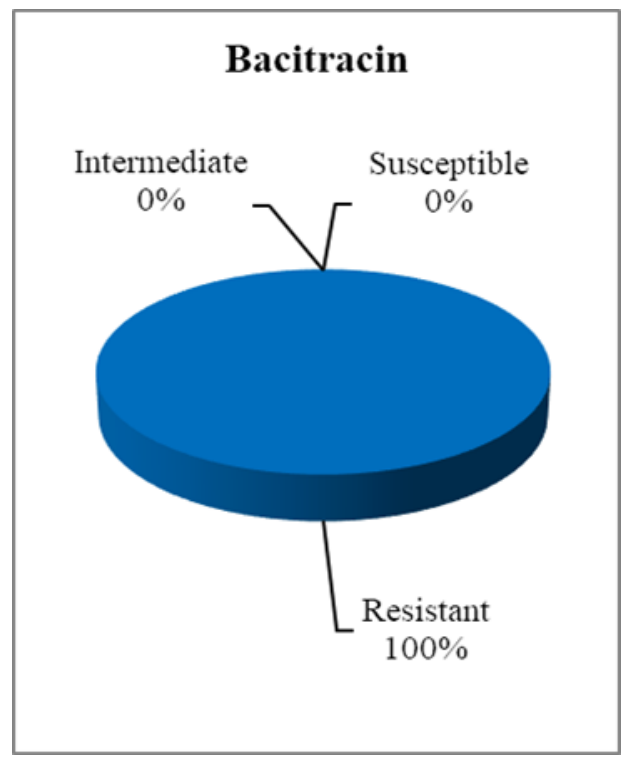

Figure 30. Bacitracin Sensitivity: Isolates were $100 \%$ Resistant; $0 \%$ Intermediate; and $0 \%$ Susceptible.

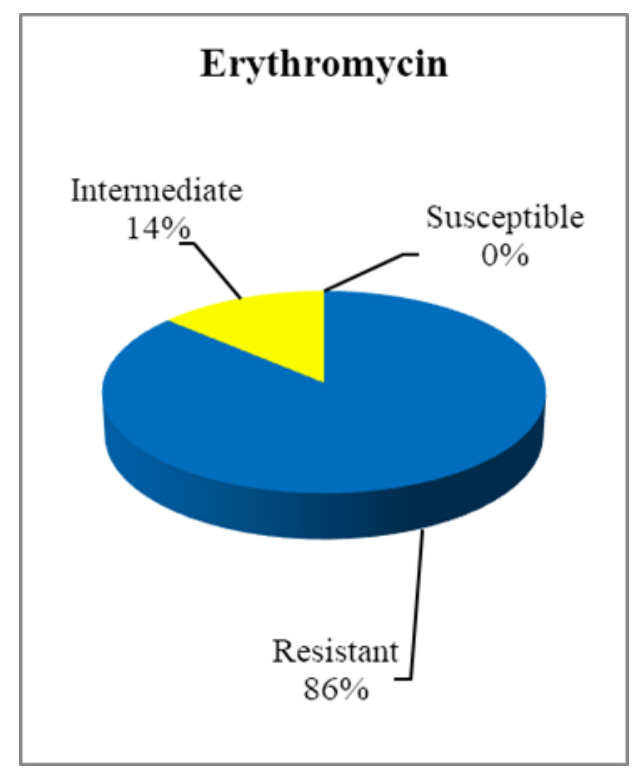

Figure 31. Erythromycin Sensitivity: Isolates were $86 \%$ Resistant; $13 \%$ Intermediate; and 5\% Susceptible.

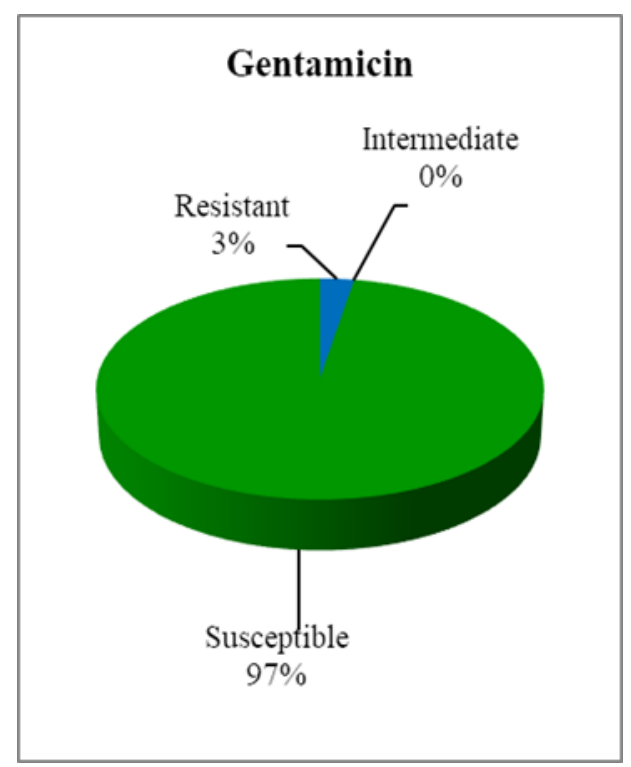

Figure 32. Gentamicin Sensitivity: Isolates were 3\% Resistant; 0\% Intermediate; and 97\% Susceptible. 


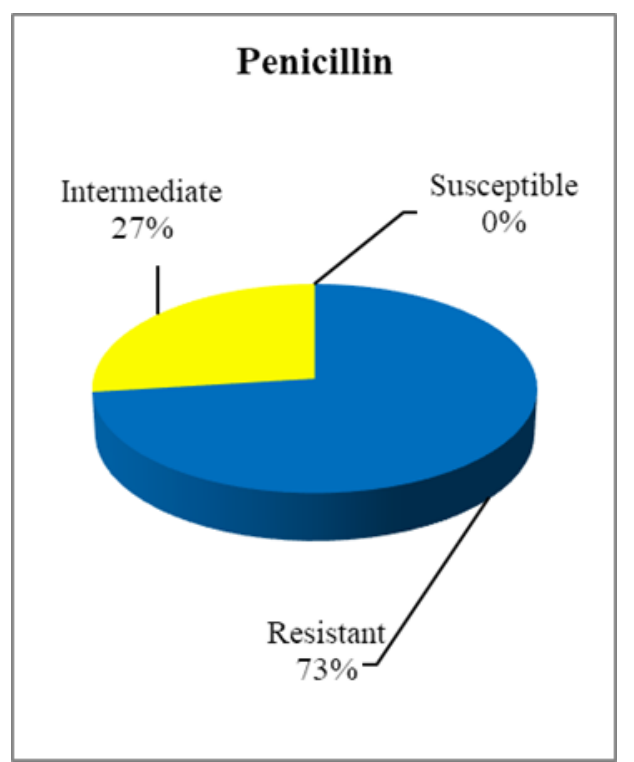

Figure 33. Penicillin Sensitivity: Isolates were 73\% Resistant; 27\% Intermediate; and 0\% Susceptible.

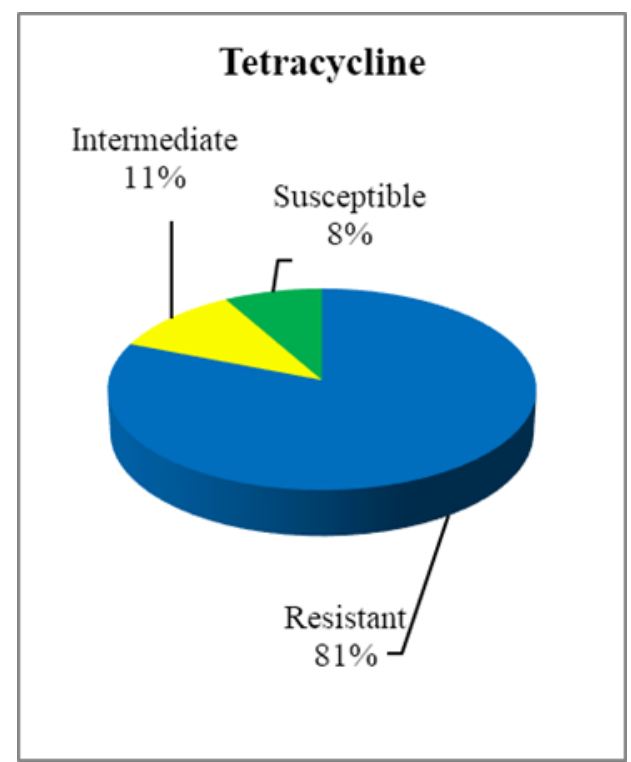

Figure 34. Tetracycline Sensitivity: Isolates were $81 \%$ Resistant; $11 \%$ Intermediate; and 8\% Susceptible. 


\subsection{QUESTIONNAIRE RESULTS}

The survey was broken down into seven sections: poultry, feed, housing, sanitation, egg handling, biosecurity and human illness potentially due to interaction with the birds. For each site, a questionnaire was filled out and the results were tabulated based on the answers given to and/or observations by the researcher.

Samples were collected from 29 sites within San Luis Obispo County between March and May 2014. Table 5 indicates the number of sites in the North County and South County by city. It also shows how many of the sites were positive for Salmonella spp. and the number of samples and positive isolates collected by each city. The sites for collection of samples from the backyard poultry in the San Luis Obispo County were determined by word of mouth as to the availability of test subjects. Though many areas around the county were tested, the researchers were unable to secure sample sites in South County such as

Pismo Beach, Avila and Arroyo Grande or the upper part of North County such as Paso Robles.

Table 5. Location of Sites by City

\begin{tabular}{|l|c|c|c|c|c|c|c|}
\hline \multicolumn{1}{|c|}{ City } & $\begin{array}{c}\text { North } \\
\text { County }\end{array}$ & $\begin{array}{c}\text { South } \\
\text { County }\end{array}$ & $\begin{array}{c}+ \\
\text { Sites } \\
\text { in } \\
\text { City }\end{array}$ & $\begin{array}{c}\text { \%o of } \\
+ \\
\text { Sites } \\
\text { in } \\
\text { City }\end{array}$ & $\begin{array}{c}\text { \# Samples } \\
\text { Collected } \\
\text { from City }\end{array}$ & $\begin{array}{c}+ \\
\text { Samples } \\
\text { from } \\
\text { City }\end{array}$ & $\begin{array}{c}\text { \% + } \\
\text { Samples } \\
\text { within } \\
\text { City }\end{array}$ \\
\hline Atascadero & 13 & & 13 & $100 \%$ & 23 & 17 & $73.9 \%$ \\
\hline Creston & 2 & & 1 & $50 \%$ & 3 & 1 & $33.3 \%$ \\
\hline Los Osos & & 1 & 1 & $100 \%$ & 1 & 1 & $100 \%$ \\
\hline Morro Bay & & 5 & 2 & $40 \%$ & 7 & 3 & $42.9 \%$ \\
\hline Pozo (canyon) & 2 & & 1 & $50 \%$ & 3 & 2 & $66.7 \%$ \\
\hline San Luis Obispo & & 1 & 1 & $100 \%$ & 1 & 1 & $100 \%$ \\
\hline $\begin{array}{l}\text { Santa Margarita } \\
\text { (town) }\end{array}$ & 4 & & 4 & $100 \%$ & 12 & 7 & $58.3 \%$ \\
\hline Templeton & 1 & & 1 & $100 \%$ & 1 & 1 & $100 \%$ \\
\hline
\end{tabular}




\subsubsection{Poultry}

Table 6 through Table 10 addresses the questionnaire's poultry section. The poultry data was tabulated by different strains, breeds, and species of poultry. The Tables also address the source of the poultry, number of birds per coop, number of coops per sites and the reason for the birds being kept. The Tables are further delineated as to how many samples were positive per category.

Table 6. Types of Poultry on Site: The chart lists the species of poultry by site and the positive samples.

\begin{tabular}{|l|c|c|c|c|}
\hline \multicolumn{1}{|c|}{ Type } & \# of Sites & $\begin{array}{c}\text { \% of } \\
\text { Sites with } \\
\text { Type }\end{array}$ & $\begin{array}{c}\#+ \\
\text { Samples } \\
\text { per Type }\end{array}$ & $\begin{array}{c}\%+ \\
\text { Samples } \\
\text { per Type }\end{array}$ \\
\hline Chicken & 29 & $100 \%$ & 30 & $91 \%$ \\
\hline Turkeys & 1 & $3.4 \%$ & 0 & $0 \%$ \\
\hline Geese & 2 & $6.9 \%$ & 2 & $6 \%$ \\
\hline Ducks & 3 & $10.3 \%$ & 0 & $0 \%$ \\
\hline Pigeons & 1 & $3.4 \%$ & 1 & $3 \%$ \\
\hline
\end{tabular}


Table 7. Poultry Breeds by Site: There were various breeds of poultry at the sites. Most sites had a variety of breeds mixed with each other and other sites multiple species.

\begin{tabular}{|c|c|c|c|c|c|c|c|}
\hline $\begin{array}{l}\text { Chicken } \\
\text { Breeds }\end{array}$ & $\begin{array}{c}\# \\
\text { Sites } \\
\text { with } \\
\text { Breed }\end{array}$ & $\begin{array}{c}\text { Site + } \\
\text { with } \\
\text { Breed }\end{array}$ & $\begin{array}{c}\text { \% + } \\
\text { Site } \\
\text { with } \\
\text { Breed }\end{array}$ & Chicken Breeds & $\begin{array}{c}\text { \# Sites } \\
\text { with } \\
\text { Breed }\end{array}$ & $\begin{array}{c}\text { Site + } \\
\text { With } \\
\text { Breed }\end{array}$ & $\begin{array}{c}\text { \% + } \\
\text { Site } \\
\text { with } \\
\text { Breed }\end{array}$ \\
\hline Americana & 5 & 3 & $60 \%$ & $\begin{array}{l}\text { Leg Horn (white or } \\
\text { brown) }\end{array}$ & 4 & 3 & $75 \%$ \\
\hline Arachana & 6 & 6 & $100 \%$ & Missouri Stars & 1 & 1 & $100 \%$ \\
\hline Australops & 2 & 1 & $50 \%$ & $\begin{array}{l}\text { Old English } \\
\text { Wheatons }\end{array}$ & 1 & 1 & $100 \%$ \\
\hline Banni & 1 & 1 & $100 \%$ & Partridge & 1 & 1 & $100 \%$ \\
\hline Bantoms & 2 & 1 & $50 \%$ & Polish & 1 & 1 & $100 \%$ \\
\hline Barred Rock & 20 & 16 & $80 \%$ & Rhode Island Red & 20 & 17 & $85 \%$ \\
\hline Barnverbles & 1 & 1 & $100 \%$ & Russian Orlfols & 1 & 1 & $100 \%$ \\
\hline Black Barred & 1 & 1 & $100 \%$ & $\begin{array}{lll}\begin{array}{l}\text { Silkie } \\
\text { black) }\end{array} & \text { (white } & \text { or } \\
\end{array}$ & 4 & 4 & $100 \%$ \\
\hline $\begin{array}{l}\text { Black Sex- } \\
\text { linked }\end{array}$ & 1 & 1 & $100 \%$ & Wellsumers & 1 & 1 & $100 \%$ \\
\hline Blue Hamburg & 1 & 1 & $100 \%$ & Wyancottie & 1 & 1 & $100 \%$ \\
\hline Brahmas & 1 & 1 & $100 \%$ & & & & \\
\hline Buff Orpington & 13 & 11 & $84.7 \%$ & & & & \\
\hline Cochins & 3 & 3 & $100 \%$ & $\begin{array}{c}\text { Other Poultry } \\
\text { Breeds }\end{array}$ & & & \\
\hline Cornish Game & 1 & 0 & $0 \%$ & Royal Turkeys & 1 & 1 & $100 \%$ \\
\hline Dark Samatras & 1 & 1 & $100 \%$ & Ducks - unknown & 1 & 1 & $100 \%$ \\
\hline Delaware & 1 & 0 & $0 \%$ & Geese unknown & 1 & 1 & $100 \%$ \\
\hline $\begin{array}{l}\text { Golden } \\
\text { Orpington }\end{array}$ & 1 & 1 & $100 \%$ & $\begin{array}{l}\text { Indian Runners } \\
\text { Ducks }\end{array}$ & 1 & 0 & $0 \%$ \\
\hline $\begin{array}{l}\text { Golden Sex- } \\
\text { Linked }\end{array}$ & 1 & 1 & $100 \%$ & Peking Ducks & 2 & 2 & $100 \%$ \\
\hline Hybrids & 1 & 1 & $100 \%$ & Squab (pigeons) & 1 & 1 & $100 \%$ \\
\hline $\begin{array}{l}\text { Lavender } \\
\text { Orpington }\end{array}$ & 1 & 0 & $0 \%$ & Swan Geese & 1 & 1 & $100 \%$ \\
\hline
\end{tabular}


Table 8 shows this study's basic data regarding each of 29 sample sites. It captures the number of birds and coops per site, whether the site was positive for Salmonella spp., how many samples were collected and how many samples were positive for Salmonella spp.

Table 8 . Numbers of Poultry and Coops by Site

\begin{tabular}{|c|c|c|c|c|c|}
\hline Site & $\begin{array}{c}\text { \# of } \\
\text { Birds } \\
\text { on Site }\end{array}$ & $\begin{array}{c}\text { \# of } \\
\text { Coops } \\
\text { on Site }\end{array}$ & $\begin{array}{c}\text { Site }+ \\
\text { (Yes/No) }\end{array}$ & $\begin{array}{c}\text { \# Samples } \\
\text { collected at } \\
\text { Site }\end{array}$ & $\begin{array}{c}+ \\
\text { Samples } \\
\text { per Site }\end{array}$ \\
\hline $\mathbf{1}$ & 3 & 1 & N & 1 & 0 \\
\hline $\mathbf{2}$ & 52 & 1 & Y & 1 & 1 \\
\hline $\mathbf{3}$ & 6 & 1 & N & 1 & 0 \\
\hline $\mathbf{4}$ & 6 & 1 & N & 1 & 0 \\
\hline $\mathbf{5}$ & 5 & 1 & N & 1 & 0 \\
\hline $\mathbf{6}$ & 35 & 3 & Y & 3 & 2 \\
\hline $\mathbf{7}$ & 40 & 2 & Y & 2 & 2 \\
\hline $\mathbf{8}$ & 5 & 3 & Y & 3 & 3 \\
\hline $\mathbf{9}$ & 41 & 7 & Y & 7 & 2 \\
\hline $\mathbf{1 0}$ & 23 & 2 & N & 2 & 0 \\
\hline $\mathbf{1 1}$ & 36 & 2 & Y & 2 & 4 \\
\hline $\mathbf{1 2}$ & 17 & 2 & Y & 2 & 1 \\
\hline $\mathbf{1 3}$ & 8 & 1 & Y & 1 & 1 \\
\hline $\mathbf{1 4}$ & 4 & 2 & Y & 2 & 1 \\
\hline $\mathbf{1 5}$ & 5 & 1 & Y & 1 & 1 \\
\hline $\mathbf{1 6}$ & 6 & 1 & Y & 1 & 1 \\
\hline $\mathbf{1 7}$ & 4 & 1 & Y & 1 & 1 \\
\hline $\mathbf{1 8}$ & 10 & 1 & Y & 1 & 1 \\
\hline $\mathbf{1 9}$ & 10 & 1 & Y & 1 & 1 \\
\hline $\mathbf{2 0}$ & 7 & 1 & Y & 1 & 1 \\
\hline $\mathbf{2 1}$ & 4 & 1 & Y & 1 & 1 \\
\hline $\mathbf{2 2}$ & 5 & 1 & Y & 1 & 1 \\
\hline $\mathbf{2 3}$ & 6 & 2 & Y & 2 & 1 \\
\hline $\mathbf{2 4}$ & 7 & 1 & Y & 1 & 1 \\
\hline $\mathbf{2 5}$ & 17 & 1 & Y & 1 & 1 \\
\hline $\mathbf{2 6}$ & 4 & 1 & Y & 1 & 1 \\
\hline $\mathbf{2 7}$ & 14 & 1 & Y & 1 & 1 \\
\hline $\mathbf{2 8}$ & 4 & 1 & Y & 1 & 1 \\
\hline $\mathbf{2 9}$ & 55 & 2 & Y & 2 & 1 \\
\hline $\mathbf{T O T A L}$ & $\mathbf{4 3 9}$ & $\mathbf{5 0}$ & $\mathbf{2 4 - N}$ & $\mathbf{5 0}$ & $\mathbf{3 3}$ \\
\hline & & & & & \\
\hline
\end{tabular}


Owners reported where they purchased or how they acquired their birds on Table 9. Some owners had multiple sources of where their birds came from. Knowing the source of the poultry is imperative to any zoonotic outbreak, especially if a trace back investigation is needed to identify where the pathogens were introduced into the supply chain. Table 9 also indicates the number of sites for each source that was positive for Salmonella spp..

Table 9. Source of Poultry

\begin{tabular}{|l|c|c|c|}
\hline \multicolumn{1}{|c|}{ Sources } & \# of Sites & Sites + & $\mathbf{\%}+$ Sites with Source \\
\hline Atascadero Hay and Feed & 10 & 10 & $100 \%$ \\
\hline Farm Supply & 2 & 0 & $0 \%$ \\
\hline Santa Margarita Feed & 5 & 5 & $100 \%$ \\
\hline Direct from Hatchery & 2 & 2 & $100 \%$ \\
\hline Offspring & 7 & 5 & $71 \%$ \\
\hline Friends & 6 & 4 & $67 \%$ \\
\hline Rescue & 2 & 0 & $0 \%$ \\
\hline Came with property & 2 & 2 & $100 \%$ \\
\hline Los Osos Pet Store & 1 & 1 & $100 \%$ \\
\hline Unknown & 1 & 0 & $0 \%$ \\
\hline
\end{tabular}

The owners reported the uses for and purpose of their birds (see Table 10). Many had more than one category for which they used their birds. All owners seem to have the same objective for their birds to lay eggs even if they were turkeys, geese or ducks. Having poultry as pets was the second largest usage. Table 10 also shows all Salmonella spp. positive sites per purpose category. 
Table 10. Purpose of Poultry (some sites had dual purpose for the poultry)

\begin{tabular}{|l|c|c|c|}
\hline \multicolumn{1}{|c|}{ Purpose } & \# of Sites & Sites + & \% + Sites \\
\hline Eggs & 29 & 24 & $82.7 \%$ \\
\hline Meat & 3 & 3 & $100 \%$ \\
\hline Pets & 13 & 9 & $69 \%$ \\
\hline Therapy/Pleasure & 2 & 1 & $50 \%$ \\
\hline 4-H/ Show & 4 & 3 & $75 \%$ \\
\hline Guarding Property & 1 & 1 & 100 \\
\hline Yard Keeping/Bugs & 2 & 1 & $50 \%$ \\
\hline
\end{tabular}

\subsubsection{Feed}

Most sites fed King's Feed Brand as noted in Table 11. It is one of the most popular feeds and carried by most of the pet stores and feed stores in the county. But there were sites that fed several types of feed due to the age of birds or having various types of poultry.

Table 11. Brands of Feed

\begin{tabular}{|l|c|c|c|}
\hline \multicolumn{1}{|c|}{ Brand of Feed } & \# of Sites & Sites + & \% + Site using feed \\
\hline King's Feed & 21 & 21 & $100 \%$ \\
\hline Templeton Grain and Feed & 1 & 1 & $100 \%$ \\
\hline Nutrena All Natural & 3 & 1 & $33.3 \%$ \\
\hline Santa Margarita Feed & 2 & 0 & $0 \%$ \\
\hline Lemos & 2 & 1 & $50 \%$ \\
\hline Farmers & 1 & 1 & $100 \%$ \\
\hline Producers Pride & 1 & 1 & $100 \%$ \\
\hline Swonsens Farms & 1 & 0 & $0 \%$ \\
\hline
\end{tabular}

Feed type was dependent on the birds' dietary needs which is based on their age and/or stage of development (see Table 12). Layers usually eat a combination of scratch with either pellets or crumble. Owners also supplemented the feed with: oyster shell for calcium, Diatomaceous Earth for intestinal parasites, or Meal Worms for waterfowl and as enrichment for chickens. All sites feed table scraps which included mainly vegetables, fruits, rinds, eggs shells, and one site fed cooked rice. 
Table 12. Types of Feed and Supplements

\begin{tabular}{|l|c|c|c|c|}
\hline \multicolumn{1}{|c|}{$\begin{array}{c}\text { Types of Feed and } \\
\text { Supplementals }\end{array}$} & \# of Sites & \% & Site + & \% \\
\hline Scratch & 11 & $37.9 \%$ & 8 & $72.7 \%$ \\
\hline Pellets & 8 & $27.5 \%$ & 5 & $62 . \%$ \\
\hline Crumble & 7 & $24.1 \%$ & 7 & $100 \%$ \\
\hline Chick Starter (medicated) & 4 & $13.7 \%$ & 4 & $100 \%$ \\
\hline Layer & 6 & $20.6 \%$ & 6 & $100 \%$ \\
\hline Waterfowl & 1 & $3.4 \%$ & 1 & $100 \%$ \\
\hline GMO Free & 3 & $3.4 \%$ & 1 & $33.3 \%$ \\
\hline Oyster Shell & 8 & $27.5 \%$ & 7 & $87.5 \%$ \\
\hline Diatomaceous Earth & 1 & $3.4 \%$ & 1 & $100 \%$ \\
\hline Meal Worms & 5 & $17.2 \%$ & 4 & $80 \%$ \\
\hline Table Scraps & 29 & $100 \%$ & 29 & $100 \%$ \\
\hline
\end{tabular}

\subsubsection{Housing}

The sites had various types of coops (as determined by photographs). Sites with mutiple show birds or different types of poultry had several coops on the property (refer to Table 13). Coops with nesting boxes had the highest positive samples for Salmonella spp.. The second highest was coops with daily yard access where outside contamination sources such as pests and wildlife have access.

Table 13. Housing and Coop Types

\begin{tabular}{|l|c|c|c|c|}
\hline \multicolumn{1}{|c|}{ Housing \& Coop Types } & \# Coops & $\begin{array}{c}\text { \% with } \\
\text { coop type }\end{array}$ & + Samples & $\begin{array}{c}\text { \% + with } \\
\text { coop type }\end{array}$ \\
\hline Coop-small total confinement & 6 & $12 \%$ & 3 & $91 \%$ \\
\hline Coop with daily yard access & 12 & $24 \%$ & 9 & $27 \%$ \\
\hline In house (residence - young) & 3 & $6 \%$ & 2 & $4 \%$ \\
\hline Coop that is mobile & 1 & $2 \%$ & 1 & $2 \%$ \\
\hline Caged & 1 & $2 \%$ & 1 & $2 \%$ \\
\hline Free Yard access - continual & 1 & $2 \%$ & 0 & $0 \%$ \\
\hline Fenced area only & 8 & $16 \%$ & 3 & $91 \%$ \\
\hline Covered Fenced area with nesting box & 11 & $22 \%$ & 10 & $33 \%$ \\
\hline Covered Fenced area with shelter & 7 & $14 \%$ & 4 & $12 \%$ \\
\hline
\end{tabular}


Tables 14 and 15 took the information from Table 8 to address the overall number of coops by sites and number of birds per coops combined with the sites positive and the number of positive samples for Salmonella spp.

Table 14. Number of Coops on Site

\begin{tabular}{|c|c|c|c|c|c|c|}
\hline \# Coops/Areas & \# Sites & $\begin{array}{c}\text { \% of } \\
\text { Sites }\end{array}$ & Site + & $\begin{array}{c}\text { \% + } \\
\text { Sites }\end{array}$ & $\begin{array}{c}\text { Samples } \\
+\end{array}$ & $\begin{array}{c}\%+ \\
\text { Samples }\end{array}$ \\
\hline 1 & 19 & $65.5 \%$ & 15 & $51.7 \%$ & 15 & $45.4 \%$ \\
\hline 2 & 6 & $20.6 \%$ & 5 & $17.2 \%$ & 6 & $18.1 \%$ \\
\hline 3 & 2 & $6.8 \%$ & 2 & $6.8 \%$ & 5 & $15.1 \%$ \\
\hline 6 & 1 & $3.4 \%$ & 1 & $3.4 \%$ & 3 & $9.0 \%$ \\
\hline 7 & 1 & $3.4 \%$ & 1 & $3.4 \%$ & 4 & $12.1 \%$ \\
\hline
\end{tabular}

Table 15. Number of Birds per Coop

\begin{tabular}{|c|c|c|c|c|}
\hline \# of Birds & \# Coops & $\begin{array}{c}\mathbf{\%} \\
\text { Birds/Coop }\end{array}$ & $\begin{array}{c}\text { Samples } \\
+\end{array}$ & $\begin{array}{c}\%+ \\
\text { Samples }\end{array}$ \\
\hline $1-5$ & 21 & $42 \%$ & 16 & $49 \%$ \\
\hline $6-10$ & 13 & $26 \%$ & 10 & $30 \%$ \\
\hline $11-15$ & 5 & $10 \%$ & 1 & $3 \%$ \\
\hline $16-20$ & 2 & $4 \%$ & 1 & $3 \%$ \\
\hline $21-25$ & 2 & $4 \%$ & 2 & $6 \%$ \\
\hline $26-30$ & 5 & $10 \%$ & 1 & $3 \%$ \\
\hline $31-35$ & 1 & $2 \%$ & 1 & $3 \%$ \\
\hline $50+$ & 1 & $2 \%$ & 1 & $3 \%$ \\
\hline
\end{tabular}




\subsubsection{Sanitation}

Most sites cleaned their coops monthly as indicated by Table 16 . Those sites with this husbandry practice also had the most positive samples of Salmonella spp..

Table 16. Sanitation

\begin{tabular}{|l|c|c|c|c|}
\hline \multicolumn{1}{|c|}{ When Coop Cleaned } & \# Sites & $\begin{array}{c}\text { \% of } \\
\text { Sites }\end{array}$ & Site + & $\begin{array}{c}\%+ \\
\text { Sites }\end{array}$ \\
\hline Daily & 0 & $0 \%$ & 0 & $0 \%$ \\
\hline Weekly & 5 & $17 \%$ & 4 & $80 \%$ \\
\hline Monthly & 19 & $66 \%$ & 17 & $89.5 \%$ \\
\hline $2-3$ months & 2 & $7 \%$ & 2 & $100 \%$ \\
\hline Never (compost in coop) & 1 & $3 \%$ & 1 & $100 \%$ \\
\hline Unknown & 2 & $7 \%$ & 1 & $50 \%$ \\
\hline
\end{tabular}

Sanitation practices also include the handling of equipment or dedicated clothes used in poultry areas especially as fomites inadvertently can spread microbes and/or pathogens.

Table 17 looks at shoes that could be a source of contamination between poultry coops and the human households or environments.

Table 17. Separate Mucking Shoes

\begin{tabular}{|l|c|c|c|c|}
\hline Dedicated Mucking Shoes & \# of Sites & $\begin{array}{c}\text { \%o of } \\
\text { Sites }\end{array}$ & Site + & $\begin{array}{c}\text { \% + } \\
\text { Sites }\end{array}$ \\
\hline Yes & 6 & 20.6 & 5 & $83.3 \%$ \\
\hline No & 23 & 79.3 & 19 & $82.6 \%$ \\
\hline
\end{tabular}




\subsubsection{Egg Handling}

Table 18 looks at the knowledge and practices of poultry owners on the proper way to handle eggs. Did the owners collect the eggs daily in a timely manner, clean the eggs properly with wash when warm versus cold or by sanding off debris, store the dirty eggs with clean eggs or above the clean eggs, and/or keep the eggs on the counters or in the refrigerator? Only 5 owners had an overall understanding of proper egg handling whereas the others lacked healthy and hygienic practices or were deficient in their knowledge relevant to current industry practices (Clauser, 2009; Bunning, et al, 2010).

Table 18. Proper Egg Handling: Standards based on Colorado State University Extension

\begin{tabular}{|l|c|c|c|c|}
\hline \multicolumn{1}{|c|}{ Proper Egg Handling } & \# of Sites & \% of Sites & Site + & \% + Sites \\
\hline Yes & 5 & $17.2 \%$ & 3 & $60 \%$ \\
\hline No & 23 & $72.4 \%$ & 21 & $91.3 \%$ \\
\hline Not Applicable (immature birds) & 1 & $3.4 \%$ & 1 & $100 \%$ \\
\hline
\end{tabular}

\subsubsection{Biosecurity}

Various questions make up this category (see Table 19): specific biosecurity plans; separate shoes and clothes to deal with poultry; access to other animals/pets on property; pests access (rodents, birds, wildlife); human contact beyond caretakers; housed within 30 feet of residence; visible signs of disease in the poultry as noticed by the researcher. 
Table 19. Biosecurity on Site

\begin{tabular}{|c|c|c|c|c|c|c|c|}
\hline Site & $\begin{array}{c}\text { Bio- } \\
\text { security } \\
\text { Plans }\end{array}$ & $\begin{array}{c}\text { Dedicated } \\
\text { shoes and } \\
\text { clothing }\end{array}$ & $\begin{array}{c}\text { Contact } \\
\text { only with } \\
\text { caretakers }\end{array}$ & $\begin{array}{c}\text { Within } \\
\mathbf{3 0} \mathbf{f t} \\
\text { of } \\
\text { residence }\end{array}$ & $\begin{array}{c}\text { Lack of } \\
\text { contact } \\
\text { with } \\
\text { other } \\
\text { animals }\end{array}$ & $\begin{array}{c}\text { Lack of } \\
\text { pests, } \\
\text { wildlife, } \\
\text { rodents, } \\
\text { birds }\end{array}$ & $\begin{array}{c}\text { Visible } \\
\text { signs of } \\
\text { other } \\
\text { diseases }\end{array}$ \\
\hline Yes & 0 & 6 & 3 & 18 & 0 & 0 & 4 \\
\hline No & 29 & 23 & 26 & 11 & 29 & 29 & 25 \\
\hline
\end{tabular}

Table 20. Over-all Biosecurity per Site (based on Table 19 above)

\begin{tabular}{|c|c|c|c|}
\hline Site & Overall biosecurity & Site + & $\%+$ Sites \\
\hline Yes & 0 & 0 & 0 \\
\hline No & 29 & 24 & $82 \%$ \\
\hline
\end{tabular}

\subsubsection{Human Illness}

The results dealing with the questions regarding family illness were not tabulated due to their questionable accuracy. The self-reporting subjects usually would be deterred from reporting candidly due to the sensitive nature of the thesis topic and bacteria samples collected. However, one subject did say she had salmonellosis six months prior to this study's sample collection. She said that the San Luis Obispo County Health Department traced her illness back to the contact with and exposure to raw chicken meat during food preparation within her occupational duties as a kitchen lady at a county school. She offerred a copy of the report as needed for review. At that time there was a current Foster Farms meat recall due to $S$. Heidelberg (CDFA 2014). 
In hindsight, the topic of hygiene should have been addressed in the questionnaire. Questions regarding whether the owners, their family members or visitors wash their hands before or after contact with the birds, their surroundings, feed, equipment, etc. should have been devised. These questions would have been indicators of risky behaviors (Basler et al., 2016) leading to increased exposure to zoonotic poultry diseases and jeopardizing overall human health. 


\section{DISCUSSION}

This study looked at the prevalence of Salmonella spp. in populations of backyard poultry. Collection at 29 sites yielded 24 testing positive for Salmonella spp. with 33 samples from the 50 samples collected being positive for Salmonella spp.. These percentages of $82.8 \%$ and $66 \%$ respectively are higher (see Tables 1 and 2 ) than any international study fore mentioned in Limitations and Assumptions. The sample cultures were double verified as Salmonella spp. by the specific Salmonella media selective plates.

As this study did not test for the specific Salmonella spp. serovars, the different serotypes remain unknown. Yet the HardyCHROM ${ }^{\mathrm{TM}}$ SS plate did allow for the differentiation in two types of Salmonella colonies: 1) $\mathrm{H}_{2} \mathrm{~S}$ producing which showed black and 2) non- $\mathrm{H}_{2} \mathrm{~S}$ producing which showed teal in color.

Salmonella isolates were not serotyped as this study focused on sample collection where the poultry was housed or kept. There is no way of knowing if the Salmonella spp. isolates were contaminants from the environment or directly influenced by wildlife, food, bedding or other sources. The sample collections were from poultry areas heavily used by the birds. The collection was done by walking the entire coop with the Envirobootie ${ }^{\mathrm{TM}}$ paying special attention to areas around nesting, water, food, and feces piles. The samples were cultured in the laboratory to isolate Salmonella spp. whether $\mathrm{H}_{2} \mathrm{~S}$-producing or non- $\mathrm{H}_{2} \mathrm{~S}$ producing. Clear delineated colonies were isolated and cultured in TSA filled test tubes to be later tested for antibiotic sensitivity. 


\subsection{ANTIBIOGRAM Discussion}

The results from the Antibiogram Sensitivity Test Levels are most telling, and of great concern, as many of the profiles were multidrug resistant in vitro. Twelve different Antibiogram profiles emerged from the 37 positive Salmonella spp. isolates.

Six of the most common antimicrobials used in the medical field were used in the KirbyBauer Antibiogram Test to verify the sensitivity of the Salmonella spp. isolates at the standard levels of concentration in vitro. The Antimicrobials used were Ampicillin $10 \mu \mathrm{g}$ (AM), Penicillin 10 units (P), Tetracycline $30 \mu \mathrm{g}$ (TE), Bacitracin $10 \mu \mathrm{g}$ (B), Gentamicin $10 \mu \mathrm{g}(\mathrm{GM})$, Erythromycin $15 \mu \mathrm{g}(\mathrm{E})$. The Salmonella isolate results ran the gamete of multidrug resistance to these common antimicrobials. However, it was to be expected that the Salmonella Isolates would be resistant to Bacitracin as only gram positive microorganisms are susceptibility (Wreth, 2018). Bacitracin was the control in this study as Salmonella is gram negative .

In reviewing the Salmonella spp. isolates, it is notable that the percentage of resistance to the most common antibiotics available is concerning (see Table 4). In this study, 2 of the 3 mechanisms for antibiotics to halt the bacteria's ability to produce functional cell walls or synthesize protein is disrupted causing the destruction of the bacteria is represented. The first mechanism is the disruption of the cell wall production and integrity. Ampicillin, Penicillin and Bacitracin use the first mechanism to destroy the invading bacteria by the inhibition of the cell wall synthesis. Tetracycline, Gentamicin and Erythromycin use the second mechanism to interfere with protein synthesis which ultimately inhibits basic cellular functions (Greene, 2006; Drlica and Perlin, 2011). 
This study shows that two antibiotics, Ampicillin and Gentamicin, at the standard dosages used, had the highest susceptibility rates on the Salmonella spp. isolates in vitro. The impact of these 2 drugs on the Salmonella spp. was: 19 isolates were sensitive to Ampicillin, and 36 of the isolates were sensitive to Gentamicin (see to Table 4). Only 1 isolate was resistant to Gentamicin, and 7 isolates to Ampicillin overall. At these standard dosage levels, Ampicillin had 11 isolates at the intermediate sensitivity and Gentamicin had 0 at intermediate. At higher dosages or more concentrated levels at the infection site, these intermediate levels could move to susceptible sensitivity, but it is not precise as to how much higher the doses would need to be nor was it tested for in this study.

Most of the Salmonella spp. isolates were highly resistant to the antibiotics Bacitracin (100\%), Erythromycin (87\%), Tetracycline (81\%), and Pencillin (73\%) (see Table 4). This resistance in vitro can be an indicator that Salmonella spp. are becoming multidrug resistant in the environment and adaptations to counter antibiotic mechanisms such as impeding protein synthesis and blocking cell wall production are not as productive. The Salmonella spp. isolates that are most concerning are in Profile 1 (see Figure 5), Profile 4 (see Figure 9), Profile 6 (see Figure 15), and Profile 10 (see Figure 23) due to being multidrug resistance. Profile 1 is completely resistant to the all antimicrobials tested and could be deemed a potential pathogenic microbe. The other Profiles fore-mentioned had 4-5 antimicrobials that they were resistant to and can be considered multidrug resistant in vitro. The other 5 Profiles were resistant to 3 antibiotics in vitro. Profiles 8 (see Figure 21) and Profile 12 (see Figure 27) were resistant to 2 antibiotics. Overall it can be concluded that there is multidrug resistance developing in Salmonella spp. in the poultry population and their environment in San Luis Obispo County. 
As many of Salmonella isolates are showing multidrug resistance in vitro, it can be concluded that the Salmonella spp. isolates pose a definite health risk to humans and animals in the county. Conclusions as to where these Salmonella spp. isolates originate cannot be answered definitively without further testing and isolating the genotypes by either DNA or serotypes by pluri-test assays to identify the serovars. Also, further testing of the environment is needed specifically focusing on the feed, litter and waterers to see if they are source and/or cloaca swab would pinpoint specific birds as the source.

Companion organisms play a confounding role when isolating and culturing the samples for Salmonella spp.. Proteus spp. was always visible in the cultures and at times swarmed the Salmonella making it very difficult to isolate a clean sample. But after several culture plates the Salmonella spp. would have distinctive colony growth from which to isolate a culture. Using two types of culture plates that were designed specifically for Salmonella culture isolation made it easier to identify and verify the presence of Salmonella spp..

\subsection{QUESTIONNAIRE DisCUSSION}

The questionnaire was done to understand the environment the poultry lived in and husbandry practices of each owner regarding the care and maintenance of their flock. The questionnaire was broad yet only a few questions pertained to the biosecurity and maintenance of the birds. Many of the owners had little understanding of how poultry should be cared for. They did not seem to recognize that their daily care routines were not adequate for biosecurity and/or safety from zoonotic diseases. In fact, many were unaware that poultry carry diseases that can cause illness in humans. 
The study allowed the owners to self-report to their answers. Self-reporting can be misleading especially when dealing with questions regarding any illnesses. The same researcher reiterated the questions to clarify any issues that may arise. Also, the researcher took photographs of the poultry and their habitats to make further observational notations about the sites.

\subsubsection{Poultry}

The type of poultry may play a role in the presence of Salmonella spp. as some species are more susceptible to infection and have carrier status (Saif et al., 2008). In this study, the sites that had a variety of poultry species present such as geese and pigeons tested positive (see Table7). But more likely the source of the poultry such as what hatchery the chicks came from could be a possible contamination source. Other studies have specifically shown that hatcheries are sources of Salmonella spp. infections in the flocks (CDC, 2012). This study did not specifically trace back the Salmonella spp. to a certain feed store or hatchery to test that source. However, Atascadero Hay and Feed was a major source of the chickens (see Table 9) as owners from around the county purchased their chicks during the annual "Chick Days" held each spring. Atascadero Hay and Feed purchased their chicks from Ideal Poultry Breeding Farms, Inc. in Cameron, Texas, Privett Hatchery Inc. in Portales, New Mexico and sometimes from Belt Hatchery in Fresno, California. The second largest source was Santa Margarita Feed and Farm Supply who ordered their chicks from Belt Hatchery. Farm Supply also purchased some of their chicks from Belt Hatchery 
and Privett Hatchery. Again, there is no correlation to the sites being positive from the feed stores and/or hatcheries as they were not specifically tested.

The backyard flocks in this study consisted of a variety of breeds. The most popular chickens were Rhode Island Reds, Orpingtons, Barred Rocks, and Silkies (see Table 7). These breeds' popularity also coincided with the highest Salmonella spp. positives. However, knowing which breed was shedding Salmonella cannot be determined as this study tested the poultry housing environment and fecal matter versus cloaca swabs.

\subsubsection{Feed}

This study did not test the feed specifically, nor the feed storage containers or the feed bowls. The feed may have been inadvertently tested as the area around the feed bowls were utilized when walking the coop with the Envirobootie ${ }^{\mathrm{TM}}$ II. It is an area that feces accumulates due to birds spending time around their feed bowls. In other studies, the feed was a definitive source of Salmonella contamination or introduction of Salmonella into the poultry populations (Foley and Lynne, 2008; Leotta et al., 2010; Medalla et al., 2017).

Kings Feed was the most widely used brand by the poultry owners in this study (see Table 11). King's Feed has organic and non-organic feed types. All 21 sites that fed Kings were positive for Salmonella spp. It is interesting to note that this brand could be a source of Salmonella contamination, but no definitive direct correlation can be made as a source of Salmonella due to the feed not being tested directly as an isolated sample. 


\subsubsection{Housing}

Types of housing present ranged from pens in the house for raising-up chicks to coops with the birds having free access to the yard (see to Table 13). In this study, most of the cagefree and range-free poultry tested positive for Salmonella spp.. Seventy-nine percent of the sites housed 1-10 birds together ranging from a small cage for 1 to 2 birds to larger coops with nesting boxes. Some sites gave access to yards or allowed birds to walk around the property during the day but were locked up at night in the coop. That the 24 Salmonella spp. positive sites were either free-range or cage-free, except one site that had a single caged bird, suggests that environmental contagions play a role in Salmonella spp. spread. With $66 \%$ samples being positive for Salmonella spp. from cage-free or range-free birds, the housing situation could be an issue in increasing the risk of exposure to environmental Salmonella spp. contamination exposure to humans.

Crowding can play a role in the spread of pathogens due to stress and close contact to sources of microbes, but this was not an issue specific to this study (see Table 15). One site had 1-3 birds in a pen and another site had 1 chicken in a cage. Most had 10 to 30 birds living in large coops ranging size of 5'x 8' to $20^{\prime} \times 20^{\prime}$ with many coops having access to a grassy yard. So, the issue of crowding did not seem to play a role on whether the site was contaminated by Salmonella spp. as the ratio of birds to the various size of housing were acceptable.

Site 2 was very close to reaching its capacity with cross-species of poultry. The coop was an outside room attached to the side of the house and had both chickens and pigeons in the small coop as children ran barefoot through the coop then into the house and other pets 
also had free access to the coop. The exact source of the Salmonella spp. contamination could not be determined as there are various factors that could play a role in the site being positive: pigeons being higher carriers of Salmonella (Saif et al., 2008), animal handling, composting feces in the coop and biosecurity on the property. Again, no cloacal swabs were taken to verify the exact source of the Salmonella spp. whether it was from the chickens or the pigeons at Site Two, but the site was positive with the poultry present.

\subsubsection{Sanitation}

Sanitation is an issue that can foster Salmonella spp.. Nineteen sites cleaned the coops monthly and 5 cleaned the coops weekly (see Table 16). The fecal matter was removed to another area for composting or to be disposed of. The sites' lack of cleanliness practices probably leads to the culmination of feces that harbors Salmonella spp. as $89.5 \%$ of the monthly and $80 \%$ of the weekly sites tested positive.

Site 2 (see Figure 35), where chickens and pigeons were housed together, tested positive for Salmonella spp. as the coop was never cleaned and feces was allowed to build-up to decompose. Due to husbandry practices at this site, Salmonella spp. was present along with signs of other health issues in the flock.

This study collected samples from the environment where the poultry was housed. Areas of concentration were around the food, water, and nesting areas where there is a heavy density of poultry activity which usually means a larger a buildup of fecal matter. The lack 


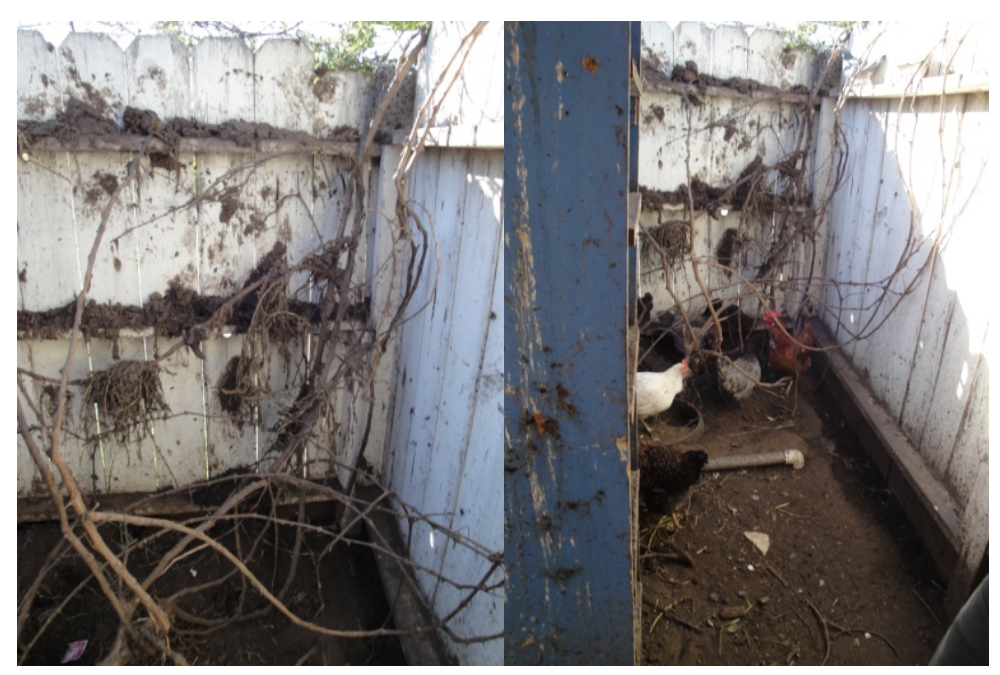

Figure 35. Coop at Site 2: Houses chickens and pigeons. Fecal matter is not removed but allowed to compost in the coop and was about 8 inches deep.

of coop cleanliness posed an issue in sample collection as feces was dried out, but fresh fecal matter seemed be found around the nesting boxes. Even if the coop had been recently cleaned, sample collection focused on fresh and moistened feces from the area around nesting, feed and water bowls.

Another important sanitation area which seems to elude owners is the need to routinely clean feed bowls and waterers. Many owners did not clean these regularly, even when they had fecal or food matter in them. These areas could be a direct source of contamination efficiently spreading of Salmonella spp. throughout the flock.

Sanitation is imperative in controlling the spread of Salmonella spp. not only to others in the flock but also to the humans or other animals that may be in contact with the birds. Poor sanitation leads to the spread of zoonotic diseases and increases pathogenic opportunities for cross contamination. 


\subsubsection{Egg Handling}

Only 5 sites had proper egg handling procedures and 3 of these sites tested positive for Salmonella spp. (see Table 18). Twenty-one of the 24 sites that did not have proper egg handling practices tested positive for Salmonella spp.. These positive sites can potentially lead to an increased risk for Salmonella spp. exposure to humans. Human caretakers run the risk of contracting zoonotic diseases if they are not diligent in washing and handling eggs properly. Humans who are young or old and suffer immune deficiencies should not eat raw eggs or handle/collect eggs directly from the coop without taking precautions of washing their hands afterwards.

\subsubsection{Biosecurity}

Biosecurity is a major aspect in the fight against the spread of any microorganism. It is one of the keys in arresting the spread of a disease. The majority of the properties did not have adequate biosecurity plans (see to Table 20). Two properties had coccidiosis which was evident by the red grainy fecal droppings on the ground (Saif et al., 2008; Merck, 2012).

Many factors play a role in the insufficient biosecurity: not having designated clothes or separate shoes for interactions with poultry, not having dedicated cleaning equipment for the coops, placement on the property of the fecal compost sites, other animals (see Figure 36), wildlife or insects having access to the poultry and compost piles, influx of people interacting with poultry that may have their own birds, not properly handling the eggs, access for the birds to backyard where family members congregate or children play rather 


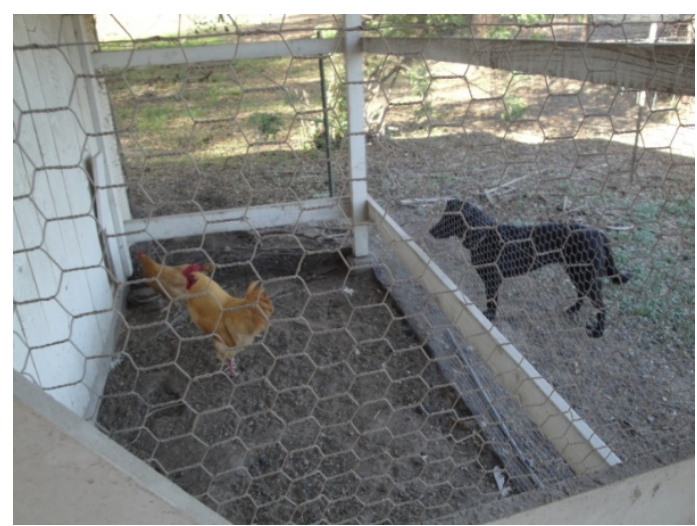

Figure 36: Coop at Site 7: Other animals have access to the coop by digging under the fence.

than their own isolated yards and cleaning feed dishes and waterers in kitchen sinks rather than outside (Flynn, 2008; CDC, 2012). Two urban sites clearly treated their poultry as pets. The researcher observed a child under 10 years old was holding a chicken under her shirt and kissing it. While at another site, the children were also hugging and taking the birds in the house after walking through the coop barefoot. All 29 sites lacked one form or another of biosecurity which meant that they all run the risk of exposure to poultry diseases yet only 24 sites were positive (see Table 19).

The simple act of having separate mucking shoes is important in stopping the cross contamination from the coop into the owner's house. Six sites had separate mucking shoes which were mainly ranches, yet there were other factors that contributed to inadequate biosecurity which lead to 5 of these sites being positive. Of course, having a specific pair of shoes for the coop then wearing them in the house defeats this purpose or using them for other chores can also allow for cross contamination in other areas of the property. Meticulous biosecurity is imperative to the health of the flock and owners especially in halting the spread of zoonotic diseases that pose an animal or public health risk. 


\section{CONCLUSION}

This study clearly shows that backyard poultry and their environment are a reservoir for Salmonella spp. in San Luis Obispo County. As the frequency of poultry becoming backyard pets increases, a Salmonella spp. outbreak becomes a possiblity leading to an upsurge in human health issues. Moreover, the potential contamination of humans can be complicated by serotypes showing multidrug resistance against common antibiotics used by the medical profession. The public should be made aware of the inherent risks involved with the care and housing of backyard poultry.

With the increase in backyard poultry households especially in urban areas, it will become more imperative for poultry caretakers to have training on proper handling and husbandry practices to minimize the intrinsic exposure to zoonotic diseases. Poultry are not pets though are often treated as such, so misnomers abound. The novice owner should be offered education by San Luis Obispo Health County, local Agricultural Education Extension, or County Animal Services as poultry have numerous zoonotic diseases that can become a potential family health risk and ultimately a public health concern. Minimally, sources that sell poultry should provide biosecurity brochures with the very basics of poultry care, handling and egg processing to the consumer.

Poultry intermittently shed Salmonella spp. but there are other bacteria that coexist with Salmonella such as Proteus, and E.coli, both which may cause human illness or illness in other family pets. Again, consumer education emphasizing biosecurity and proper care could decrease these inherent disease risks that are posed by poultry for cross 
contamination with humans and other animals. In addition, further public health studies should be conducted to connect Salmonella spp. to human caretaker illnesses.

There is still the question whether Salmonella spp. being present in the local backyard populations could impact the county's poultry industry by causing a large-scale outbreak. Wildlife, especially birds and rodents, can transfer the bacteria, though Salmonella spp. is not as contiguous or detrimental as other poultry diseases, such as New Castles which required door to door eradication of all fowl (Flynn, 2008; Saif et al., 2008). Yet, it should be of concern that antibiotic resistance is becoming more prevalent. It should be a red flag to the poultry industry that multidrug resistant pathogens exist in poultry environments. Furthermore, as the industry moves to cage-free or range-free production systems the incidents of Salmonella spp. may increase as the flocks intermingle more, have exposure to multiple environmental contaminating sources and eggs lay for extended periods on tainted surroundings. Even with the precautions of the Improvement Poultry Program (IPP) sourced flocks, these production systems run the risk of environmental contaminants interfering with the biosecurity and health of the flock as cage-free birds have 3.5 times more Salmonella spp. in their populations (Leotta et al., 2010; Sanchez et al., 2015).

Additional implications for the poultry industry are vast as the consumer and lawmakers pressure the producers to move towards cage-free housing and antibiotic-free poultry. This is evident as the first step in change was demonstrated when California's Proposition 2, known as the Farm Animal Cruelty Statue, passed in 2008. As of January 1, 2015, Proposition 2 became state law under Division 20 of the California Health and Safety Code Chapter 13.8 [\$25990-25994] which regulates the size of animal confinement cages in production facilities. It specifically prohibits poultry/battery cages that do not allow for the 
bird to turn around freely, lie down, stand up, or fully extend their limbs. This confinement regulation has prompted awareness from the consumer to demand more cage-free and range-free birds (California Legislature, 2008). However, cage-free birds, as stated before, run the risk of exposure to more Salmonella serotypes from wildlife even at the commercial level; but when at the backyard flock level, there is even more of an exposure to wildlife and possible introduction of diseases from the surrounding populations (Sanchez et al., 2015).

This movement towards cage-free and range-free housing can also boost poultry's exposure to microorganisms that are harbored in contaminated litter, feed, and water. Birds' contact risks are greater with these husbandry practices especially as poultry can intermittently shed Salmonella spp. without visible clinical signs. The flock amplification of Salmonella spp. could be further compounded by the lack of medicated feed which keeps gut flora populations to manageable levels (Poppe, 2000; Sanchez et al., 2105). However, the use of antibiotics in the feeds can have an adverse effect by assisting in the microorganism resistance. The poultry industry will have to re-evaluate their practices to create a delicate balance between protecting their flock's health and production values while meeting the mounting demands of the consumer for improved animal welfare combined with antibiotic and hormone free meat. In the movement for change, the USDA and CDFA have put limits on the usage of antibiotics recently (CDFA, 2018). But, it may be a little too late for Salmonella control or reduction of environmental microorganisms as the emergence of multidrug resistant Salmonella spp. has happened worldwide (Van Hoorebeke et al., 2009; Xavier et al., 2011; Bhuvaneswari et al., 2015; Manning et al., 
2015). As demonstrated by this study, Salmonella spp. has developed between $73 \%-100 \%$ multidrug resistance to commonly prescribed antibiotics.

To minimize the hazards of exposure to zoonotic poultry diseases and the probability of a multidrug resistant Salmonella outbreak within human and backyard poultry populations, a break in one of the Epidemiology Triangle's three rings (see Figure 1), whether the host, environment or agent, must happen. The easiest two rings for poultry caretakers to control are the host and environment (Flynn, 2008). The host, poultry, can be vaccinated for Salmonella and bought from IPP sources that are certified Salmonella free. The environment is the other source that needs to be controlled with proper sanitation practices and biosecurity measures of dedicated clothing, shoes, equipment; limiting access to birds by wildlife and rodents; routine sanitation methods for disposal of fecal matter; proper egg processing practices; limiting cross-contamination of birds by visitors who have their own flocks; and proper hygeine after handling birds which includes washing hands with soap and water.

Finally, it comes down to the education and training of the owners on biosecurity and poultry husbandry practices. To minimize the exposure of humans and pets to poultry zoonotic diseases, brochures on poultry care and biosecurity should be given to anyone who buys poultry. A good give-away is the annual avian calendar published by The Avian Health Group in conjunction with the USDA and CDFA which highlights avian diseases and has a link to obtaining a certificate in Avian Disease Prevention (CDFA, 2018). Only through education and practical training can disease prevention and awareness be known by backyard poultry owners - thus, preventing the possibility of zoonotic diseases becoming more of a public health risk from environmental drug-resistant Salmonella spp.. 


\subsection{FUTURE WORK}

Further studies should be conducted to include sampling and testing of feed, litter, hatchery sources and the surrounding poultry free areas in the vicinity of the coop. Tests should be performed to see if there is a possibility of cross-contamination from other environmental sources, such as wildlife, as this study did not focus on those areas. Also, a random cloaca sampling of the birds could be done unless the stress of handling the birds compromises their health.

Expanded Antibiogram tests should be conducted to include more antimicrobials on the market such as flemoxcin, cephalexin, neomycin, ciprofloxacin, doxycycline, levofloxacin, vancomycin, or the 18 antimicrobials panel used in the National Antimicrobial Resistance Monitoring System (NARMs) program (Medalla et al., 2017). This study found multidrug resistance within the 6 antimicrobials tested but to see if the drug resistance is more expansive, testing more antimicrobials would be beneficial. Knowing the vastness of multidrug resistance in the poultry population and its environment would increase the ability of the medical profession to handle a zoonotic disease outbreak within the human population.

Others tests to verify the Salmonella spp. as to specific serotyping could be conducted if time and funds are available. PCR testing on each sample should be run to DNA fingerprint the Salmonella spp.; or even EnteroPluri-Tests could be conducted to type them by chemical reactions. During this study, one EnteroPluri-Test was conducted to see what type of wild Salmonella might be present. The 15 biochemical reactions in the EnteroPluriTest identified Salmonella suis. This serotype would be consistent with possible 
Salmonella species that are specific to wild boar that populate and migrate through Pozo, California.

Finally, to see antibiotic resistance trends in the county, mapping the location sites of the Salmonella spp. isolate by each antibiotic would give a clearer overview of the movement of the multidrug resistance in the environment. Since the samples collected were a mix of urban and rural backyard flocks, the trends should be interesting. Further studies should be done to see if there is stronger presence of Salmonella spp. in the rural communities as wildlife reservoirs are frequently in contact with these poultry populations verses the urban backyard flocks. Analyzing the topography could show pockets of resistance that are surrounded by mountains or if there is a difference between the North County and South County's Salmonella spp. serovars. Furthermore, epidemiological mapping could be useful in a trace back investigation during an outbreak and give a clearer understanding of Salmonella spp.'s movement in the environment.

This study began the investigation into the presence of Salmonella spp. in backyard poultry and their environment. It introduced the foundation for which further studies could identify specific Salmonella serovars and their antibiotic resistance, movement of Salmonella spp. in poultry populations and their environments and epidemiological mapping for trends in serovars and antimicrobial resistance. All future proposed studies could be vital in understanding zoonotic poultry diseases and probably risks to public health. 


\section{REFERENCES}

Ahmed, A. M., Y. Ishida, T. Shimamoto. 2009. Molecular characterization of antimicrobial resistance in Salmonella isolate from animals in Japan. J. Appl. Microbiol. 106:402-409. doi:10.111/j.1365-2672.2008.04009.x

Ahmed, M. M., M.M. Rahman, K. R. Mahbub, M. Wahiduzzaman. 2011. Characterization of antibiotics resistant Salmonella spp. isolated from chicken eggs of Dhaka City, Journal of Scientific Research. 3(1):191-196. doi:10.3329/jsr.v3il.6109

Aminov, R. 2010. A brief history of the antibiotic era: lessons learned and challenges for the future. Front. Microbiol. 1(article134):1-7. doi:10.3389/fmicb.2010.00134

Barrow, P. A., M. A. Jones, A.L. Smith, P. Wigley. 2012. The long view: Salmonella- the last 40 years. Avian. Pathol. 41(5):413-420. doi: 10.1080/03079457.2012.718071

Basler, C., N. Thai-An, T. C. Andersen, T. Hancock, C. B. Behravesh. 2016. Outbreaks of human Salmonella infections associated with live poultry, United States, 19902014. Emerg. Infect. Dis. 22(10):1705-1711. doi: 10.3201/eid2210.150765

Bauer, A.W., W. M. M. Kirby, J. C. Sheris, M. Turk. 1966. Antibiotic susceptibility testing by a standardized single disk method. Am. J. Clin. Pathol. 45(4):493-496.

Baumler, A. J., R. M. Tsolis, F. Heffron. 2000. Virulence mechanisms of Salmonella and their genetic basis. In: C. Wray and A. Wray, editors, Salmonella in domestic animals. CABI Publishing, CAB International, Oxon, United Kingdom. p. 57-72.

Beam, A., L. Garber, J. Sakugawa, C. Kopari. 2013. Salmonella awareness and related management practices in U.S. urban backyard chicken flocks. Prev. Vet. Med. 110(3-4):481-488. doi: 10.1016/j.prevetmed.2012.12.004

Behravesh, C. B., D. Brinson, B. A. Hopskins, T. M. Gomez. 2014. Backyard poultry flocks and Salmonella: recurring, yet preventable public health challenge. Clin. Infect. Dis. 58(10):1432-1438. doi: 10.1093/cidciu067

Bhuvaneswari, M., S. Shanmughapriya, K. Natarajaseenivasan. 2015. Prevalence of multidrug-resistant (MDR) Salmonella Enteritidis in poultry and backyard chickens from Tiruchrirappalli, India. Microbiol. J. 5(2):28-35. doi: 10.3923/mj.2015.28.35

Bopp, C. 2003. Salmonella serotype Typhi. In: World Health Organization Manual for the laboratory identification and antimicrobial susceptibility testing of bacterial pathogens of public health importance in the developing world. p. 103-120. http://www.int/csr/resources/publications/drugresist/en/IIIAMRManual.pdf?ua=1. (Accessed 14 January 2014.) 
Brenner, F. W., R. G. Villar, F. J. Angulo, R. Tauxe, B. Swaminathan. 2000. Salmonella nomenclature. J. Clin. Microbiol. 38(7):2465-2467. doi: 0095-1137/00

Bunning, M and J. Avens. 2010. Home-produced chicken eggs. Colorado State University Extension. Food and Nutrition Series-Food Security Fact Sheet No. 9.377. (Updated 12 May 2010). http://www.extension.colostate.edu/topicareas/nutrition-foodsaftey-health/home-produced-chicken-eggs-9-377. (Accessed 10 May 2017.)

CDFA. 2012. California agriculture highlights 2012. http://www.cdfa.ca.gov/statistics. (Accessed 5 March 2014.)

CDFA. 2017. California Agriculture Highlights 2015-16. http://www.cdfa.ca.gov/statistics. (Accessed 31May 2018.)

CDFA. 2018. California Agricultural Exports 2016-17. http://www.cdfa.ca.gov/statistics. (Accessed 31 May 2018.)

CDFA. 2018. Avian Health Program avian health calendar. http://www.cdfa.ca.gov/ahfss/Animal_Health/avian_health/pdfs/Calendar.pdf. (Accessed 2 January 2018.)

CDFA. 2018. Antimicrobial stewardship materials: how is the California law different from the federal law. https://www.cdfa.ca.gov/ahfss/aus/._ (Accessed 2 January, 2018.)

California Legislature. 2008. Health and Safety Code. Division 20. Miscellaneous Health and Safety Provisions [24000 - 26217] (division 20 enacted by stats. 1939, ch. 6 ) chapter 13.8. Farm Animal Cruelty [25990 - 25994] (Chapter 13.8 added November 4, 2008, by initiative Proposition 2, Sec. 3.). http://www.leginfo.legislature.ca.gov/faces/codes_displayText.xhtml?lawCode=HS Canddivision $=20$.andtitle $=$ andpart $=$ andchapter $=13.8$.andarticle . (Accessed 20 April 2015.)

CVMA. 2018. Livestock antibiotic rules for California. California Veterinarian. JanuaryFebruary. p. 10-11. http:www.cvma.net/wpcontent/uploads/2018/01/LivestockAntibioticRulesforCASB27_CV-JF_2018._(Accessed 12 May 2018.)

CDC. 2012. Salmonella web page. http://www.cdc.gov/Salmonella/index.htm. (Accessed 5 March 2013.)

CDC. 2013. Antibiotic resistance threats in the United States 2013. p. 71-72, 99. https:/www.cdc.gov/drugresistance/threat-report-2013/pdf/ar-threats-2013-508.pdf. (Accessed 22 February 2015.)

CDC. 2014. Multistate outbreak of multi-drug resistant Salmonella Heidelberg infectious linked to Foster Farm chicken. (Final Update) Salmonella Web page. http://www.cdc.gov/Salmonella/heidelberg-10-13.htm. (Accessed 1 August 2014.) 
CDC. 2017. Multistate outbreaks of human Salmonella infections linked to live poultry in backyard flocks, 2017 (Final Update October 19, 2017). http://www.cdc.gov/Salmonella/live-poultry-06-17/index.html. (Accessed 31 May 2018.)

CFSPH. 2005. Salmonellosis paratyphoid, non-typhoidal salmonellosis. Iowa State University, Ames IA.

Chin, J.. 2000. Salmonellosis disease in control of USA communicable disease manual. $17^{\text {th }}$ ed. American Public Health Association. p. 440-444.

Chiu, C., L. Su, C. Chu. 2004. Salmonella enterica serotype Cholraesuis: epidemiology, pathogenesis, clinical disease, and treatment. Clin. Microbiol. Rev. 17(2):311-322. doi: 10.1128/CMR.17.2.311-322.2004

Clauser, P.J. 2009. Virginia Cooperative Extension. Proper handling of eggs: from hen to consumption. http://pubs.ext.vt.edu/2902/2902-1091/2902-1091.pdf. (Accessed 15 May 15 2014.)

CLSI. 2012. Performance standards for antimicrobial disk susceptibility tests. approved Standard. $11^{\text {th }}$ ed. 31(1).

Dale, E. and C. Brown. 2013. Zoonotic disease from poultry. Brazilian Journal of Veterinary Pathology. 6(20):76-82. https://pdfs.semanticscholar.org/5c9a/cc1b5b49b8856b117549dd15447b1629e56e.p df. (Accessed 1 January 2014.)

Davis, M. D., G.D. Butcher, F. B. Mather. 2003. Avian diseases transmissible to humans. Doc PS23 University of Florida. FL Cooperative Extension Institute of Food and Agriculture Extension, Gainesville, FL. 32611. http://edis.ifas.ufl.edu/pdffiles/PS/PS01900.pdf. (Accessed 5 June 2015.)

Drlica, K. and D. S. Perlin. 2011. Antibiotic resistance understanding and responding to an emerging crisis. Pearson Education, Inc. FT Press Upper Saddle River, NJ.

Flynn, K. 2008. Protecting California's livestock and poultry, Animal Health Branch, emergency preparedness support. CATA Conference 2008. San Luis Obispo, California. 25 June.

FDA. 2009. Prevention of Salmonella Enteritidis in shell eggs during production, storage and transportation. Final Rule. Federal Register. 74:33030-33101. https://www.federalregister.gov/documents/2009/07/09/E9-16119/prevention-ofsalmonella-enteritidis-in-shell-eggs-during-production-storage-and-transportation. (Accessed 21 May 2014.) 
FDA. 2012. Bad bug book handbook of foodborne pathogens microorganisms and natural toxins. Salmonella spp.. Washington D.C.

https://www.fda.gov/downloads/Food/FoodSafety/FoodborneIllness/FoodborneIllne ssFoodbornePathogensNaturalToxins/BadBugBook/UCM297627.pdf. (Accessed 21 May 2014.)

Foley, S. L. and A. M. Lynne. 2008. Food animal-associated Salmonella challenges: pathogenicity and antimicrobial resistance. J. Anim. Sci. 86 (Suppl 14): E173-E187. doi: $10.2527 /$ jas.2007-0447

Foley, S. L., T. J. Johnson, S. C. Ricke, R. Nayak, J. Danzeisen. 2013. Salmonella pathogenicity and host adaptation in chicken -associated serovars. Microbiol. Molr. Biol. Rev. 77(4):582-607. doi: 10.1128/MMBR.00015-13

FSA. 2004. Recommendations on the best practical procedures to sample and test poultry flocks for Salmonella. http://www.UKmeat.org/Broilers.htm. (Accessed 4 March 2015.)

Gast, R. K., R. Guraya, D. R. Jone, K. E. Anderson. 2014. Contamination of eggs by Salmonella Enteritidis in experimentally infected laying hens housed in conventional or enriched cages. Poult. Sci. 93(3):728-733. doi: 10.3382/ps.201303641

Gruenberg, W. 2012. Overview of Salmonellosis. Merck Veterinary Manual on-line edition. http://www.merckmanual.com/digestive-system/salmonellosis. (Accessed 2 June 2014.)

Global Salmonella surveillance and laboratory support project of the World Health Organization. 2003. ed. R.S. Hendriksen, 4th ed. Laboratory protocols level training course identification of Salmonella.

http://www.who.int/ihr/lyon/surveillance/ihr_astsalmonella_2010_en.pdf. (Accessed 14 January 2014.)

Greene, C. E.. 2006. Infectious diseases of the dog and cat. Saunders Elsevier Inc. $3^{\text {rd }}$ ed. Ch 39. p. 355-360.

Grimont, P. A. D., F. Grimont, P. Bouvet. 2000. Taxonomy of the genus Salmonella. In: C. Wray and A. Wray, editors, Salmonella in domestic animals. CABI Publishing, CAB International, Oxon, United Kingdom. p. 1-17.

Hafez, M. H. and S. Jodas. 2000. Salmonella in turkeys. In: C. Wray and A. Wray, editors, Salmonella in domestic animals. CABI Publishing, CAB International, Oxon, United Kingdom p. 133-155.

Hardy Diagnostics. 2009. Poultry sampling devices. Online. (Reviewed 2014) https://catalog.hardydiagnostics.com/cp prod/Content/hugo/PoultrySampling.htm. (Accessed 5 March 2014.) 
Helmuth, R. 2000. Antibiotic resistance in Salmonella. In: C. Wray and A. Wray, editors, Salmonella in domestic animals. CABI Publishing, CAB International, Oxon, United Kingdom. p. 89-106.

Henzeler, D. J. and H. M. Opitz. 1992. The role of mice in the epizootiology of Salmonella Enteritidis infection on chicken layer farms. Avian Diseases. 36:625-631.

Henzeler, D. J., E. Ebel, J. Sanders, D. Kradel, J. Mason. 1994. Salmonella Enteritidis in eggs from commercial chicken layer flocks implicated in human outbreaks. Avian Diseases. 38:37-43.

Holt, P. S.. 2000. Host susceptibility, resistance and immunity to Salmonella in animals. In: Salmonella in domestic animals. ed. Wray, C. and Wray, A.. CABI Publishing, CAB International, Oxon, United Kingdom. Ch. 5. p. 73-87.

Howard, Z. R., C. A. O’Bryan, P. G. Crandall, S. C. Ricke. 2012. Salmonella Enteritidis in the shell eggs: current issues and prospects for control. Food Res. Int. 45:755-764. doi: 10.1016/j.foodres.2011.04.030

Hudzicki, J. 2009. Kirby Bauer disk diffusion susceptibility protocol. http://www.asmscience.org/content/education/protocol/protocol.3189. (Accessed 23 September 2018.)

Jones, F.T. and S. C. Ricke. 2003. Observation on the history of the development of antimicrobials and their use in poultry feeds. Poult. Sci. 82(4):613-617. doi: $10.1093 / \mathrm{ps} / 82.4 .613$

Keen, P. L. and M. H. M. M. Montforts. 2012. Antimicrobial resistance in the environment, ed. Wiley-Blackwell. Hoboken, NJ. Ch. 24. p. 539-548.

Leotta, G., K. Suzuki, F. L. Alvarez, L. Nunez, M. G. Silva, L. Casto, M. L. Faccioli, N. Zarate, N. Weiler, M. Alvarez, J. Copes. 2010. Prevalence of Salmonella spp. in backyard chickens in Paraguay. Int. J. of Poult. Sci. 9 (96):533-536. doi: 10.3923/ijps.2010.533.536

Levinson, W. 2012. $12^{\text {th }}$ Ed. Review of medical microbiology and immunology. McGraw Hill Lange Co. p.128-130.

Manning, J., V. Gole, K. Chousalkar. 2015. Screening for Salmonella in backyard chickens. Prev. Vet. Med. 120(2):241-5. doi: 10.1016/j.prevetmed.2015.03.019

Marculescu, A., G. H. Rapuntean, N. A. Oros, M. Cernea. 2007. The antibiotic resistance phenomenon in Salmonella strains isolated from pigs. Lucrari Stiintifice Medicnia Veterinara, XL:105-108.

Martinez, J. and L. F. Baquero. 2009. Antibiotics and the evolution of antibiotics Resistance In: Encyclopedia of Life Sciences (ELS). John Wiley and Sons, Ltd: Chichester. doi: 10.1002/97804700115902.a0021782 
Medalla, F., G. Weidong, B. E. Mahon, M. Judd, J. Folster, P. M. Griffin, R. M. Hoekstra. 2017. Estimated incidence of antimicrobial drug-resistant non-typhoidal Salmonella infections, United States, 2004-2012. Emerg. Infect. Dis. 23(1):29-37. doi: $10.3201 /$ eid2301.160771

Merck Veterinary Manual. 2012. Overview of Salmonellosis. on-line edition. http://www.merckmanual.com/digestive-system/salmonellosis. (Accessed 2 June 2014.)

Odumeru, J. A. and C. G. Leon-Velarde. 2012. Salmonella detection methods for food and food ingredients. In: B. S.M. Mahomond. editor, Salmonella - a dangerous foodborne pathogen p. 373-385. https://www.intechopen.com/books/salmonella-adangerous-foodborne-pathogen/salmonella-detection-methods-for-food-and-foodingredients. (Accessed 25 March 2014.)

OIE Guidelines on Detection, Control and Prevention of Salmonella spp. in Poultry. 2009. Terrestrial Animal Health Standards Commission Report. Article X.X.X.I. https://www.aphis.usda.gov/import_export/animals/oie/downloads/tahc_sep09/tahc _prev_detec_cont_salm_poul_78_sep09.pdf. (Accessed 13 January 2014.)

Poppe, C. 2000. Salmonella infections in the domestic fowl. In: C. Wray and A. Wray, editors. Salmonella in domestic animals. CABI Publishing, CAB International, Oxon, United Kingdom. p. 107-132.

Ribeiro, V. B., N. Lincopan, M. Landgraf, B. D. G. M. Franco, M. T. Destro. 2011. Characterization of class 1 intergrons and antibiotic resistance genes in multidrugresistant Salmonella Enterica isolates from foodstuff and related sources. Braz. J. of Microbiol. 42(2):685-692. doi: 10.1590/s1517-838220110002000033

Saif, Y. M. ed., A. M. Fadley, J. R. Glisson, L. R. McDougald, L. K. Nolan. 2008. Diseases of poultry. $12^{\text {th }}$ ed. Blackwell Publishing, Ames. IA. p. 619-674.

Sanchez, S., M. Franca, N. M. Nemeth. 2015. Microbiological hazards of wild birds and free-range chickens. In: M. Jay-Russel and M. Doyle, editors. Food safety risks from wildlife, food microbiology and food safety. Springer, Cham. p. 89-130.

Scallan, E., R. M. Hoekstra, F. J. Angula, R.V. Tauxe, M. A. Widdowson, S. L. Roy, J. L. Jones, P. M. Griffin. 2011. Foodborne illness acquired in the United Statesmajor pathogens. Emerg. Infect. Dis. 17(1):7-15. doi:10.3201/eid1701.P11101

Spiller, R. 2000. Introduction to poultry management. California Polytechnic State University, San Luis Obispo, CA. PM 145 Lecture Class. Fall 2000.

Steele, J. H.. 1963. Epidemiology of Salmonellosis. Symposium Public Health Reports. December. 78(12):1065-1088. https://www.ncbi.nlm.nih.gov/pmc/articles/PMC1915402/pdf/pubhealthreporig000 84-0059.pdf. . (Accessed 21 May 2015.) 
Su, L.H., C. H. Chui, C. Chu, J. T. Ou. 2004. Antimicrobial resistance in non-typhoidal Salmonella serotypes: a global challenge. Clin. Infect. Dis. 39(4):546-551. doi: $10.1086 / 422726$

USDA. 2011. Poultry 2010 urban chicken ownership in Los Angeles County, California. United States Department of Agriculture, Animal and Plant Health Inspection Service, Veterinary Service. August. Washington, DC. https://www.aphis.usda.gov/animal_health/nahms/poultry/downloads/poultry10/Pou ltry10_dr_Urban_Chicken_LA.pdf. (Accessed 12 January 2013.)

USDA. 2014. Poultry production and values, 04.29.2014 pdf. National Agricultural Statistical Services. Washington, DC. http://www.nass.usda.gov. (usda.mannlib.cornell.edu) (Accessed 5 May 2014.)

USDA. 2014. The National Poultry Improvement Plan and auxiliary provisions Title 9 animals and animal products parts 145-147 and 56. United States Department of Agriculture, Animal and Plant Health Inspection Service, Washington, DC. http://www.poultryimprovement.org/documents/auxilaryprovisions.pdf. (Accessed 21 May 2014.)

USDHHS. 2011. Guidance for industry: prevention of Salmonella Enteritidis in shell eggs during production, storage, and transportation. FDA. Rockville MD. https://www.fda.gov/downloads/Food/GuidanceRegulation/UCM285137.pdf. (Accessed 21 May 2014.)

USDHHS and CDC. 2013. Antibiotic resistance threats in the United States, 2013. p. 71-76. Washington, DC. https://www.cdc.gov/drugresistance/threat-report2013/pdf/ar-threats-2013-508.pdf. (Accessed 15 June 2015.)

Van Hoorebeke, S., F. Van Immerseel, J. De Vaylder, R. Ducatelle, F. Hasesebrouck, F. Pasmans, A. De Jruif, J. Dewulf. 2009. Faecal sampling underestimates the actual prevalence of Salmonella in laying hen flocks. Zoonoses. Public. Health. 56(8):471476. doi: 10.111/j.1863-2378.2008.01211x

Wales, A., M. Breslin, B. Carter, R. Sayers, R. Davies. 2007. A longitudinal study of environmental Salmonella contamination in caged and free-ranged layer flocks. Avian. Pathol. June. 36(3):187-197. doi:10.1080/03079450701338755

Waltman, W. D. 2000. Methods for cultural isolation of Salmonella. In: C. Wray and A. Wray, editors. Salmonella in domestic animals. CABI Publishing, CAB International, Oxon, United Kingdom. p. 355-372.

Wreth, B. J. 2018. Overview of antibacterial drugs. (Reviewed 2018). Professional Merck Manual. Merck \& Co., Inc., Kenilworth, NJ. https:/www.merckmanuals.com/professional/infectious-diseases/bacteria-andantibacterial-drugs/overview-of-antibacterial-drugs. (Accessed 19 August 2018.)

Whiley, H. and K. Ross. 2015. Salmonella and eggs: from production to plate. Int. J. Environ. Res. Public. Health.12:2543-2556. doi: 10.3390/ijerph120302543 
WHO Veterinary Public Health Unit. 1994. Guidelines on detection and monitoring of Salmonella infected poultry flocks with reference to Salmonella Enteritidis. ed. C. Wray and R. H. Davies. Geneva World Health.

http://www.who.int/iris/handle/10665/66292. (Accessed 5 May 2014.)

Wright, J. G., L. A. Tengelsen, K. E. Smith, J. B. Bender, R. K. Frank, J. H. Grendon, D. H. Rice, A. M. B. Thiessen, C. J. Gibertson, S. Sivapalasingam, T. J. Barrett, T. E. Besser, D. D. Hancock, F. J. Angulo. 2005. Multi-drug resistant Salmonella Typhimurium in four animal facilities, Emerg. Infect. Dis. 11(8):1235-1241. doi: 10.3201/eid1108.05011

Xavier, J., D. Pascal, E. Crespo, H. L. Schell, J.A. Trinidad, D.J. Bueno. 2011. Seroprevalence of Salmonella and Mycoplasma infection in backyard chickens in the state of Entre Rios in Argentina. Poul. Sci. 90(4):746-751. doi: $10.3382 /$ ps.2010.01036

Younus, M., M.A Khan, I. Khan. 2012. Pathology of salmonellosis as a zoonotic hazard in poultry and humans: a public health study. LAP Lambert Academic Publishing, Deutschland, Germany. 


\section{Protocols}

\section{Collection of Samples}

In the field-Collecting Samples

- Fill out questionnaire with owner and have them sign a release form.

- Take photos of coop and poultry areas.

- Put down a sterile pet pad as field workspace in hatch-back of car.

- Wash hands with antibacterial gel. Then put on disposable rubber gloves.

- Take out 1-10 ml tube of skim milk (2x) broth from cooler. Wipe down the outside of skim milk tube and Envirobootie ${ }^{\mathrm{TM}}$ Whirl Bag with a separate alcohol pad.

- Label the Envirobootie ${ }^{\mathrm{TM}}$ Whirl Bag (sample collected) with Date, Sample \# and any identifier letter. Use a sharpie.

- Pour the Skim Milk (1 tube) into the Whirl Bag and massage skim milk into the Envirobootie ${ }^{\mathrm{TM}}$ then seal it.

- Put plastic booties over shoes when at the coop.

- When at the coop, remove the Envirobootie ${ }^{\mathrm{TM}}$ from the Whirl Bag and place over the plastic boot as entering the coop.

- Walk around the coop looking for fresh feces and moist areas around the water, nesting areas and bedding areas. Making sure to cover the majority of the coop.

- Remove Envirobootie ${ }^{\mathrm{TM}}$ before leaving coop and place back into Whirl Bag. Seal the bag tight. Place bag into sterile jar with a lid. Label jar with sample collection number as the Whirl Bag.

- Wipe down the jar with an alcohol pad before placing in cooler on blue ice packs.

- For each coop and/or separate poultry area use a new Envirobootie ${ }^{\mathrm{TM}}$ at a site or at a new site.

- Follow the above protocols for each sample collect. Always remember to use new gloves and plastic boots to avoid cross-contamination.

- Take all collected samples to laboratory within six hours to process.

- Disinfect shoes before leaving site with bleach and water. 

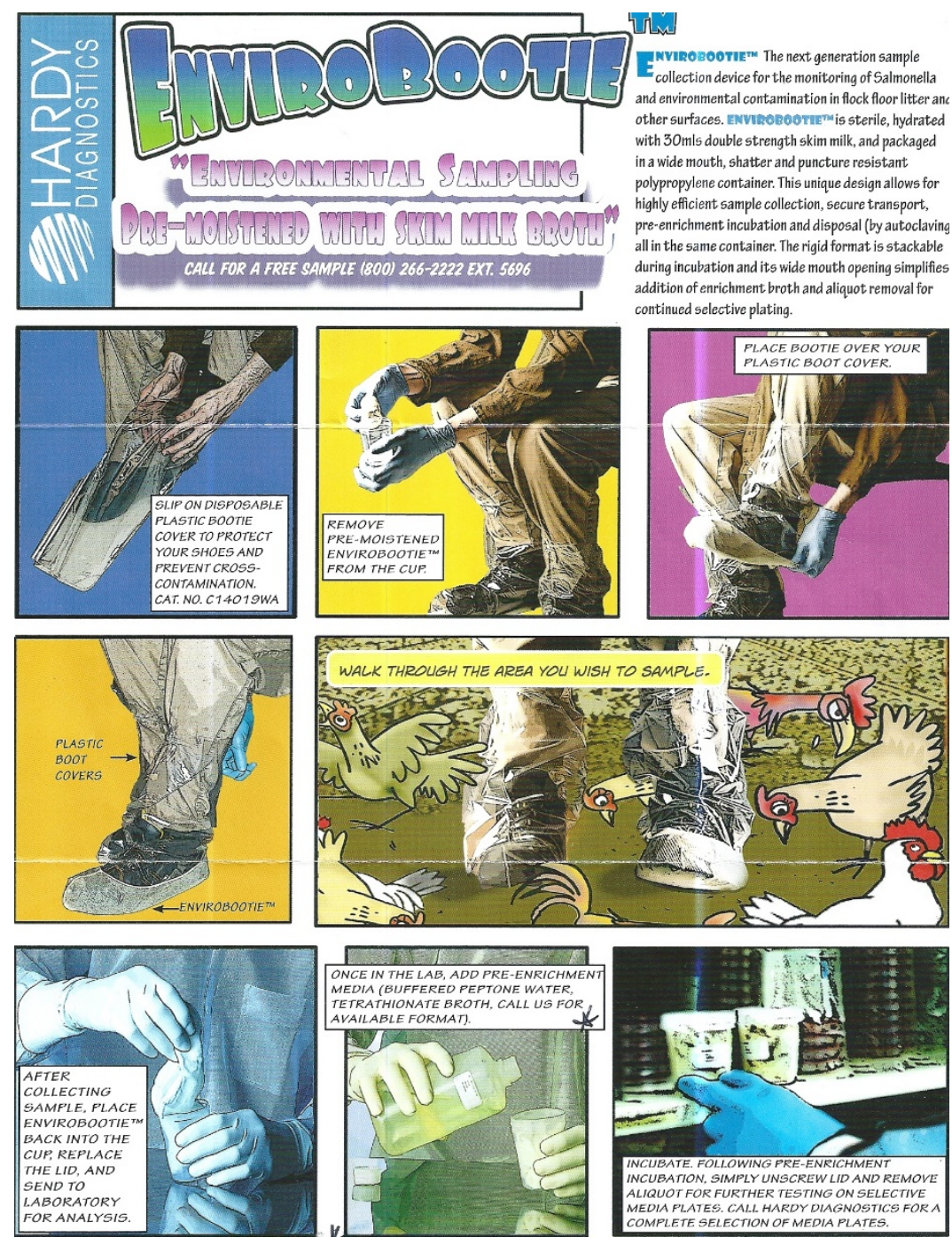

Figure 37. HARDY Diagnostic EnviroBootie ${ }^{\mathrm{TM}}$ II proper procedure on how to utilize it within the coop and enrich for micro-organisms. Published with permission of HARDY Diagnostic.

\section{At the Laboratory-Processing Samples}

- Wipe down the lab bench with Envirocide ${ }^{\circledR}$. Lay down a sterile pad.

- Open the cooler and take out the samples one at a time.

- Wipe the outside of the labeled sample jar with a paper towel wet with Envirocide ${ }^{\circledR}$.

- Wipe the lid of the buffered enriched peptone water down with Envirocide ${ }^{\circledR}$.

- Add $100 \mathrm{ml}$ of peptone water to the sample Whirl Bag. Swirl the Whirl Bag to disperse the peptone water in and around the Envirobootie ${ }^{\mathrm{TM}}$. Seal Whirl Bag loosely to allow bacterial growth without bag rupturing and place back into Jar. Put 
the lid loosely back on Jar. And swirl the Jar to make sure the liquid has disbursed again.

- Wipe down the outside of the jar with a wet paper towel with Envirocide ${ }^{\circledR}$.

- Place into the incubator for 48 hours at $35^{\circ} \mathrm{C}+/-2^{\circ} \mathrm{C}$.

- Wipe down gloves with Envirocide ${ }^{\circledR}$ in to avoid any cross contamination before changing gloves in between samples.

- Throw out any paper towels or gloves, etc. that came in contact with samples in Biohazard bins. Clean lab bench with Envirocide ${ }^{\circledR}$.

Isolating and Re-isolating Colonies on Plates and Slants

Isolating for Salmonella spp. Colony

- Put on Gloves then prepare the lab bench as above.

- Light a Bunsen burner to create a clean zone to work in aseptic conditions. Remove samples from the incubator and place in clear zone on one side of the burner.

- Process one sample at a time that has been enriching in the Peptone Water for 48 hours.

- Wipe the outside of sample jar before opening with Envirocide ${ }^{\circledR}$.

- Label the underside of the HardyCHROM ${ }^{\mathrm{TM}}$ SS with same Sample number and the date plated. Use a sharpie.

- Open the jar and slightly lift up the Whirl Bag to unseal. Be careful as the Whirl Bags may have broken open. Avoid splashing any of the liquid out of the jar.

- Open a sterile cotton swab. Dip it into the liquid that surrounds Envirobootie ${ }^{\mathrm{TM}}$ in the Whirl Bag in the jar.

- Use the wet swab to inoculate HardyCHROM ${ }^{\mathrm{TM}}$ SS plate. Move the swab in a zigzag pattern over the plate. Turn plate $90^{\circ}$ and run the swab over plate again slightly crossing over the first zigzag; then repeat a $3^{\text {rd }}$ time. (Standard culture plating method).

- Put lid on plate. Make sure the sample number matches the jar sample number. Wipe down plate outside with Envirocide ${ }^{\circledR}$.

- Place the HardyCHROM ${ }^{\mathrm{TM}}$ SS plate in the incubator upside down for 24-48 hours at $35^{\circ} \mathrm{C}+/-2^{\circ} \mathrm{C}$. Check growth in 24 hours.

- Put lid on Whirl Bag sample jar. Wipe outside down with Envirocide ${ }^{\circledR}$ and put in refrigerator to slow and preserve bacterial growth. Keep the sample jar just in case there is a need to re-culture or until there is an isolated colony on first plate. Place in refrigerator at $4^{\circ} \mathrm{C}$.

- Follow the above plating protocols for each sample. Making sure to wipe down gloves with Envirocide ${ }^{\circledR}$ then replacing gloves in between samples. 
- Clear lab bench by putting away Bunsen burner and disposing of all materials that came in contact with the samples the biohazard bins. Wipe down the lab bench with Envirocide ${ }^{\circledR}$.

\section{Salmonella spp. Isolate Verification}

- Prepare the lab bench as above creating an aseptic clean zone to work in.

- Make sure to wear gloves.

- Remove the plates from the incubator after 48 hours.

- Read the HardyCHROM ${ }^{\mathrm{TM}}$ SS plates. Black centered colonies will be $\mathrm{H}_{2} \mathrm{~S}$ producing Salmonella spp. Teal centered colonies will be $\mathrm{H}_{2} \mathrm{~S}$ non-producing Salmonella spp. Circle the chosen colony with a sharpie on the outside bottom of the plate.
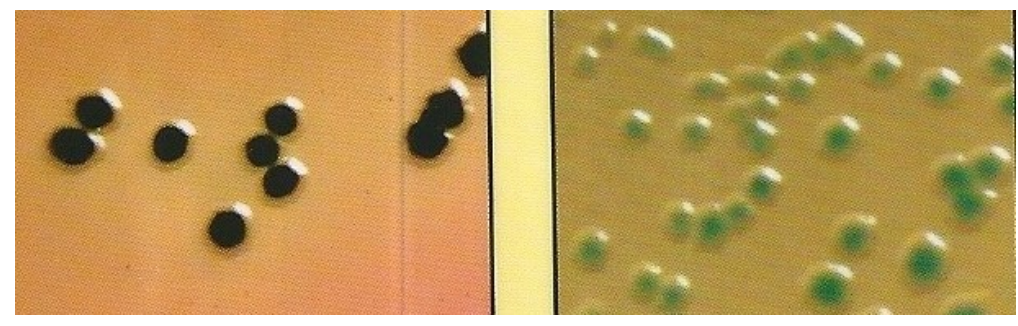

Figure 38. HardyCHROM ${ }^{\mathrm{TM}}$ SS plate: Black centered colonies will be $\mathrm{H}_{2} \mathrm{~S}$ producing Salmonella spp.; and Teal centered colonies will be $\mathrm{H}_{2} \mathrm{~S}$ non-producing Salmonella spp.. Published with permission of Hardy Diagnostics.

- Label the bottom of HardyCHROM ${ }^{\mathrm{TM}}$ Salmonella plate with date plated and sample number that matches the label on the HardyCHROM ${ }^{\mathrm{TM}}$ SS plate.

- Before opening the Sample plate and the new plate, wipe them down with Envirocide $^{\circledR}$. Then open them and lay them in the clear zone.

- Put a loop into the Bunsen burner to heat it up or "flame" it so that it is devoid of any microbes. Let cool quickly.

- Using a flamed loop scoop up the selected colony from the HardyCHROM ${ }^{\mathrm{TM}}$ SS.

- Using the flamed loop with the colony, streak in a zigzag pattern the HardyCHROM ${ }^{\mathrm{TM}}$ Salmonella. Turn plate $90^{\circ}$ and streak again crossing over the previous streak slightly. Then rotate the plate and repeat a $3^{\text {rd }}$ time (standard streaking pattern used).

- Put the lids on the plates. Wipe down each with Envirocide ${ }^{\circledR}$.

- Put the new plate HardyCHROM ${ }^{\mathrm{TM}}$ Salmonella into the incubator for 24-48 hours at $35^{\circ} \mathrm{C}+/-2^{\circ} \mathrm{C}$. Check growth in 24 hours. 
- Keep the HardyCHROM ${ }^{\mathrm{TM}} \mathrm{SS}$ in case there is a need to re-isolate the colonies. Place in refrigerator at $4{ }^{\circ} \mathrm{C}$ to slow growth and maintain the colonies.

- Check the growth on the HardyCHROM ${ }^{\mathrm{TM}}$ Salmonella in 24 hours.

- Follow the above plating protocols for each sample. Making sure to wipe down gloves with Envirocide ${ }^{\circledR}$ in between samples and then replace gloves.

- Dispose of the Whirl Bag jar in Biohazard once successful at getting a colony on the HardyCHROM ${ }^{\mathrm{TM}}$ Salmonella plate with the same sample number.

- Follow the same protocols as above to clean-up the lab bench and area.

NOTE: Environmental samples can have many microorganisms in them. Thus, isolating colonies can be difficult as other microbes can swarm or surround them and not allow for true isolation. If this happens re-isolate that colony again on a HardyCHROM ${ }^{\mathrm{TM}}$ SS until one can be selected easily. Making sure to label the samples properly with date plated and sample number and if teal or black. Follow the protocols for plating and wiping down with Envirocide ${ }^{\circledR}$ to avoid cross-contamination.

\section{Inoculating TSA Slants}

- Put on gloves. Then using the same protocols as above to set up the lab bench.

- Under aseptic conditions, take the out the HardyCHROM ${ }^{\text {тм }}$ Salmonella plates from the incubator. Read the plates for colonies that are pink to magenta in color as they will be Salmonella spp. Select a colony and circle it on the outside of the plate.
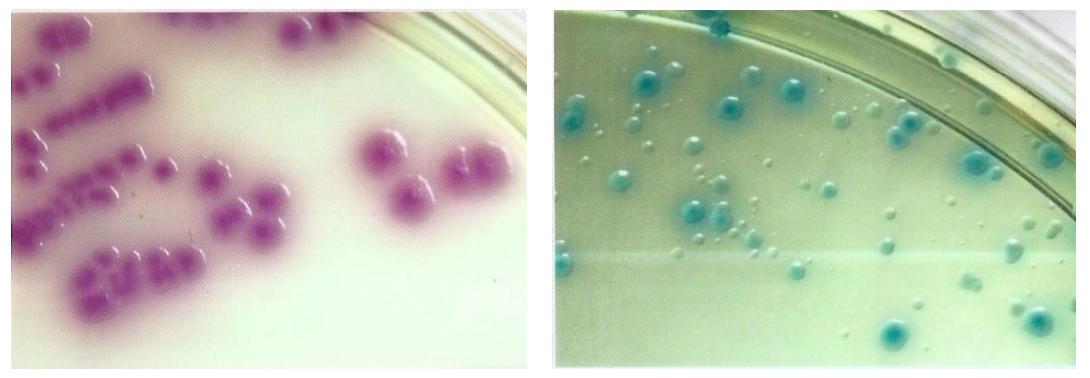

Figure 39. HardyCHROM ${ }^{\mathrm{TM}}$ Salmonella plate: Salmonella with be magenta as it reacts to the pink substrates in the agar; the Blue substrates will be used by other bacteria (E. coli); there can be white or natural color colonies present too. Published with permission of Hardy Diagnostics.

- Label the TSA slant (agar) test tube with the date inoculated and the sample number. Place in a test tube rack that is within the clean zone.

- When ready, run the test tube cap through the flame quickly 3 times. Then remove the cap. Then place it back in test tube rack. 
- Using a loop that has been flamed and cooled, scrap the selected colony from the HardyCHROM $^{\mathrm{TM}}$ Salmonella plate. Squiggle the loop along the top of the TSA slant.

- Run the lip of tube through the flame 3 times.

- Replace the top and run it through the flame 3 times. Then place TSA tube back into rack.

- Put lid back on to the HardyCHROM ${ }^{\mathrm{TM}}$ Salmonella plate and wipe with Envirocide ${ }^{\circledR}$.

- Repeat the above procedure for each sample. Wiping gloves with Envirocide ${ }^{\circledR}$ each time. Replace gloves each time after wiping them down.

- Place test tube rack into the incubator for $24-48$ hours at $35^{\circ} \mathrm{C}+/-2^{\circ} \mathrm{C}$.

- Cleanup the lab bench as in above procedures. Making sure to dispose of any materials that came in contact with the samples in Biohazard bins.

- Once there is substantial growth on the slants, place rack in refrigerator at $4^{\circ} \mathrm{C}$ to slow and maintain growth.

- HardyCHROM тм Salmonella can be disposed of in the Biohazard bins once growth is strong on the slants.

- When all experiments are finished, cover the slants with mineral oil and place back in refrigerator for storage.

\section{Kirby-Bauer Method}

\section{Inoculating TSB Media}

- Prepare the biosafety cabinet as above as using lab bench protocols. Wear gloves while doing all of this.

- Under the biosafety cabinet with the vent on and in aseptic conditions to create a clean zone to prepare the TSB which will become the culture broth media.

- Remove the TSA slants from the refrigerator. Take to the cabinet placing them in the clean zone.

- Label the TSB Broth Media Test Tubes with the date inculcated and the sample number.

- Run the test tube caps through the Bunsen burner 3 times quickly. Do this for both the TSB Broth Media and the TSA Slant Sample. Then remove the caps and place test tubes in rack.

- With a flamed loop, pick a sesame seed size sample of the colony from the TSA slant sample. 
- Dip the loop into the Broth Media Test Tube and swirl around. Replace cap and run through the flame 3 times quickly.

- Replace cap to the TSA Slant and run through the flame 3 times.

- Repeat the same protocols for each TSA Slant sample. Remembering to wipe down gloves with Envirocide ${ }^{\circledR}$ in between handling each sample then replacing them.

- Put the TSA Slants back into the refrigerator at $4^{\circ} \mathrm{C}$.

- Place the inculcated TSB Broth Media into the incubator for $12-16$ hours at $35^{\circ} \mathrm{C}$ $+/-2^{\circ} \mathrm{C}$.

- Clean the biosafety cabinet area with the same protocols as above. Dispose of any sample materials and debris in Biohazard bins. Also, dispose of any sample plates or jars that are not needed anymore.

\section{Antibiogram Sample Plating}

- Under the biosafety cabinet and in aseptic conditions, prepare the agar plates for the antimicrobial disks. Must be done within 12-16 hours of making the Broth Sample.

- Label the agar plate on the bottom with the date plated and the sample number as written on the TSB Broth Sample Test Tube.

- Adjust the culture density for the Kirby-Bauer standard of 0.05 McFarland based on viewing the lines of Wickerham card through the broth.

- Under the cabinet, open the TBS Broth Sample test tube after swiping it through the flame 3 times quickly.

- Use a sterile cotton swab to dip into the TSB Broth Sample.

- With a moistened swab, cover the entire TSA agar plate. Rotate and swab again, repeat a third time.

- Allow plate to dry for 5 minutes.

- Swipe the lip of test tube through flame 3 times. Replace cap from the TSB Broth Sample and swipe through the flame 3 times quickly then put back in rack.

- Using a multi-antibiotic disk dispenser, push the disks in to the TSA agar. The dispenser will place the disks $2 \mathrm{~mm}$ apart. Use the following antibiotic disks as labeled: Ampicillin $10 \mu \mathrm{g}(\mathrm{AM})$, Penicillin 10 units (P), Tetracycline $30 \mu \mathrm{g}$ (TE), Bacitracin $10 \mu \mathrm{g}$ (B), Gentamicin $10 \mu \mathrm{g}$ (GM), Erythromycin $15 \mu \mathrm{g}$ (E).

- Let the disks settle into the agar for about 5 minutes. Then place into the incubator for 24 hours at $35^{\circ} \mathrm{C}+/-2^{\circ} \mathrm{C}$.

- Repeat the above procedure for each TSB Broth Sample. Remembering to wipe gloves with Envirocide ${ }^{\circledR}$ in between each sample and then replacing the gloves. 
- Clean the biosafety cabinet area with the same protocols as above. Dispose of any sample materials and debris in Biohazard bins. Also, dispose of any sample plates or jars that are not needed anymore.

- After 24 hours, measure the diameter of the "clearing" zone (halo) around the antibiotic disks. Measure the clearing around the disk with a mm ruler and record the results. If the circles overlap, measure the radius from center of disk to the edge and multiple by 2 to get the diameter of the halo. This does not need to be done under a fume hood, just on a clean lab bench with paper as the plates will not be opened.

- Using the "clearing zone" chart for Salmonella spp., interpret the size of the halo as "resistant, susceptible or intermediate." Record results for each antibiotic.

- Then dispose of all samples (except the TSB Slants) and materials in the biohazard bins.

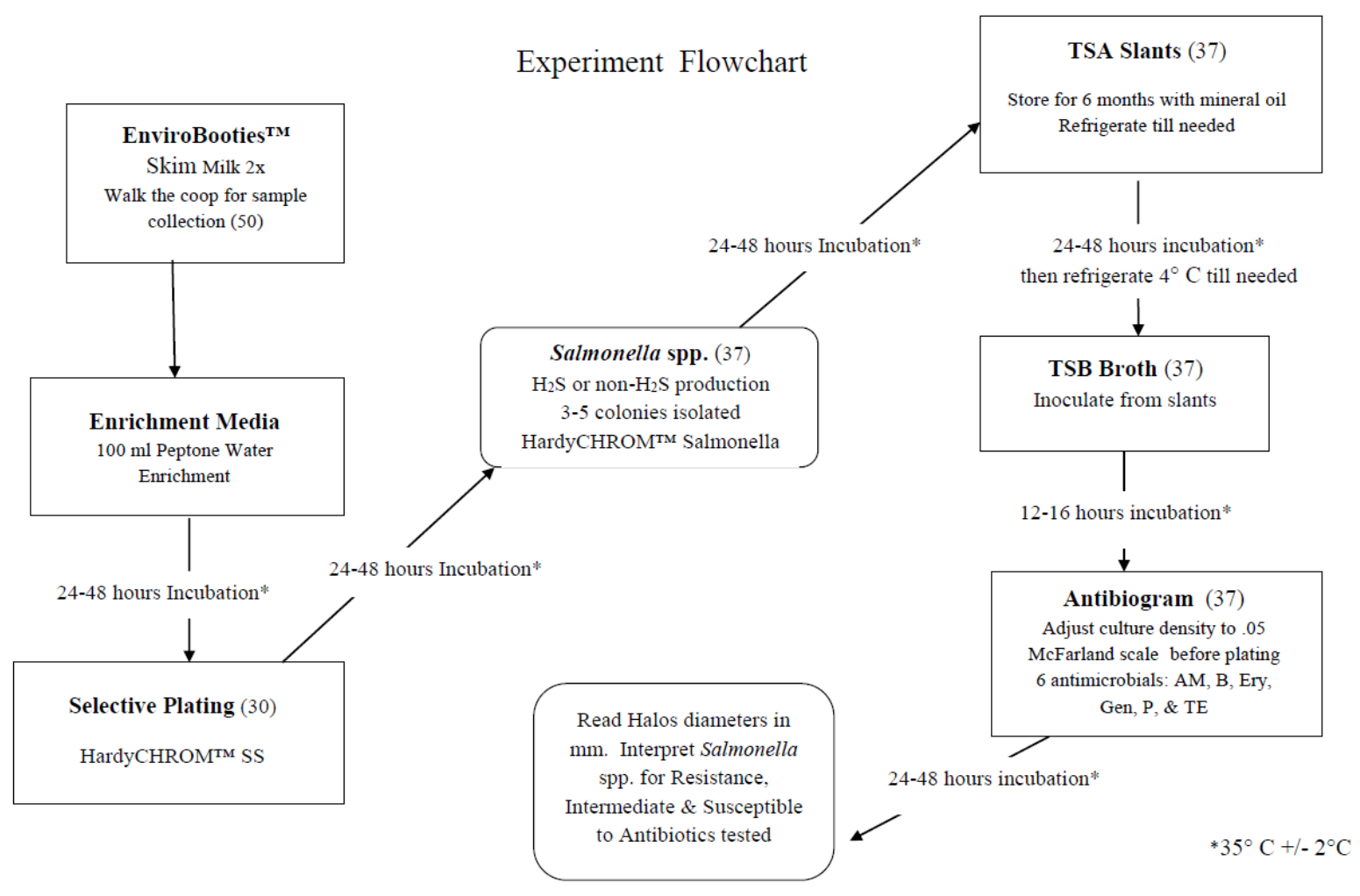

Figure 40. Experiment Flowchart 


\section{Materials PuRChased at THE Following:}

- Sampling \& Laboratory Supplies: Hardy Diagnostics, Santa Maria, California

- Alcohol Swabs \& Hand Sanitizer: CVS Pharmacy, San Luis Obispo, California

- Pet Pride Absorbent Training Pads: Ralph's, San Luis Obispo, California (distributed by Kroger, Ohio).

\section{Protocol AdDitional ReAdings}

Andrews, W.H., H. Wang, A. Jacobson, T. Hammack. FDA's Bacteriological analytical manual (BAM). Chapter 5: Salmonella. ed 8, Revision A/ 1998. (Updated July 2018)

https://www.fda.gov/Food/FoodScienceResearch/LaboratoryMethods/ucm2006949. htm\#TOC._(Accessed 3 September 2018.)

CDPH. 2009. Epidemiologic summary of salmonellosis in California 2009-2012, December 16. prepared by Kate Cummings, Akiko Kimura. (Updated 7 September 2015) https://www.cdph.ca.gov/Programs/CID/DCDC/CDPH\%20Document\%20Library/ SalmonellaEpiSummary09-12.pdf. (Accessed 14 October 2015.)

FDA. 2004. Microbiology Methods and Bacteriological Analytical Manual (BAM). Detection of Salmonella environmental samples from in poultry houses. Washington, DC. https://www.fda.gov/Food/FoodScienceResearch/LaboratoryMethods/ucm114709.h tm. (Accessed 13 January 2014.)

Hardy Diagnostics. 2013. Envirobootie ${ }^{\mathrm{TM}}$ Brochure EB60K. Santa Maria, CA. http://hardydiagnostics.com/enviro-bootie/. (Accessed 13 January 2014.)

Hardy Diagnostics. 2013. Catalog HardyCHROM ${ }^{\mathrm{TM}}$ : HardyCHROM ${ }^{\mathrm{TM}}$ SS G327 and HardyCHROM $^{\text {TM }}$ Salmonella G309. Santa Maria, CA. pg. 11-13. http://hardydiagnostics.com/hardyCHrom\%20ss/. (Accessed 13 January 2014.)

Laboratory Services, Minnesota Department of Agriculture. 2016. Salmonella Flipbook. prepared by Matthew J. Forstner. https://www.fda.gov/downloads/Food/FoodScienceResearch/RFE/UCM517352.pdf (Accessed 23 June 2017.) 
National Committee for Clinical and Laboratory Standards .2013. Performance standards for antimicrobial disk and dilution susceptibility tests for bacteria isolated from animals. 5th ed. CLSI standard VET05. Wayne, PA: Clinical and Laboratory Standards Institute.

National Committee for Clinical and Laboratory Standards. 2018. Performance standards for antimicrobial disk and dilution susceptibility tests for bacteria isolated from animals. 5th ed. CLSI standard VET01. Wayne, PA: Clinical and Laboratory Standards Institute; 2018.

Park, S.H., M. Aydin, A. Khatiwara, M. C. January Dolan, D. F. Gilmore, J. L. Bouldin, S. Ahn, S. C. Ricke. 2014. Current and emerging technologies for rapid detection and characterization of Salmonella in poultry and poultry products. Food Microbiology. 38:250-262.

Rambach, A.1990. New plate medium for facilitates differentiation of Salmonella spp. from Proteus spp. and other enterica bacteria. Applied and Environmental Microbiology. 56(1):301-303.

Van der Zee, H., J. H.J. Huis in't Veld. 2000. Methods for rapid detection of Salmonella. In: Salmonella in Domestic Animals. ed. Wray, C. and Wray, A.. CABI Publishing, CAB International, Oxon, United Kingdom. Ch. 22. Pgs. 373-391. 
Name:

Address:

City/State/Zip:

Telephone: Email:

$\square$ Sample Collection Time:

Sample \#

\section{Background Questions:}

How many chickens are in your flock?

Where are your chickens housed?

What chicken breeds?

Where did you acquire your chickens from?

What is the purpose of your chickens?

Who cares for your chickens?

How many times of day do you/others interact with your chickens?

How many times a day do you collect the eggs?

Where do you put your collected eggs?

When do you wash your eggs?

What is your egg washing method?

How many times do you clean the coop weekly?

What do you do with the feces? 
What are your biosecurity procedures for the chickens?

Do you have separate clothing and shoes for the coop? Yes No (circle one)

Where do you keep these clothes and shoes?

Do others who have chickens have access to your chickens? Yes No (circle one)

What are your biosecurity measures for others when they visit your chickens?

Other animals/pets that have contact with the chickens or backyard area:

What pest problems do you have (i.e. rodents, wild birds, predators)

What type of chicken feed do you use? $\square$ Organic $\quad \square$ Normal $\quad \square$ Medicated

Brand Name and Type:

Do you use any of the following in feed or water: $\square$ Antibiotics $\square$ Diatomaceous Earth

$\square$ Coccidiostats

Do you feed fresh food/table scraps $\square$ Yes $\square$ No What do you feed?

Family Members who have contact with the chickens:

Children: \#

Adults:

Ages

Ages 
Have you experienced any of the following while owning your chickens:

$$
\text { Times Duration Currently }
$$

Fever

Diarrhea

Vomiting

Stomach pains/cramps
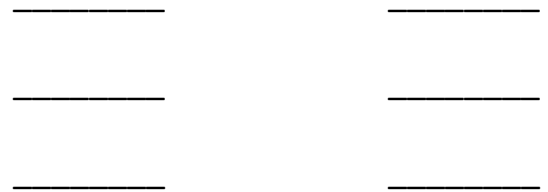

Have anyone in your family who has had contact with the chickens experienced the following:

(Who= relationship only. i.e. child, mother, grandfather etc.-no names)

Who:

Who:

Who:

Who:

Who:

Who:

Times

Fever

Diarrhea

Vomiting

Stomach pains/cramps
Age:

Age:

Age:

Age:

Age:

Age:

\section{Currently}




\section{COOP SAMPLE COLLECTION RELEASE}

I,__ , located at

in the city of California, give my permission to Nicole Land and her associates to enter my property to collect fecal samples of my poultry coop/area for an Independent Study course at Cuesta College in San Luis Obispo, California.

As a willing participant in the study, I agree to fill out a questionnaire about my poultry care and practices; and to allow photographs to be taken of collection area where the poultry is housed and roams. I understand that the participants in the study will be kept anonymous but the collection results and photographs will be used in published scientific papers and a Master's Thesis at California Polytechnic State University.

I agreed to the above on the day of 2014

Signature

Sample \# 


\section{ANTIBIOGRAM SENSITIVITY TEST RESUltS}

Antibiogram Sensitivity Test results for each positive Salmonella Isolate based on the halo measurements (mm) for each antibiotic tested: Bactrian (B), Ampicillin (AM), Penicillin (P), Erythromycin (E), Tetracycline (TE), and Gentamycin (GM). The Salmonella Isolates were grouped into Profiles from like resistance, intermediate and susceptible patterns. The Isolate numbers that are highlighted gray are teal colonies or $\mathrm{H}_{2} \mathrm{~S}$ non-producing Salmonella spp.

Table 21. Antibiogram Sensitivity Test Results

\begin{tabular}{|c|l|c|c|c|c|c|c|}
\hline Profile & \multicolumn{1}{|c|}{ Isolate \# } & B & AM & P & E & TE & GM \\
\hline 1 & $52314-6 *$ & 7 & 7 & 7 & 7 & 9 & 12 \\
\hline 2 & $32214-3$ & 6 & 6 & 6 & 13 & 15 & 23 \\
\hline 2 & $3814-5 \mathrm{C}$ & 6 & 13 & 6 & 11 & 15 & 18 \\
\hline 3 & $51614-2 \mathrm{~L} \# 2$ & 7 & 16 & 7 & 15 & 8 & 23 \\
\hline 4 & $32114-1$ & 6 & 15 & 6 & 11 & 10 & 23 \\
\hline 4 & $3814-1$ & 6 & 14 & 6 & 10 & 12 & 18 \\
\hline 4 & $51614-7$ & 7 & 15 & 7 & 7 & 9 & 18 \\
\hline 4 & $51714-1$ & 7 & 14 & 11 & 7 & 9 & 19 \\
\hline 4 & $52714-3 \mathrm{R} \# 1$ & 7 & 14 & 11 & 7 & 10 & 22 \\
\hline 5 & $51614-2 \mathrm{~L} \# 3$ & 7 & 16 & 7 & 10 & 16 & 21 \\
\hline 6 & $32214-1$ & 6 & 9 & 6 & 6 & 6 & 18 \\
\hline 6 & $41114-10 \mathrm{C}$ & 6 & 6 & 6 & 6 & 6 & 18 \\
\hline 6 & $41114-6 \mathrm{R}$ & 6 & 6 & 6 & 6 & 10 & 16 \\
\hline 6 & $51614-4 *$ & 7 & 7 & 7 & 9 & 8 & 20 \\
\hline 7 & $41114-9 \mathrm{G}$ & 6 & 25 & 15 & 6 & 9 & 21 \\
\hline 7 & $41114-3 \mathrm{~B}$ & 6 & 23 & 12 & 6 & 8 & 23 \\
\hline 7 & $51614-6 \mathrm{~T}$ & 6 & 21 & 12 & 7 & 9 & 15 \\
\hline 7 & $52314-2 \mathrm{H}$ & 7 & 19 & 12 & 7 & 9 & 18 \\
\hline 7 & $51614-1$ & 7 & 21 & 15 & 8 & 8 & 20 \\
\hline 7 & $51614-5 \# 2$ & 7 & 22 & 15 & 7 & 8 & 20 \\
\hline 7 & $51614-6 \mathrm{~B}$ & 7 & 18 & 12 & 7 & 8 & 20 \\
\hline 7 & $52714-2$ & 7 & 18 & 12 & 7 & 8 & 20 \\
\hline 7 & $51614-5 \# 1$ & 7 & 23 & 13 & 7 & 8 & 21 \\
\hline 7 & $32114-2$ & 6 & 21 & 14 & 6 & 9 & 21 \\
\hline & Resistant & $\leq 8$ & $\leq 13$ & $\leq 11$ & $\leq 13$ & $\leq 14$ & $\leq 12$ \\
\hline & Intermediate & $9 \mathrm{TO} 12$ & $14 \mathrm{TO} 16$ & 21 & $14-22$ & $15-18$ & $13-14$ \\
\hline & Susceptible & $\geq 13$ & $\geq 17$ & $\geq 22$ & $\geq 23$ & $\geq 19$ & $\geq 15$ \\
\hline
\end{tabular}


Cont. Table 21. Antibiogram Sensitivity Test Results

\begin{tabular}{|c|l|c|c|c|c|c|c|}
\hline Profile & \multicolumn{1}{|c|}{ Isolate \# } & B & AM & P & E & TE & GM \\
\hline 8 & $51714-2 \mathrm{LR} \# 1$ & 6 & 15 & 7 & 19 & 19 & 22 \\
\hline 8 & $51714-2 \mathrm{LR} \# 2$ & 7 & 15 & 7 & 18 & 19 & 23 \\
\hline 9 & $51614-2 \mathrm{~L} \# 1$ & 7 & 19 & 7 & 15 & 8 & 20 \\
\hline 10 & $32214-2$ & 6 & 20 & 6 & 6 & 9 & 20 \\
\hline 10 & $41114-5 \mathrm{~L}$ & 6 & 21 & 10 & 6 & 8 & 20 \\
\hline 10 & $52714-1$ & 7 & 17 & 9 & 7 & 10 & 18 \\
\hline 10 & $51614-8$ & 7 & 20 & 8 & 7 & 9 & 19 \\
\hline 10 & $51714-2 \# 1$ & 7 & 18 & 8 & 7 & 9 & 20 \\
\hline 10 & $52714-3 \mathrm{R} \# 2$ & 7 & 18 & 11 & 9 & 10 & 20 \\
\hline 10 & $52314-1$ & 7 & 17 & 11 & 7 & 10 & 21 \\
\hline 10 & $51714-2 \# 2$ & 7 & 22 & 9 & 7 & 7 & 22 \\
\hline 11 & $3814-7 \mathrm{G}$ & 6 & 15 & 6 & 12 & 20 & 20 \\
\hline 12 & $51614-3 \mathrm{H}$ & 7 & 14 & 7 & 14 & 18 & 17 \\
\hline & Resistant & $\leq 8$ & $\leq 13$ & $\leq 11$ & $\leq 13$ & $\leq 14$ & $\leq 12$ \\
\hline & & & & 12 TO & & & \\
& Intermediate & $9 \mathrm{TO} 12$ & $14 \mathrm{TO} 16$ & 21 & $14-22$ & $15-18$ & $13-14$ \\
\hline & Susceptible & $\geq 13$ & $\geq 17$ & $\geq 22$ & $\geq 23$ & $\geq 19$ & $\geq 15$ \\
\hline
\end{tabular}

